\title{
Therapeutic Targeting of the Complement System: From Rare Diseases to Pandemics
}

\author{
Peter Garred, Andrea J. Tenner, and (iD Tom E. Mollnes \\ Laboratory of Molecular Medicine, Department of Clinical Immunology, Rigshospitalet, Copenhagen, Denmark, and Faculty of Health and \\ Medical Sciences, University of Copenhagen, Copenhagen, Denmark (P.G.); Departments of Molecular Biology and Biochemistry, \\ Neurobiology and Behavior, and Pathology and Laboratory Medicine, University of California, Irvine, California (A.J.T.); and Research \\ Laboratory, Nordland Hospital, Bodø, Norway, Faculty of Health Sciences, K.G. Jebsen TREC, University of Troms $\emptyset$, Troms $\emptyset$, Norway \\ (T.E.M.); Centre of Molecular Inflammation Research, Norwegian University of Science and Technology, Trondheim, Norway (T.E.M.); and \\ Department of Immunology, Oslo University Hospital and University of Oslo, Oslo, Norway (T.E.M.)
}

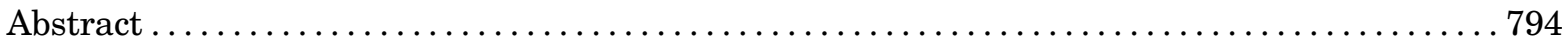

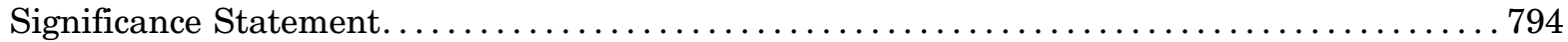

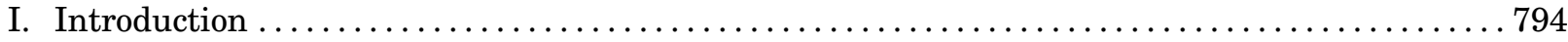

A. An Overview of the Complement System .................................. 794

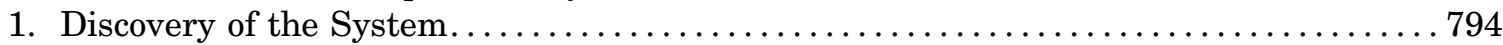

2. The History of Complement Research from the $1880 \mathrm{~s}$ to $1980 \mathrm{~s} \ldots \ldots \ldots \ldots \ldots \ldots \ldots 796 \ldots \ldots \ldots$

B. The Complement System Approach in the Clinic: The Therapeutic Era ............. 796

1. The Revolution of Complement Research for the Last 3 Decades ................ 796

2. Complement from Bench to Bedside: Today's Indications . . . . . . . . . . . . . . 798

II. Complement Deficiencies and Loss- or Gain-of-Function Mutations. . . . . . . . . . . . . 798

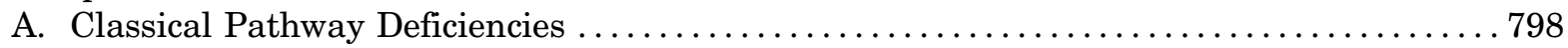

1. The Components of the Classical Pathway, Their Activation, and Regulation........ 798

2. Deficiencies of the Classical Pathway Components......................... 799

3. Disturbances of the Classical Pathway and Therapeutic Targets ................ 799

B. Lectin Pathway Deficiencies.......................................... 799

1. The Components of the Lectin Pathway, Their Activation, and Regulation ......... 799

2. Deficiencies of the Lectin Pathway Components ......................... 800

3. Disturbances of the Lectin Pathway and Therapeutic Targets................ 802

C. Alternative Pathway Deficiencies .................................... 802

1. The Components of the Alternative Pathway, Their Activation, and Regulation .... 882

2. Deficiencies of the Alternative Pathway Components ...................... 802

3. Disturbances of the Alternative Pathway and Therapeutic Targets ............. 803

D. Terminal Pathway Deficiencies ...................................... 804

1. The Components of the Terminal Pathway, Their Activation, and Regulation....... 804

2. Deficiencies of the Terminal Pathway Components ......................... 804

3. Disturbances of the Terminal Pathway and Therapeutic Targets . .............. 805

E. Therapeutic Approach to Treat Complement Deficiencies or to Enhance Its Efficacy .... 805

1. Substitution of Purified Components and Plasma $\ldots \ldots \ldots \ldots \ldots \ldots \ldots \ldots \ldots \ldots \ldots$

2. Prophylactic and Symptomatic Treatment ............................ 805

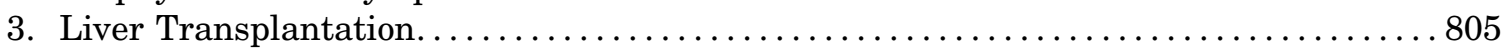

4. Triggering of Complement Activation in Individuals with a Normal Complement

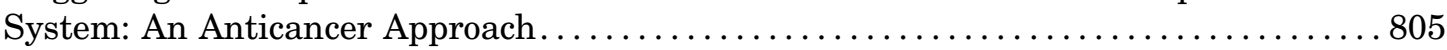

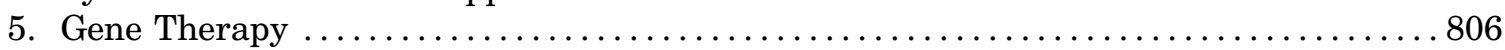

III. Role of Complement in Disease Pathophysiology $\ldots \ldots \ldots \ldots \ldots \ldots \ldots \ldots \ldots \ldots \ldots \ldots \ldots$

Address correspondence to: Tom E. Mollnes, Research Laboratory, Nordland Hospital, N-8092 Bodø, Norway. E-mail: t.e.mollnes@ gmail.com

A.J.T. received funding from National Institutes of Heath (NIH) National Institute on Aging [Grants R01AG060148 and R21AG061746].

Conflict of Interest: T.E.M. is a member of the Scientific Advisory Board of Ra Pharma/UCB. A.J.T. is a consultant for Montis.

https://doi.org/10.1124/pharmrev.120.000072. 


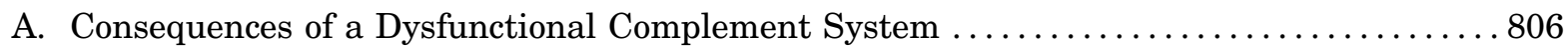

1. Decreased Regulatory Activity and Increased Activation Potential . . . . . . . . . 806

2. Pathophysiologic Role of an Uncontrolled Overactivated System ............... 806

3. Complement Attack on Host Cells when They Lack Regulators . . . . . . . . . . . 807

4. Complement Attack in Tissue Damage and Common Pathophysiological Mechanisms to Treat a Broad Panel of Diseases ................................ 808

IV. Therapeutic Complement Inhibition .................................... 809

A. Diseases with a Potential for Complement Therapeutic Modulation ................. 809

1. Introduction: The Search for Complement as Pathophysiologic Mediator .......... 809

2. Neurologic Diseases............................................. 809

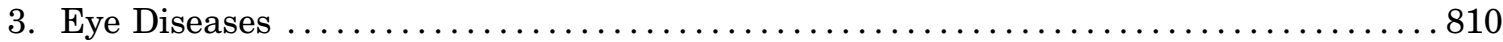

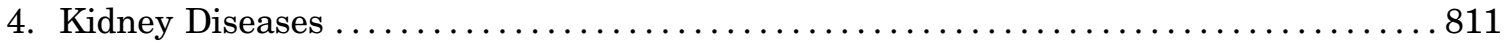

5. Hematologic Diseases ......................................... 812

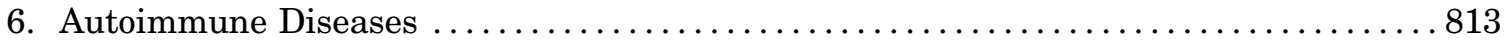

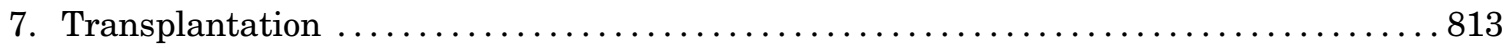

8. Systemic Inflammation: Trauma Sepsis and the Pandemic Coronavirus Disease

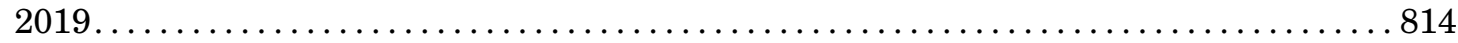

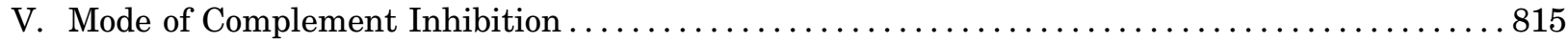

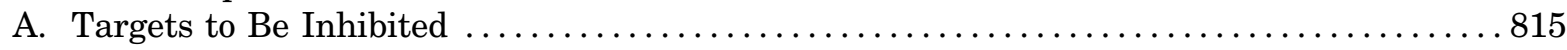

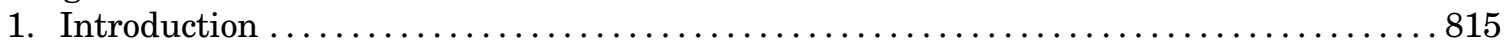

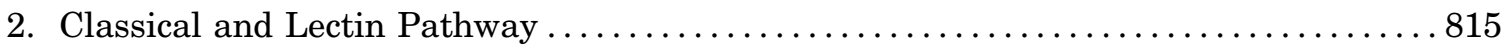

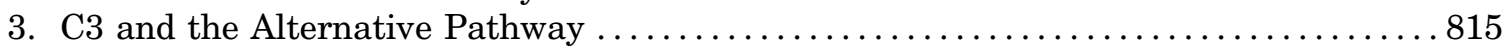

4. Terminal Pathway ................................................ 815

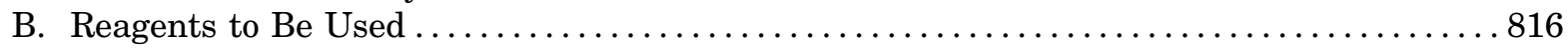

1. Monoclonal Antibodies and Their Derivatives.......................... 816

2. Small Molecular Peptides and Peptidomimetics........................ 816

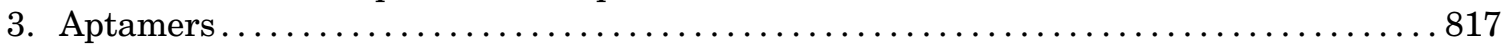

4. Recombinant Proteins and Conjugates............................... 817

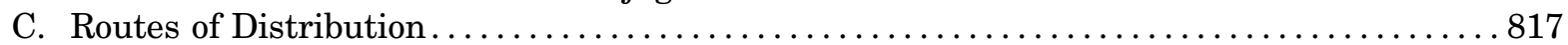

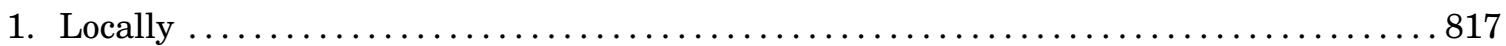

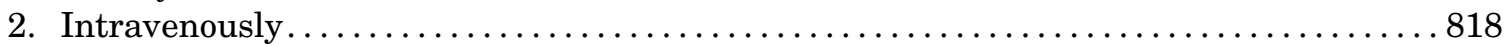

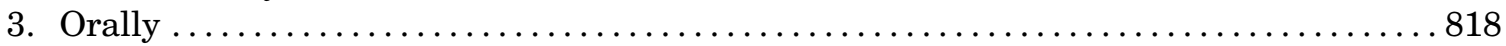

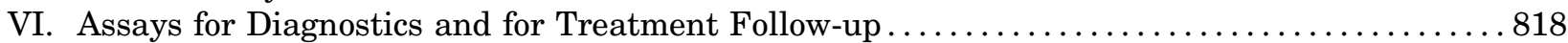

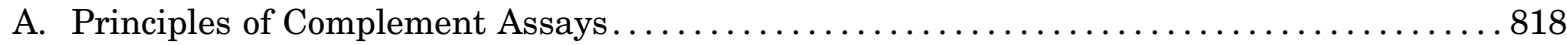

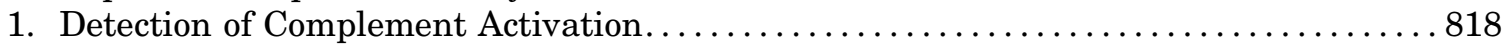

2. Screening for Total Complement Activity $\ldots \ldots \ldots \ldots \ldots \ldots \ldots \ldots \ldots \ldots \ldots \ldots \ldots \ldots$

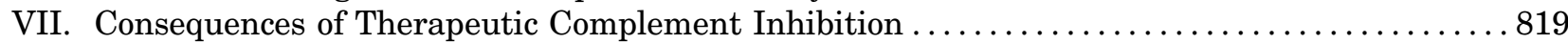

A. Safety and Adverse Effects ........................................ 819

1. Safety and Adverse Effects of Established C5 Inhibition ................... 819

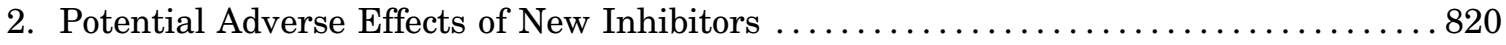

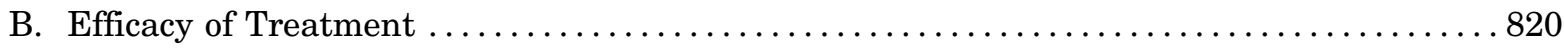

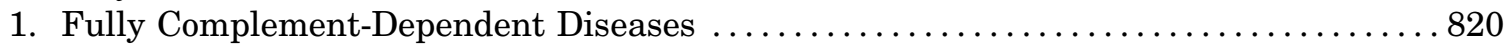

2. Diseases with Complex Pathophysiology ............................. 820

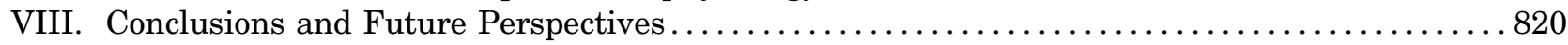

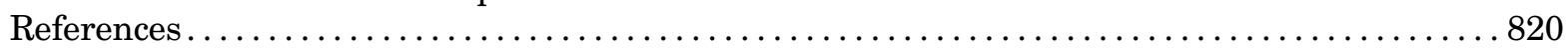

\begin{abstract}
ABBREVIATIONS: AAV, anti-neutrophilic cytoplasmic antibodies-associated vasculitis; aHUS, atypical HUS; AMD, age-related macula degeneration; APS, antiphospholipid syndrome; CAPS, catastrophic APS; C3aR, C3a receptor; C5aR1, C5a receptor 1; C5aR2, C5a receptor 2; C4BP, C4b-binding protein; C3G, C3 glomerulopathy; C3GN, C3 glomerulonephritis; CL, collectin; CNS, central nervous system; COVID-19, coronavirus disease 2019; CR, complement receptor; CRP, C-reactive protein; DAF, decay-accelerating factor; DAMP, damage-associated molecular pattern; DDD, dense deposit disease; Fc, fragment crystallizable; FDA, Food and Drug Administration; Gd-IgA1, galactose-deficient IgA1; GPI, glycosyl phosphatidyl inositol; HUS, hemolytic-uremic syndrome; iC3b, inactive C3b; IL, interleukin; mAb, monoclonal antibody; MAP-1, mannose-binding lectin/ficolin/collectin associated protein 1; MASP, MBL-associated serine protease; MBL, mannose-binding lectin; 3MC syndrome, Malpuech, Carnevale, Michels, and Mingarelli syndrome; MCP, membrane cofactor protein; MS, multiple sclerosis; NeF, nephritic factor; NLRP3, nucleotide-binding oligomerization domain-like receptor 3; PAMP, pathogen-associated molecular pattern; PAR, protease-activated receptor; PNH, paroxysmal nocturnal hemoglobinuria; PTX3, pentraxin 3; sC5b-9, soluble C5b-9; sCR1, soluble complement receptor 1; SLE, systemic lupus erythematosus; SNP, single-nucleotide polymorphism; SP, surfactant protein; TCC, terminal complement complex; TLR, Toll-like receptor; VEGF, vascular endothelial growth factor.
\end{abstract}


Abstract_L The complement system was discovered at the end of the 19th century as a heat-labile plasma component that "complemented" the antibodies in killing microbes, hence the name "complement." Complement is also part of the innate immune system, protecting the host by recognition of pathogen-associated molecular patterns. However, complement is multifunctional far beyond infectious defense. It contributes to organ development, such as sculpting neuron synapses, promoting tissue regeneration and repair, and rapidly engaging and synergizing with a number of processes, including hemostasis leading to thromboinflammation. Complement is a double-edged sword. Although it usually protects the host, it may cause tissue damage when dysregulated or overactivated, such as in the systemic inflammatory reaction seen in trauma and sepsis and severe coronavirus disease 2019 (COVID-19). Damage-associated molecular patterns generated during ischemia-reperfusion injuries (myocardial infarction, stroke, and transplant dysfunction) and in chronic neurologic and rheumatic disease activate complement, thereby increasing damaging inflammation. Despite the long list of diseases with potential for ameliorating complement modulation, only a few rare diseases are approved for clinical treatment targeting complement. Those currently being efficiently treated include

\section{Introduction}

The complement system has been essentially ignored and/or unknown in the clinic, and treatment of diseases with dysfunction of complement has been limited. There are several reasons for this. First, the willingness to consider this cascade as a component of disease initiation or progression has been virtually absent since most clinicians find it too complicated. Second, the relevance of the system in human diseases has been unclear. Third, lack of drugs has been a limitation for conducting clinical trials. The status for the complement system as late as in the 1980s was described in a summary after the Complement Meeting in the Royal Society in London in 1984, published in Immunology Today (now Trends in Immunology). Mike Hobart (1984) concluded,"Many immunologists hold that complement is baffling or irrelevant or, most conveniently, both, but a recent meeting emphasized that complement is interesting and that it may be important, even only as an elegant model system."

In recent years there has been a "clinical complement revolution," and we have learned that complement indeed is important, and although it is an elegant biochemical system, it is more than that. Modulation of the system has already come to clinical use, and the medical community would see gains in patient outcomes with a better awareness and understanding of the complement system (Mastellos et al., 2017; Ricklin et al., 2017, 2018; Gialeli et al., 2018; Harris et al., 2018; Tomlinson and Thurman, 2018; Wong and Kavanagh, 2018; Bordron et al., 2020). The hemostatic system with the coagulation and fibrinolytic cascades is well known paroxysmal nocturnal hemoglobinuria, atypical hemolyticuremic syndrome, myasthenia gravis, and neuromyelitis optica spectrum disorders. Rare diseases, unfortunately, preclude robust clinical trials. The increasing evidence for complement as a pathogenetic driver in many more common diseases suggests an opportunity for future complement therapy, which, however, requires robust clinical trials; one ongoing example is COVID-19 disease. The current review aims to discuss complement in disease pathogenesis and discuss future pharmacological strategies to treat these diseases with complementtargeted therapies.

Significance Statement_L The complement system is the host's defense friend by protecting it from invading pathogens, promoting tissue repair, and maintaining homeostasis. Complement is a double-edged sword, since when dysregulated or overactivated it becomes the host's enemy, leading to tissue damage, organ failure, and, in worst case, death. A number of acute and chronic diseases are candidates for pharmacological treatment to avoid complementdependent damage, ranging from the well established treatment for rare diseases to possible future treatment of large patient groups like the pandemic coronavirus disease 2019. with the consequences of bleeding or thrombosis when deficiency or dysregulation occurs. The complement cascade works along with the same principles, and phylogenetically the plasma cascades originated from a common ancestor.

In this review we aim to give an introduction to the complement system, including its primary functions. However, complement dysfunction and how we can approach diseases wherein complement participates in the pathogenesis will be highlighted. Thus, complement is a double-edged sword from being our protective friend on the one side to our enemy in the case that it gets out of control and does harm to the host. A thorough understanding of the interacting parts will pave the way for future successful pharmacological approaches to suppress excessive complement-mediated detrimental processes while not inducing long-term suppression of the beneficial effects of complement. This review will not cover a detailed list of ongoing trials and all possible drugs to be developed but rather highlight the general approaches on how to meet the challenges and alternatives of when and how to treat complement dysfunction. For those interested in a complete overview of ongoing trials and the corresponding drugs we recommend using https: / / clinicaltrials.gov / and "complement" as search key. This list is complete and continuously updated in contrast to tables printed in articles that are recently outdated.

\section{A. An Overview of the Complement System}

1. Discovery of the System. The complement system was discovered during the $1880 \mathrm{~s}-1890$ s by several 
scientists, including Paul Ehrlich, George Nuttall, Hans Buchner, and, notably, Jules Bordet (Buchner, 1891; Ehrlich, 1899; Skarnes and Watson, 1957; Nesargikar et al., 2012). It was discovered as a heat-labile factor in serum that contributed to bacterial killing and first named "alexin." Later it was termed "complement" based on Bordet's classic experiments from 1895 in which he distinguished two factors responsible for serum killing of a Gram negative bacterium: one was a heat-stable factor representing the antibodies against

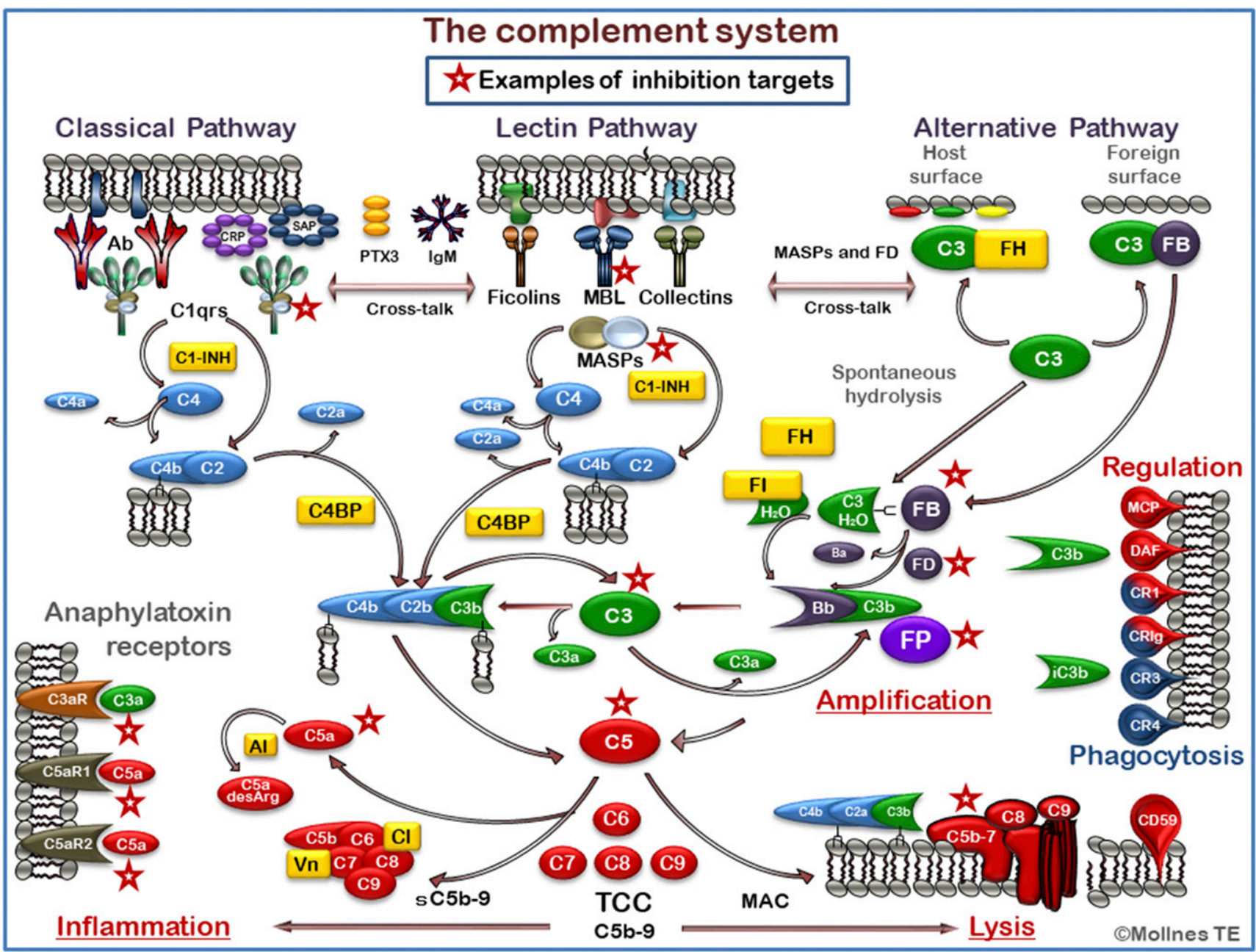

Fig. 1. An overview of the complement system with focus on most relevant targets for therapeutic inhibition. The complement system acts as a recognition system and can recognized danger and be activated through three initial pathways (upper part of figure), all converging to the cleavage of $\mathrm{C} 3$ to generate $\mathrm{C} 3 \mathrm{a}$ and $\mathrm{C} 3 \mathrm{~b}$ (middle part of figure). The classical pathway (CP) is typically activated by antibodies, but amyloid $\beta$ fibrils and pentraxins, including CRP, serum amyloid P component (SAP), and PTX3, can activate C1. The lectin pathway (LP) is activated through recognition of carbohydrates by MBL, ficolins, and collectins. Furthermore, LP activation may be mediated through IgM antibodies (e.g., directed against damaged self antigens). Both the $\mathrm{CP}$ and the $\mathrm{LP}$ activate $\mathrm{C} 4$ to $\mathrm{C} 4 \mathrm{a}$, and $\mathrm{C} 4 \mathrm{~b}$ and $\mathrm{C} 2$ subsequently bind to $\mathrm{C} 4 \mathrm{~b}$ and make the $\mathrm{C} 4 \mathrm{bC} 2 \mathrm{~b}$ convertase after $\mathrm{C} 2$ is cleaved to $\mathrm{C} 2 \mathrm{a}$ and $\mathrm{C} 2 \mathrm{~b}$. The alternative pathway (AP) is activated by foreign or damaged cells, as facilitated by the continuous spontaneous hydrolysis of C3. AP also has an important function in the complement system providing an amplification loop enhancing C3 activation independent of which pathway that is initially activated. This effect is enhanced due to properdin (FP), the only positive regulator in the complement system, which stabilizes the C3 convertase. Cleavage of C3 leads to formation of a C5 convertase, cleaving C5 into C5a and C5b. The anaphylatoxins C3a and C5a bind to the receptors C3aR, C5aR1, and C5aR2, leading to downstream production of proinflammatory and/or anti-inflammatory mediators (lower left part of figure). C5b initiates the formation of the TCC, which forms the membrane attack complex (MAC) if inserted into a membrane (bottom part of figure). This may lead to lysis of bacteria and cells or in sublytic doses to activation of cells. The cleavage and inactivation of C3b generate iC3b, binding to complement receptors CR3 (CD11b/CD18) and CR4 (CD11c/CD18) and facilitating phagocytosis, oxidative burst, and downstream inflammation (right part of figure). The complement system is tightly regulated by soluble inhibitors (marked in yellow), including C1-inhibitor (C1-INH), factor $\mathrm{H}$ (FH), factor I (FI), C4BP, carboxidase inactivation of the anaphylotoxins (AI), vitronectin (Vn), and clusterin (CLU), keeping the continuous low-grade activation in the fluid phase in check. Host cell membranes are equipped with a number of inhibitors to protect them against attack by complement (right part of figure), including MCP (CD46), CR1 (CD35), DAF (CD55) controlling C4 and C3 activation, and CD59 protecting against final assembly of the C5b-9 complex. Some selected attractive targets for therapeutic inhibition are indicated by red asterisks. Although many more could have been included, we selected C1s as a specific target from the CP, MBL, and MASP-2 from the LP, factor B, factor D, and properdin as specific for the AP and then $\mathrm{C} 3$ as the major component at which all three pathways converge and would be a very efficient blocker of the system. C5 is the next main candidate to block completely, as it will block the inflammatory potent C5a fragment and formation of the inflammatory and lytic C5b-9 complex or the solueble form sC5b-9. In addition, C5a can be inhibited, preserving the C5b-9 pathway, or the C5b7 can be blocked to prevent C5b-9 formation, leaving C5a open. Finally, the anaphylatoxin receptor's axes can be blocked to prevent signaling. In particular, blocking of C5aR1 will attenuate the proinflammatory inflammation, whereas the effects of blocking C3aR and C5aR2 receptors are to be studied in more detail since they might have more anti-inflammatory effects. FB, factor B. (The figure is a modified version of one published in J Leukoc Biol (2014) 101:193-204. Barratt-Due A, Pischke SE, Nilsson PH, Espevik T, Mollnes TE. Copyright by Mollnes TE.) 
the microbe, and the second was a heat-labile factor named "complement" since it "complemented" the antibodies in killing. Complement was present in all sera and belonged to the innate immunity, whereas specific antibodies were present only in sera from hosts that had been immunized or previously infected, except for a small group of IgM antibodies present early in life, including the $\mathrm{ABO}$ antibodies, which are frequently called natural antibodies.

The natural antibodies are not produced after typical immunization. In our context, those of particular importance are the IgM antibodies that bind to damaged self tissue, such as in ischemia-reperfusion injury, and activate complement immediately (Fleming and Tsokos, 2006; Zhang et al., 2006a). Thus, the complement system can use already-present IgM antibodies directly from "first line of defense" as a recognition mechanism. In addition, complement can directly bind to and kill many microbes, preventing disease and thus being unrecognized as a first line of defense in these cases. Secondly, complement cooperates with the adaptive immune response boosting the B-cell-mediated antibody response in the days and weeks after immunization and thus instructs adaptive immune defense (Carroll and Isenman, 2012) as a sensor and regulator of the speed and extent of the adaptive response. Thus, the complement system is not working alone. It is a prototype of crosstalk interaction with a number of other biologic systems, including the hemostatic systems leading the pathophysiological condition thromboinflammation (Ekdahl et al., 2016).

The complement system has in periods been a neglected field of research attention after its discovery. Below is a brief section on the history of complement during the first 100 years after discovery, and from thereafter the revolution during the last 3 decades until today is described.

Initially, complement was regarded only as a defense system to protect the host from infections. Today the system is known as a pluripotent homeostatic system with a number of functions beyond the microbial defense. For further reading on the complement system in general, several reviews have been published (e.g., Ricklin et al., 2010; Carroll and Sim, 2011; Ehrnthaller et al., 2011; Harboe et al., 2011; Ricklin and Lambris, 2013; Holers, 2014; Bajic et al., 2015; Merle et al., 2015; Hajishengallis et al., 2017; Wong and Kavanagh, 2018; Cedzyński et al., 2019; Reis et al., 2019; West et al., 2020). A cartoon of the system is presented in Fig. 1 with a short description of the structure, activation, and function in the legend.

2. The History of Complement Research from the 1880 s to 1980s. Although important contributions to the characterization of complement, including the initial discovery of discrete components, occurred in the early part of the 20th century, the recognition that there were three distinct initial pathways acting as recognition of danger and fully capable of inducing lytic activity was not fully appreciated until the second half of the 20th century. The biochemistry of C3 (MullerEberhard et al., 1960) and the three initial pathways (Pillemer et al., 1954; Pillemer, 1955; Lepow et al., 1963; Daha et al., 1976), the assembly of the common terminal C5b-9 complex, and the detection of C3 in injured tissue (Lachmann et al., 1962) were largely defined at that time because of the creative use and sometimes necessary brute force of technological advances in protein chemistry (Reid et al., 1972), biochemistry, and monoclonal antibody technology, which are briefly chronicled in Sim et al. (2016). The nature of the membrane attack complex (Podack et al., 1980) was intensively studied, and after 3 decades it is still debated whether it acts by leaky patches (Esser, 1991) or by a physical hole (Bhakdi and Tranum-Jensen, 1991). The biochemical identification and functional characterization of many of the complement regulator proteins (Lachmann and Muller-Eberhard, 1968) and receptors (Fearon, 1980), the use of animal models for in vivo mechanistic studies, and the identification of individuals genetically deficit in these components drove a plethora of novel insights on the critical importance of this system in human health and disease.

\section{B. The Complement System Approach in the Clinic: The Therapeutic Era}

1. The Revolution of Complement Research for the Last 3 Decades. It is now appreciated that there are over 40 proteins that can be counted as part of the complement system, including the canonical components, receptors for activation-generated cleavage products, and regulators of the cascade (Fig. 1). The influence of complement fragments (e.g., C3d, C3a, and C5a) on the type and extent of the adaptive response became evident, as reviewed in Luque et al. (2019), Reis et al. (2019), and Lo and Woodruff (2020). Novel complement control proteins are still being discovered, often with tissue-specific expression (Cong et al., 2020), and are reviewed in Gialeli et al. (2018). However, the domain protein structures have similar features (Forneris et al., 2016). The evasion by microbes of complement-mediated killing has demonstrated the constant battle as these pathogens evolved but also provide examples of how such regulation can be harnessed for application in mitigating excesses of complement activation. The consequences of an activated complement system with the vasculature, including but also beyond coagulation, lung tissue, brain, and the gut, are just beginning to be more fully addressed (Huber-Lang et al., 2018).

The emergence of the more rapid DNA-sequencing techniques in the 1980s, advances in NMR and X-ray crystallography at the turn of the century, and, later, the use of cryogenic electron microscopy enabled further molecular understanding of this multiple-component 
cascading system. The structures of the globular head domain of C1q and C3 (Gaboriaud et al., 2003; Janssen et al., 2005) and how complement is activated by IgG hexamers (Diebolder et al., 2014) were practically breathtaking in the impact they would have on the field. Combined with other sophisticated protein chemistry approaches, these advances enabled initial rational drug design for these pivotal proteins (Fredslund et al., 2008; Schuster et al., 2008; Skjoedt et al., 2012; Schmidt et al., 2016; Papanastasiou et al., 2017).

The impact that the complement system has on human health and disease and the advantages of precision medicine became even more evident with the recognition that distinct combinations of genetic variants leading to more or less effective activators (such as factor B, C3) and more or less effective inhibitors (such as factor $\mathrm{H}$ ), which are collectively referred to as a "complotype," confer differential sensitivity to infection and autoimmunity (Harris et al., 2012). Indeed, the identification of variants of factor $\mathrm{H}$ as being the major genetic risk factor in age-related macular degeneration (AMD) in 2005 (Daiger, 2005; Hageman et al., 2005) was a major stimulus in the investigation of complement in the role of neurodegenerative diseases of the elderly. In subsequent investigations, genetic variants in other complement components were also linked to AMD and led to clinical trials of targeted complement functions (Park et al., 2019). Genetic polymorphisms also can critically affect responses to complement drugs, such as that reported for C5 inhibition in the treatment of paroxysmal nocturnal hemoglobinuria $(\mathrm{PNH})$ and discussed below (Nishimura et al., 2014). Even more recently, the identification of intracellular complement activities, the "complosome," has provided intriguing evidence of far-reaching consequences of complement components on cellular metabolism and, subsequently, on both innate and adaptive immune responses [as reviewed in Kemper and Kohl (2018) and West et al. (2020)]. The impact of this intracellular complement system on the complement therapeutic landscape remains to be determined.

Although the liver was long thought to be the site of complement protein production [reviewed in Perlmutter and Colten (1986)], it became increasingly apparent that various complement components can be differentially induced in a variety of cell types and tissues (Minutti et al., 2017; Kemper and Kohl, 2018), including the brain (Singhrao et al., 1999). For example, complement components can be induced in the central nervous system (CNS) resident neurons, astrocytes, oligodendrocytes, cerebrovascular smooth muscle cells, and microglia during development or induced by injury or aging [reviewed in Tenner (2020)]. These findings have been confirmed recently by single-cell RNA sequencing (Zhou et al., 2020).

In tissues, as evident in the central nervous system, there appears to be transcriptional control to the sequence of induction of complement proteins depending on the type and level of signaling received by the cells. C1q can be synthesized in the absence of the $\mathrm{C} 1$ serine proteases $\mathrm{C} 1 \mathrm{r}$ and $\mathrm{C} 1 \mathrm{~s}$ in peripheral myeloid cells (Bensa et al., 1983) and is rapidly upregulated in response to injury (Lee et al., 2000). The addition of interferon- $\gamma$, perhaps as a signal of increased damage, was required to detect $\mathrm{C} 1 \mathrm{r}$ and $\mathrm{C} 1 \mathrm{~s}$ production by macrophages (Bensa et al., 1983). It then became clear that the $\mathrm{C} 1 \mathrm{q}$ molecule itself independent of $\mathrm{C} 1$ or other complement activities contributed to critical functions for both homeostasis, such as clearance of apoptotic cells, neuronal blebs, and cellular debris, and sculpting the adaptive immune system through induction of cytokines in myeloid cells that could subsequently facilitate a limit on adaptive responses [e.g., to self peptides ingested by phagocytes, as reviewed in Thielens et al. (2017)].

One of the most unexpected and paradigm-shifting discoveries in the past 2 decades has been the identification of the role of the classical complement pathway components $\mathrm{C} 1$ through $\mathrm{C} 3$ in synapse pruning (refinement) in the nervous system. Although this was first reported as mediating the ingestion of weak or unnecessary synapses during the development of retinal circuits (Stevens et al., 2007), it is now known to contribute to synaptic plasticity in adult brain, including most recently the process of forgetting (Wang et al., 2020). This pruning involves microglial ingestion of inactive C3b (iC3b)-tagged synaptic material (Stevens et al., 2007; Hong et al., 2016; Dejanovic et al., 2018) via the complement receptor (CR) 3 (Schafer et al., 2012). In addition, several groups have provided evidence for detrimental complement-mediated synapse pruning in animal models of aging, Alzheimer disease, multiple sclerosis, and other disorders that display cognitive or behavioral impairments (Stevens et al., 2007; Hong et al., 2016; Lui et al., 2016; Sekar et al., 2016; Vasek et al., 2016; Werneburg et al., 2020) and more recently in motor neuron disease (Vukojicic et al., 2019). Importantly for translation to the human condition, the accumulation of $\mathrm{C} 1 \mathrm{q} / \mathrm{C} 3 \mathrm{~b}$-tagged synapses and decreased synaptic density are also found in multiple human disorders, such as tauopathies, Alzheimer disease, and West Nile Virus-induced cognitive loss (Lui et al., 2016; Vasek et al., 2016; Wu and Sun, 2019). Surface-exposed phosphatidyl serine or annexin V (Györffy et al., 2018), decreased mitochondrial functions (Györffy et al., 2020), and loss of CD47 (Lehrman et al., 2018) have been associated with enhanced C1q binding and synapse engulfment in developmental or injury models similar to characteristics influencing the clearance of apoptotic cells.

Awareness and consideration of the above homeostatic, neuronal, and other reparative functions (Bossi et al., 2014; Thielens et al., 2017) are critical when selecting a target to pharmacologically inhibit harmful 
downstream complement activities, particularly in the case of chronic versus acute treatment.

2. Complement from Bench to Bedside: Today's Indications. Currently, when this review was written, there are four diseases for which complement-targeted drugs are approved for routine clinical use by the US Food and Drug Administration (FDA) and the European Medicines Agency. The "complement revolution" into the clinic started when eculizumab (Soliris), a mAbblocking cleavage of C5, was shown to be very efficient in protecting from hemolysis in PNH in 2007 (Brodsky et al., 2008; Parker, 2009), and this was later followed by treatment of atypical hemolytic-uremic syndrome (aHUS) (Tschumi et al., 2011; Loirat et al., 2016). Recently it was also approved for the neurologic diseases generalized myasthenia gravis (Dhillon, 2018) and neuromyelitis optica spectrum disorders (Selmaj and Selmaj, 2019). For details of these rare diseases, see separate sections below.

Eculizumab has been the only approved complement inhibitor for routine use until recently when ravulizumab (Ultomiris) and Zilucoplan were introduced. Ravulizumab is the second generation of eculizumab; in other words, some minor amino acid modifications were made in the eculizumab molecule, thereby increasing the half-life substantially so treatment intervals could be increased from every 2 nd to every 8 th week. It has the same binding site to C5 as eculizumab (i.e., blocking its cleavage and thereby preventing the release of C5a and formation of C5b-9) (Kulasekararaj et al., 2019; Lee et al., 2019; McKeage, 2019; Stern and Connell, 2019; Lee and Kulasekararaj, 2020).

Zilucoplan is an entirely different drug structurally from the antibody mentioned above but with the same principal function. It is a synthetic, macrocyclic peptide inhibitor for subcutaneous self-administration with principally the same function as eculizumab, blocking the cleavage of C5 (Beecher et al., 2019; Albazli et al., 2020; Howard et al., 2020). A phase 2 randomized, double blind, placebo-controlled, multicenter clinical trial demonstrated that Zilucoplan administration yielded rapid, meaningful, and sustained improvements over 12 weeks in a broad population of patients with moderate-to-severe acetylcholine-receptor-antibody-positive generalized myasthenia gravis (Howard et al., 2020). A phase 3 trial (Recovery After an Initial Schizophrenia Episode study) investigating the safety, tolerability, and efficacy of Zilucoplan in subjects with generalized myasthenia gravis (https://clinicaltrials.gov/ct2/show/NCT04115293) is currently ongoing. RA 101295, a close analog of Zilucoplan (RA101495), has been used in animal studies and has been shown to increase survival in baboon Escherichia coli sepsis (Keshari et al., 2017).

Below we refer to different complement therapeutic drug groups under development and in trials. We emphasize, however, that $\mathrm{C} 1$-inhibitor, a regulator of the classical and lectin complement pathways, frequently is listed among therapeutic complement inhibitors. However, it should not be regarded as a specific complement drug since it is a broad serine protease inhibitor with regulatory functions in several plasma cascade systems. Thus, patients deficient in C1-inhibitor do not have a pure complement pathophysiological phenotype but rather a disturbance in the bradykinin system. Still, it is included when the complement system is discussed because the complement laboratories do the diagnostics. The indication for use should be conditions with "pan-cascade" disturbances and not specific complement dysregulation.

\section{Complement Deficiencies and Loss- or Gain- of-Function Mutations}

Complement deficiencies can be genetic or acquired (Sjöholm et al., 2006; Botto et al., 2009; Skattum et al., 2011). Homozygous genetic deficiencies generally result in undetectable protein levels or function in plasma, whereas heterozygous deficiencies typically present with approximately half of normal levels. Without genetic analysis, they can be difficult to discriminate from an acquired deficiency, which can present with any level of decreased concentration, although very rarely a complete absence. Acquired deficiencies often affect several components. Most frequently they are caused by increased consumption due to in vivo activation and thus consumption of the components or due to liver failure, as most of the blood complement components are produced in the liver. A valuable tool to distinguish between these causes of reduced components is to measure complement activation products (Harboe et al., 2011). These will normally be elevated during in vivo activation and low, normal, or decreased when synthesis is reduced, such as by liver damage. Screening for complement deficiencies, particularly for total genetic deficiencies, is performed by hemolytic assays, which gradually have been replaced by ELISA assays (e.g., the Wieslab Total Complement Screen assay in which all the complement pathways are screened for) (Seelen et al., 2005). The principles and interpretation of these assays will be described below (see section VI and Fig. 7).

Genetic mutations with the protein present may be loss-of-function or gain-of-function mutations, whereas the synthetic rate and concentration of the protein in plasma can be normal. If the mutation leads to activation and consumption of certain proteins (e.g., C3), the serum concentration is frequently reduced. Some functional assays exist for certain proteins, but today genetic tests are used for identification of clinically relevant mutations.

\section{A. Classical Pathway Deficiencies}

1. The Components of the Classical Pathway, Their Activation, and Regulation. The classic pathway is 
shown in the upper left part of Fig. 1. The classical pathway consists of the trimolecular protein complex $\mathrm{C} \mathrm{qr}_{2} \mathrm{~s}_{2}, \mathrm{C} 4, \mathrm{C} 2, \mathrm{C} 1$-inhibitor, and $\mathrm{C} 4 \mathrm{~b}$-binding protein (C4BP). C1q is normally activated by binding to the Fc part of antibodies after they bind to its antigen. However, antibodies are not the only targets for C1q. Pentraxins like C-reactive protein (CRP), long pentraxin 3 (PTX3), serum amyloid $\mathrm{P}$, and fibrillar amyloid $\beta$ can also bind and activate $\mathrm{C} 1 \mathrm{q}$ in an antibodyindependent manner (McGrath et al., 2006; Bíró et al., 2007; Du Clos and Mold, 2011; Doni et al., 2012). C1r and $\mathrm{C} 1 \mathrm{~s}$ are proenzyme serine proteases triggered by $\mathrm{C} 1 \mathrm{q}$ bound to an activator to be activated and cleave $\mathrm{C} 4$

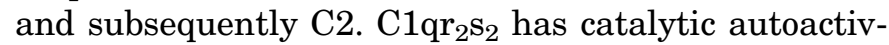
ity, which is kept under strict control by C1-inhibitor (Ziccardi, 1982). C4BP is the second regulator in the classical pathway. It serves a cofactor for factor I and thereby controls and inactivates C4b (Sjöberg et al., 2009) (Fig. 1).

Receptors for classical pathway components and activation products are mainly limited to the different C1q receptors (Ghebrehiwet and Peerschke, 2014). It remains to be elucidated whether these are therapeutic targets. No specific receptor for $\mathrm{C} 4 \mathrm{a}$ has been described, but protease-activated receptors (PARs) 1 and 4 were recently shown to bind $\mathrm{C} 4 \mathrm{a}$ (Wang et al., 2017). PARs are a subfamily of related $\mathrm{G}$ protein-coupled receptors that are activated by cleavage of part of their extracellular domain.

2. Deficiencies of the Classical Pathway Components. Deficiencies of the classical pathway are relatively rare; the phenotype varies from being healthy to presenting with a severe disease, which is usually autoimmune or infectious (Truedsson, 2015). Low C1q may be genetic or due to consumption, as seen in immune-complex diseases and acquired angioedema. Genetic deficiencies are highly associated with systemic lupus erythematosus (SLE)-like disease, which might be severe particularly when affecting the kidneys. Most of the genetic C1deficient individuals develop autoimmune disease (Kirschfink et al., 1993), but it should be noted that only a very small percentage of patients with SLE have genetic $\mathrm{C} 1$ deficiency because it is extremely rare.

C4 deficiency may have a similar phenotype as $\mathrm{C} 1$ deficiencies, but it is less severe. $\mathrm{C} 4$ has two isoforms encoded from separate genes (C4A and C4B) and up to six copies per genome (Yang et al., 2007). The C4 isoforms are very homologous and differ with only four amino acids in their sequence. Deficiency of the isoforms is very common and may be seen in between $1 \%$ and 10\% (Szilágyi and Fust, 2008). However, total C4 deficiency due to lack of both $\mathrm{C} 4 \mathrm{~A}$ and $\mathrm{C} 4 \mathrm{~B}$ is extremely rare.

Total C2 deficiency is the common classical component deficiency (frequency 1:10-20000). Half of the individuals are healthy, but some develop severe infections or autoimmune disease (Trapp et al., 1987; Yang et al., 2007). Complete deficiency of C4BP has so far not been described in humans, but nonsynonymous alterations in its sequence have been found in hemolyticuremic syndrome and recurrent pregnancy loss (Ermert and Blom, 2016).

3. Disturbances of the Classical Pathway and Therapeutic Targets. Substitution therapy exists for C1-inhibitor deficiency with several purified C1inhibitor concentrates available. However, bradykininreceptor antagonists like icatibant have gradually replaced C1-inhibior. There are no other purified components available for clinical therapy in the classical pathway nor in the rest of the complement system. Plasma infusions have occasionally been used as the source for a defective of the deficient component. For example, one patient who was C2-deficient with SLE affecting the kidneys was treated for years with plasma infusions that apparently had a good effect (Steinsson et al., 1989). However, plasma infusions are not typically used in complement deficiencies. It contains proteins from the whole plasma cascade and enzymes as well as regulators, and caution should be taken not to bring "oil to the fire." Thus, diseases related to classical pathway dysfunction are treated according to symptoms: immunosuppressive drugs for autoimmune diseases, vaccines and antibiotics in case of infections, and general care to detect early symptoms requiring treatment.

A completely different treatment approach is required when in a normal individual with the classical components intact, and the classical pathway is activated by an external structure. If this activation is fully classical pathway-specific and does not involve initial lectin or alternative pathway, inhibition of the system at the level of $\mathrm{C} 1$ would be a rational option. Targets could then be $\mathrm{C} 1 \mathrm{q}, \mathrm{C} 1 \mathrm{r}$, or $\mathrm{C} 1 \mathrm{~s}$, although chronic indications targeting $\mathrm{C} 1 \mathrm{q}$ should be avoided since it has far more biologic functions than activation of the complement system, as explained above. The prototypical example of such a purely classical pathway disease is the cold agglutinin syndrome, wherein IgM autoantibodies lyse red cells purely through a classical complement-mediated mechanism (Berentsen, 2018). Studies using blockers of $\mathrm{C} 1 \mathrm{~s}$ are discussed below under the disease chapter.

\section{B. Lectin Pathway Deficiencies}

1. The Components of the Lectin Pathway, Their Activation, and Regulation. The lectin pathway is shown at the upper middle part of Fig. 1. The lectin pathway consists of two classes of soluble patternrecognition molecules named "collectins" and "ficolins," a set of activating enzymes termed "mannose-binding lectin/ficolin/collectin associated serine proteases" (MASPs), and different regulators (Garred et al., 2016). All the recognition molecules in the lectin pathway are composed of a structure to C1q from 
classical pathway containing polypeptide chains having a C-terminal globular recognition domain and an $\mathrm{N}$-terminal collagen-like structure assembled into a triple helix structure. The triple helix structure is further assembled into macromolecules with a tulip-like appearance in electron microscopy ( $\mathrm{Lu}$ et al., 1993). The collectin protein family comprises the prototypic mannose-binding lectin (MBL) (also termed mannanbinding lectin), collectin (CL)-10 (also termed liver 1 or CL-L1), and CL-11 (also termed collectin kidney 1 or CL-K1). CL-10 and CL-11 exist as homomeric proteins as well as heteromeric complexes between CL-10 and CL-11 polypeptide chains CL10/CL-11 (also called CLLK) (Henriksen et al., 2013). In addition, the lung surfactant protein (SP)-A and SP-D also belong to the collectin family. However, they do not activate the complement system (Tenner et al., 1989), as reviewed in Murugaiah et al. (2020). The protein CL-12 (also called collectin placenta 1 or CL-P1) may be included in the family (Hansen et al., 2016). It is a transmembrane protein that correspondingly is found as a fluid analog. This analog does not activate the lectin pathway but appears to serve as a docking station for the alternative pathway molecule properdin (Ma et al., 2015; Zhang et al., 2020).

The ficolin protein family comprises ficolin-1 (M-ficolin), ficolin-2 (L-ficolin), and ficolin-3 (H-ficolin) (Endo et al., 2015). As for CL-10 and CL-11, ficolin-2 and ficolin-3 may also be found as heterocomplexes in the circulation, but the stoichiometry for theses complexes is at present unknown (Jarlhelt et al., 2020). The main functional difference between the collectins and ficolins is defined by the C-terminal globular recognition domain, which for the collectins is a calcium-dependent carbohydrate-binding domain, whereas for the ficolins it is a fibrinogen-like binding domain.

The activating enzymes of the lectin pathway comprise a set of serine protease named the MASPs after the first discovery of their interaction with the MBL molecule. The MASP family is comprised of five different proteins arising from two different genes (Yongqing et al., 2012). MASP-1 and MASP-3 are enzymes, whereas mannose-binding lectin/ficolin/collectin associated protein 1 (MAP-1) (also termed MAp-44) is a truncated lectin pathway regulator without enzymatic activity (Matsushita and Fujita, 1992; Sato et al., 1994; Degn et al., 2009; Skjoedt et al., 2010). They are derived from the MASP1 gene by alternative splicing, whereas the MASP-2 enzyme and the truncated protein MAP-2 [also termed MAp-19 or small MAP (sMAP)] are derived from the MASP2 gene (Thiel et al., 1997; Stover et al., 1999).

All the MASPs and MAPs are found in the circulation as calcium-dependent homodimers predominantly associated with recognition molecules. MASP-1 is a multifunctional protease that may activate MASP-2 and cleave C2 (Héja et al., 2012). However, it also influences the coagulation and kinin systems from multiple angles (Ekdahl et al., 2016). MASP-3 has been shown to be crucial in the activation of the alternative pathway by cleaving the proform of factor $\mathrm{D}$ to the active form initiating its enzymatic activity (Dobó et al., 2016b; Hayashi et al., 2019). Apart from profactor D, the substrate specificity of MASP-3 is not well determined, but indeed insulin-like growth factor-binding protein-5 is the first and at present the only other protein that MASP-3 has been shown to cleave except for profactor D (Cortesio and Jiang, 2006). The predominant substrate of MASP-2 is C4, and this is followed by C2, which is analogous to C1s (Rossi et al., 2001). Thus, both MASP1 and MASP-2 appear to be necessary to create a robust C3 convertase.

Recently, it has been shown that MASP-2 under certain circumstances might induce direct activation of C3 into C3a and C3b, creating a C4 and C4 bypass mechanism (Yaseen et al., 2017). This interaction might be involved in enhancing the effect of the alternative pathway amplification loop. This noncanonical activation mechanism might be of importance under several pathophysiological circumstances. The function of the noncatalytic splice variant MAP-2 also appears to have a regulatory function in the lectin pathway but to a lesser degree than MAP-1 (Rossi et al., 2001).

C1-inhibitor inhibits the enzymatic activity of MASP1 and MASP-2 (Ambrus et al., 2003). However, a contribution of antithrombin in the presence of heparin has also been reported (Presanis et al., 2004). The molecular mechanism behind MASP-3 regulation is at present unknown. MBL, ficolin-1, and ficolin-2 interact with CRP, serum amyloid P, and PTX3, whereas this does not appear to be the case for ficolin-3 (Ma et al., 2017). $\mathrm{C} 4 \mathrm{BP}$ is also a lectin pathway regulator serving as a cofactor for factor I in the cleavage and control of $\mathrm{C} 4$ and to a lesser degree $\mathrm{C} 3$, and it also has a decayaccelerating function on the C3 convertase (Blom et al., 2004). No exclusive lectin pathway receptors have been described, and the suggested receptors are limited to the different C1q receptors (Ghebrehiwet et al., 2019). None of these have firmly been established as real receptors but at present act more as binding partners. Recently the endocytic collagen receptor urokinase plasminogen activator receptor-associated protein has been shown being important for sequestration of some collectins in tissues (MBL and SP-D) (Jürgensen et al., 2019).

2. Deficiencies of the Lectin Pathway Components. Deficiencies of certain lectin pathway components are relatively common, whereas others are rare (Degn et al., 2011; Goicoechea de Jorge et al., 2018). The phenotypes vary from being healthy to presenting with a severe disease usually related to a tendency for increased infection, increased severity of different diseases without being causally related, or, surprisingly, embryonic development disturbances. The most common deficiency of the lectin pathway is due to low concentrations 
or dysfunction of MBL, which is seen in 5\%-7\% of the Caucasian population (Garred et al., 2006). Although the relevance of MBL as a single disease-causing factor is still a matter of debate, decreased MBL levels are considered to be an aggravating factor in the pathophysiology of diseases, such as cystic fibrosis (Garred et al., 1999; Dorfman et al., 2008; Degn et al., 2011) and other chronic lung diseases not related to cystic fibrosis (Chalmers et al., 2013). Common variable immunodeficiency is another example of a chronic illness wherein low levels of functional MBL appear to aggravate the disease course (Andersen et al., 2005; Fevang et al., 2005; Litzman et al., 2008).

Low levels of MBL may also have a negative impact on kidney graft survival (Bay et al., 2013; Golshayan et al., 2016; Czerewaty et al., 2019) and on long-term outcomes of cardiovascular diseases (Øhlenschlaeger et al., 2004; Vengen et al., 2012). However, this might be counterbalanced by an acute proinflammatory function of MBL since high levels of MBL have also been shown to be associated with adverse outcome in more acute situations as well (Fumagalli et al., 2017). It has been proposed that MBL association may follow a U-shaped curve since both low and high levels might be associated with disease (Troelsen et al., 2010). This has recently been elegantly demonstrated in a type 2 diabetes population cohort in that both low- and high-serum MBL (as predicted from the genetic polymorphisms) were associated with poor cardiovascular outcome and mortality (Gedebjerg et al., 2020). A similar phenomenon has been observed for MBL in patients admitted to intensive care units because of systemic inflammation and sepsis (Hellemann et al., 2007). Nevertheless, this makes interpretation of MBL disease associations difficult and requires that these studies be carefully planned and performed.

Several single-nucleotide polymorphisms (SNPs) have been identified in the promoter and exons of the MBL2 gene encoding MBL in humans that explain the high variability observed in MBL serum levels. Most of that variation can be attributed to three different SNPs (i.e., alleles B, C, and D) within the MBL2 exon 1 and SNPs in the promoter region of the MBL2 gene, which gives rise to a complex haplotype system that determines the MBL serum concentration (Garred et al., 2006). However, the serum concentration may vary considerably between individuals carrying the same haplotype. Even in homozygotes for the structural variants, MBL protein might be detected. However, this variant protein is dysfunctional with low binding avidity to ligands and cannot activate complement (Garred et al., 1999; Garred et al., 2003; Larsen et al., 2004).

CL-10 and CL-11, which are encoded by COLEC10 and COLEC11, respectively, are two highly homologous collectins that mostly circulate in the plasma as high-molecular-weight CL-10/CL-11 heterocomplexes
(Henriksen et al., 2013; Bayarri-Olmos et al., 2015, 2018). They display an identical domain distribution and a $47 \%$ sequence homology at the amino acid level, but whereas CL-11 is a known activator of the lectin pathway (Bayarri-Olmos et al., 2018), the biologic role of CL-10 on its own remains obscure. However, the heterocomplexes between CL-10 and CL-11 activate complement (Henriksen et al., 2013). Recently, exome sequencing studies in patients with Malpuech, Carnevale, Michels, and Mingarelli syndrome (3MC syndrome) revealed that several of them carry COLEC10 and COLEC11 mutations as homozygotes or compound heterozygotes, which result in complete CL-10 or CL-11 deficiencies (Rooryck et al., 2011; Munye et al., 2017). Originally described as four separate disorders, the $3 \mathrm{MC}$ syndrome is an ultra-rare congenital disorder characterized by mental retardation, growth deficiency, and physical abnormalities, such as cleft lip, hypertelorism, eyelid drooping, and skeletal malformations (Titomanlio et al., 2005). It has been suggested that CL10 and CL-11 are essential in the development of craniofacial structures by regulating neural crest cell migration and maintaining cell adhesion (Gajek et al., 2020).

For the three ficolins, only ficolin-3 deficiency, which is caused by a rare frameshift mutation in the FCN3 gene, has been described in humans with variable clinical manifestations mainly related to a tendency for increased infection, autoimmunity, and neurologic complications (Munthe-Fog et al., 2009; Schlapbach et al., 2011; Michalski et al., 2012; Troldborg et al., 2019; Babaha et al., 2020; Dadfar et al., 2020). However, polymorphisms in the FCN1 and FCN2 genes associated with different serum levels of ficolin-1 and ficolin2 , respectively and their functions have been associated with different infectious and autoimmune conditions, but no clear consensus exists about these associations (Garred et al., 2016).

MASP deficiencies are rare (Degn et al., 2011). MASP-2 deficiency was the first MASP deficiency to be described and has been associated with recurrent infections and chronic inflammatory diseases (Stengaard-Pedersen et al., 2003; Bibert et al., 2019). However, it appears not to be indispensable since deficiencies are observed in healthy individuals and blood donors (García-Laorden et al., 2020). Mutations in the MASP1 gene have also been reported in families with 3MC syndrome (Sirmaci et al., 2010; GraulNeumann et al., 2018; Basdemirci et al., 2019). The large majority of MASP genetic variants are located in exons coding for the specific serine protease domain of MASP-3 (Gajek et al., 2020). All described variants except for one destabilize the protein structure leading to intracellular degradation or decreased protein expression (Gajek et al., 2020). Regardless of their location in the MASP1 gene, all mutations obliterate MASP-3 activity, thereby reinforcing the notion that impaired 
activity of MASP-3 activity is central to the development of the $3 \mathrm{MC}$ syndrome.

Both MASP-1 and MASP-3 display a wide variety of activities, which may be the reason for the different consequences of defective MASPs. MASP-1 is known to interact with systems spanning well beyond the lectin pathway, such as coagulation and kallikrein-kinin as well as inflammatory and cellular processes, including the activation of PAR (Dobó et al., 2016a). Originally thought to be mediated by MASP-1, MASP-3 has recently been shown to be a principal profactor-D activator in blood in addition to its association with the 3MC syndrome (Iwaki et al., 2011; Dobó et al., 2016b; Oroszlán et al., 2016; Gajek et al., 2020). In the latter, the molecular substrate specificity has not been solved yet. So far substrate specificity of MASP-2 appears to be narrower than that of MASP-1 and MASP-3, but MASP2 may also cleave prothrombin into active thrombin in addition to its role in the complement system (Dobó et al., 2016a).

3. Disturbances of the Lectin Pathway and Therapeutic Targets. MBL deficiency has been regarded as an attractive pharmaceutical treatment possibility, particularly in the situation of treatment-induced neutropenia combined with MBL deficiency (Neth et al., 2001; Peterslund et al., 2001; Eisen and Minchinton, 2003; Jensenius et al., 2003). Substitution therapy both with plasma purified and MBL produced by recombinant technique has been tried in smaller scale (Valdimarsson et al., 1998; Garred et al., 2002; Petersen et al., 2006; Bang et al., 2008; Brouwer et al., 2009), but more extensive studies have not been initiated so far. Pharmaceutical regulation of the activity in the lectin pathway has gained interest over the last few years since lectin pathway activation mediated via MASP-2 has been shown to associate with several inflammatory diseases (Dobó et al., 2016a); suitability of substitution therapy for lectin pathway deficiencies remains to be determined.

An inhibitory anti-MASP-2 antibody has been suggested to be effective in pilot trials in IgA nephropathy, SLE nephritis, PNH, aHUS, and bone marrow transplantation-associated thrombotic microangiopathy (https://www.omeros.com). This has led to the initiation of phase 3 trials, which await completion. Also, inhibition of MASP-3 appears to be an attractive target in alternative pathway-related diseases, but so far results from clinical trials have not been published. Thus, it may be anticipated that pharmacological manipulation of the lectin pathway might be a feasible target in the future.

\section{Alternative Pathway Deficiencies}

1. The Components of the Alternative Pathway, Their Activation, and Regulation. The alternative pathway is shown at the upper right part of Fig. 1. The alternative pathway is the amplification loop of the complement system, enhancing the activation potential of both the classical and lectin pathways by $80 \%-90 \%$ and leading to an efficient activation of the terminal C5-C9 pathway (Harboe et al., 2004; Harboe et al., 2006). It consists of the central component $\mathrm{C} 3$; factor $\mathrm{B}$; factor $\mathrm{D}$, which is the only protease circulating in active form in plasma; and the regulatory protein's factor $\mathrm{H}$, which is the analog to the classical pathway C4BP, which is a cofactor for factor $\mathrm{I}$ in cleavage and inactivation of C3b. Properdin is the only regulatory protein in the complement system that enhances activation, and its role in complement activation was recently revised (Harboe and Mollnes, 2008). It binds to the alternative pathway convertase $\mathrm{C} 3 \mathrm{bBb}$ giving $\mathrm{C} 3 \mathrm{bBbP}$, with an extended half-life of the convertase enabling more $\mathrm{C} 3$ cleavage. The role of properdin as a recognition molecule is under debate (O'Flynn et al., 2014; Harboe et al., 2017). In addition to these fluid factors, several membrane receptors act as regulators of the alternative pathway: CR1 (CD35) binds C3b, C4b, and, to a lesser extent, $\mathrm{C} 1 \mathrm{q}$ and is a cofactor for factor I. Membrane cofactor protein (MCP) (also known as CD46), decay-accelerating factor (DAF) (also CD55), and CRIg also regulate the extent of $\mathrm{C} 3 \mathrm{~b}$ decay acceleration and/or cofactor activity (Fig. 1).

C3 is activated by several mechanisms: First, the internal thioester spontaneously hydrolyzes resulting in the formation of $\mathrm{C} 3\left(\mathrm{H}_{2} \mathrm{O}\right)$, which binds factor $\mathrm{B}$, which is subsequently cleaved and activated by factor $\mathrm{D}$, which then cleaves $\mathrm{C} 3$ to $\mathrm{C} 3 \mathrm{~b}$ and $\mathrm{C} 3 \mathrm{a}$. This was called C3 "tick-over," as described in 1980 (Tack et al., 1980), and the concept was revisited recently (Fromell et al., 2020). Second, C3 is activated by the classical/lectin C3 convertase C4bC2b (Bohlson et al., 2019). Finally, once $\mathrm{C} 3 \mathrm{~b}$ is covalently linked to foreign surfaces, it can bind to factor B, which is in turn cleaved by factor D. This surface attached the alternative pathway convertase $\mathrm{C} 3 \mathrm{bBb}$ and can continue to cleave more $\mathrm{C} 3$, depositing more C3b on the foreign surface. Such continued activity is not supported on self surfaces because it is inhibited by the regulators mentioned above. For example, factor $\mathrm{H}$ competes with factor $\mathrm{B}$ and prevents further cleavage of $\mathrm{C} 3$ and deposition of $\mathrm{C} 3 \mathrm{~b}$ on host cells. In general, factor $\mathrm{H}$ is the most important regulatory protein in the alternative pathway. This is particularly due to the protein not only inhibiting the C3 convertase in the fluid phase but also because it binds to the endothelium and other cells to protect from host surface activation (Jokiranta et al., 2005; Heinen et al., 2007). This is a particularly important mechanism when it comes to the pathogenesis of complement and to the therapeutic utility of factor $\mathrm{H} /$ factor $\mathrm{H}$ fragments as a mediator of complement inhibition in a number of diseases.

2. Deficiencies of the Alternative Pathway Components. Deficiencies of the alternative pathway are the most important with respect to development of severe human diseases. In particular, mutations in 
Cascade Principles

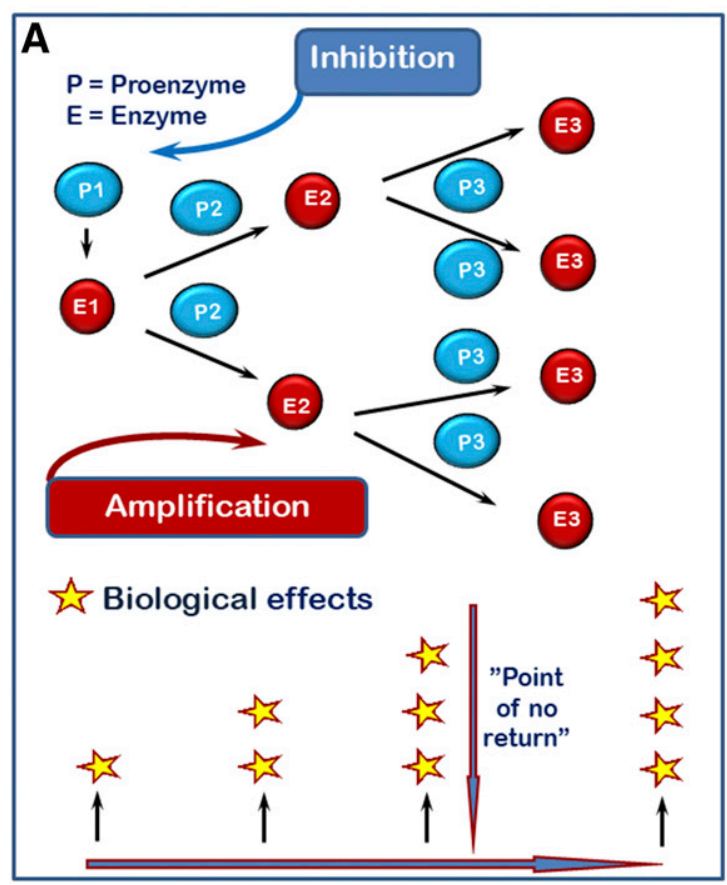

Complement dysregulation
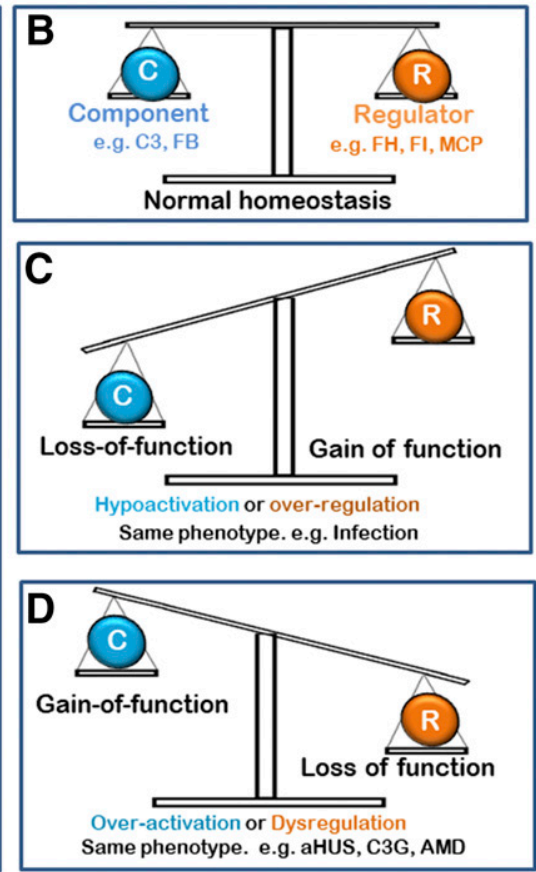

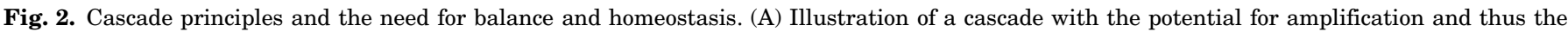

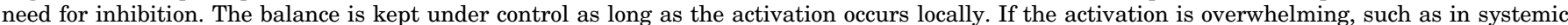

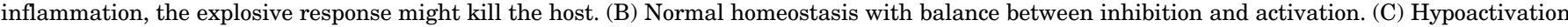

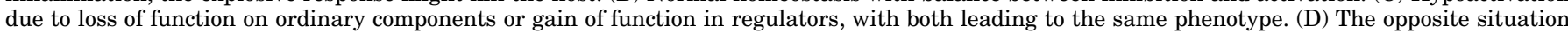

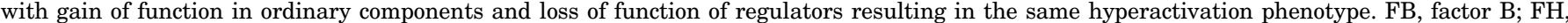
factor H; FI, factor I.

factor $\mathrm{H}$ and, secondly, in other regulators, including factor I and CD46, can lead to severe diseases due to uncontrolled turnover of $\mathrm{C} 3$ and consequent excessive activation of the whole system (Meri, 2013) (Fig. 2D). Similarly, gain of function of C3 and factor B give the same phenotype as the loss of function in the regulatory proteins since these also result in uncontrolled C3 activation (Fig. 2D). Rare genetic deficiency of C3 results in serious infections and kidney diseases (Singer et al., 1994; Reis et al., 2006). One patient who was factor B-deficient has been described (Slade et al., 2013), and a few cases of human factor-D deficiencies have been characterized wherein the patients suffer from infectious diseases, particularly Neisseria, and kidney disease (Hiemstra et al., 1989; Biesma et al., 2001; Sprong et al., 2006). In contrast, genetic properdin deficiencies are well known with different penetrance and with increased susceptibility for infections, particularly for neisserial species since these bacteria are prone to being killed by C5b-9 (Sjöholm et al., 1988; Schejbel et al., 2009). They often require C5b-9 or a higher level of C3 opsonization to be killed.

3. Disturbances of the Alternative Pathway and Therapeutic Targets. As with the classical and lectin pathways, there are no specific substitution therapies for deficient alternative components. Plasma infusion is frequently contraindicated, as it brings "oil to the fire" in cases with genetic deficiency, inducing antibody responses to the exogenously provided component, which is seen as a foreign protein. Plasma exchange may be an option if there are nephritic factors (NeFs) present, which are autoantibodies to the convertases that stabilize them and act phenotypically like a factor$\mathrm{H}$ mutation. However, this is an unsatisfactory therapy, and other treatments exist, including general immunosuppression or immunotherapy, such as rituximab to limit antibody production. However, recent years of experience have suggested complement inhibition to be the treatment of choice in most of the disturbances of the alternative pathway. It will be less demanding and give fewer adverse effects than the current therapy.

Targets to be inhibited in the alternative pathway to reduce overactivation are $\mathrm{C} 3$, factor $\mathrm{D}$, factor $\mathrm{B}$, and properdin. C3 blocks the whole cascade and not only the alternative pathway, as it is the common molecule at which the three initial pathways merge and thus would be the most potent inhibition of the system. Factor $D$ is the rate-limiting molecule of the alternative pathway and requires small amount of drug in contrast to factor $\mathrm{B}$, which is present in large amounts. Inhibition of properdin reduces the alternative activation, as it is a positive regulator.

There are several receptors that bind C3 fragments. The C3a molecule and its receptor C3aR are both therapeutic targets (Ames et al., 2001; Lohman et al., 2017; Ahmad et al., 2020). C3a is generated as a result of 
activation of any of the three initiation pathways upon cleavage of $\mathrm{C} 3$. It binds to a $\mathrm{G}$ protein-coupled seventransmembrane receptor $\mathrm{C} 3 \mathrm{aR}$. The consequences of this receptor signaling can be either proinflammatory or anti-inflammatory and vary depending on cell type. For example, C3a induces the release of histamine from mast cells and enhances proinflammatory cytokine production in macrophages but suppresses neutrophil migration to inflamed tissues [as reviewed in Coulthard and Woodruff (2015)]. In addition to the C3aR cell-type specificity, some responses require costimulation with other receptors, such as Toll-like receptors or C5aR1. To further complicate the system, it has been shown that a peptide cleavage fragment of VGF, TLQP-21, suppresses microglial activation via C3aR (El Gaamouch et al., 2020) and thus may be particularly influential in the context of Alzheimer disease because VGF has been identified as an important regulatory protein in Alzheimer disease (Beckmann et al., 2020). There is also evidence for an additional (and perhaps counter-) receptor for C3a, as enhanced expression of C3a in brain of a C3aR knockout mouse provided protection in a mouse model of endotoxic (lipopolysaccharide) shock (Boos et al., 2005). These dual activities are a challenge when trying to apply therapeutic targeting strategies in both acute and chronic disorders.

The other C3 fragment receptors serve various functions. Specifically, CR1 (CD35) binding C3b and CRIg binding $\mathrm{C} 3 \mathrm{~b}$ and $\mathrm{iC} 3 \mathrm{~b}$ protect the host cells against complement attack (He et al., 2008) and can facilitate phagocytosis of opsonized pathogens. CR2 (CD21) binds C3d covalently linked to antigen, resulting in enhanced B-cell activation upon antigen recognition by the B-cell surface immunoglobulin. CR3 and CR4 (CD11b/CD18 and CD11c/CD18) are integrins binding iC3b and serve as efficient phagocytosis receptors for microbes, cells, and particles opsonized by iC3b. There are soluble forms of several of these receptors, and interestingly some of them are possible targets for inhibition of C3 cleavage, such as sCR1 (Weisman et al., 1990), CRIg (Katschke et al., 2007), CD55 (Spitzer et al., 2004), and CD46 (Christiansen et al., 1996).

\section{Terminal Pathway Deficiencies}

1. The Components of the Terminal Pathway, Their Activation, and Regulation. The terminal pathway is shown at middle lower part of Fig. 1. When the C5 convertases from the classical or lectin pathway $(\mathrm{C} 4 \mathrm{~b} 2 \mathrm{bC} 3 \mathrm{~b})$ or the alternative pathway $(\mathrm{C} 3 \mathrm{~b} 2 \mathrm{BbP})$ have been formed, the initiation of the terminal pathway starts with the last cleavage in the cascade, with the C5 molecule being cleaved to C5a and C5b. In contrast with C3 and C4, C5 has no internal thioester and therefore cannot be covalently bound to the membrane. However, a binding site for $\mathrm{C} 6$ is exposed on the cleaved C5b, and the bimolecular C5b6 binds C7. The hydrophilic single components change to an amphiphilic state the C5b67 complex is able to bind to a nearby membrane. This usually occurs on the surface where the activation has started, but since C5b-6 is water-soluble and not always bound immediately to the activating surface, it can move to another cell membrane and attack this cell instead after binding $\mathrm{C} 7$ and subsequently assemble C8 and C9. This phenomenon is called "bystander lysis" (Lachmann and Thompson, 1970). Although the cell is not necessarily lysed, it is attached and may be activated. Of particular importance in this regard is that some complement components, in particular $\mathrm{C} 7$, are produced locally in the tissue (Würzner et al., 1994) and can bind C5b6 and initiate the terminal assembly (Würzner, 2000).

The C5b-9 terminal complement complex (TCC) exists in two forms. If inserted completely into the cell membrane it is termed the membrane attack complex. Notably, there are no membrane receptors for this complex. It is inserted because the induced amphiphilic structure results in a lipophilic state such that the complex can penetrate and make a hole in the membrane. The main membrane regulator of C5b-9 is the CD59 molecule that is able to bind C8 and C9 blocking pore formation and lysis of self cells (Meri, 1994). If the cell, which is typically a nucleated metabolically active cell, is protected from lysis, it may be activated instead and release inflammatory mediators in a process called sublytic attack, which then contributes to tissue inflammation and, if excessive, tissue destruction (Morgan and Campbell, 1985; Zhang et al., 2014b).

If C5b-7 is not bound to a surface but remains in plasma or other fluids, the sC5b-9 complex accumulates. Soluble regulators are required to cover the lipophilic sites and keep the whole complex hydrophilic and soluble. The regulatory proteins vitronectin and clusterin are attached after $\mathrm{C} 7$ is bound such that the C8 and C9 cannot incorporate into a membrane. There is no receptor for $\mathrm{sC5b}-9$, but it has been postulated that it can bind to the vitronectin receptor via the vitronectin molecule part of the complex (Biesecker, 1990). It has no known biologic function but is a very valuable tool to measure the degree of complement activation (Harboe et al., 2011).

C5a is the most potent inflammatory mediator of the complement system (Manthey et al., 2009; Wood et al., 2018). It is rapidly inactivated by carboxypeptidases cutting off the terminal arginine and thus termed C5adesArg. C5a has two membrane receptors, the traditional highly proinflammatory C5aR1 (CD88) and the later discovered C5aR2, which seems to have partly opposing effects of C5aR1, keeping this inflammation under some control (Laursen et al., 2012; Yan and Gao, 2012; Wood et al., 2018; Li et al., 2019).

2. Deficiencies of the Terminal Pathway Components. C5-C9 deficiencies are rare and typically associated with Neisseria infections, whereas association with other infections or autoimmune diseases is debated 
(Würzner et al., 1992; Tedesco et al., 1993). A high incidence of C9 deficiencies has been documented in Japan (Fukumori et al., 1989), which is of particular interest since the incidence of Neisseria is low in Japan. Consequences of C5 deficiency are of particular importance because a gradually larger patient population is treated with a complement C5 blocker, as will be detailed below. These patients have the same phenotype as genetic C5 deficiencies if treated over a long period. Except for Neisseria, these patients rarely suffer any other complications (Schejbel et al., 2013; Rondeau et al., 2019). CD59 deficiency occurs in two different forms. When there is a genetic defect in the CD59 gene, a separate phenotypical syndrome with many dysfunctions can be seen (Ben-Zeev et al., 2015), such as paroxysmal nocturnal hemoglobinuria (Yamashina et al., 1990). This is also seen when both CD55 and CD59 are lacking on the red cell membrane due to a defect in the glycosyl phosphatidyl inositol (GPI) anchor (Kinoshita, 2018).

3. Disturbances of the Terminal Pathway and Therapeutic Targets. Except for the consequences of the terminal components described above, dysregulation and imbalance of the terminal pathway are normally due to an imbalance in the earlier steps of the cascade, particularly the alternative pathway. This leads to excessive cleavage of C5 with subsequent potent inflammatory reaction and organ damage. Thus, $\mathrm{C} 5$, C5a, and the C5a receptors are important therapeutic targets for upstream imbalance and overactivation of the system. Although in most cases it is C5a that is the most pathogenic mediator, C5b-9 may contribute in addition. In such cases the rationale is to block C5 cleavage. If $\mathrm{C} 5 \mathrm{a}$ is the only mediator, a C5a/C5aR axis blocker would be ideal to keep C5b-9 intact to protect against Neisseria infection. However, in certain instances C5b-9 is the crucial mediator, such as in $\mathrm{PNH}$, and in such a case, targeting a component downstream to C5 to protect the assembly of C5b-9 but leaving C5a free for normal defense could be an actual approach.

\section{E. Therapeutic Approach to Treat Complement Deficiencies or to Enhance Its Efficacy}

1. Substitution of Purified Components and Plasma. Complement deficiencies cannot be treated with substitution of the completely missing component because of lack of access and the caveats mentioned above. Specific complement proteins have not been purified or recombinantly produced on a large scale for clinical treatment. The two components that have been proposed for large-scale production for treatment are MBL (Laursen, 2003) and factor $\mathrm{H}$ (Michelfelder et al., 2017). Indications for MBL treatment are questionable because of lack of diseases with known specific need or benefit; this is in contrast to factor-H treatment, which might be highly desired. The cost of production would most likely be relatively high, as the diseases requiring
factor-H substitution are relatively rare. A recombinant mini-factor $\mathrm{H}$ has been constructed and conjugated to CR2 (TT30), but this is not primarily to replace factor $\mathrm{H}$ but to inhibit activation where C3d is bound in the tissue, and the treatment will thus be target-specific as will be discussed below.

\section{Prophylactic and Symptomatic Treatment.} Cases of deficiencies with risk of infections should be vaccinated, particularly against pneumococci and Neisseria, and active infections should be treated with antibiotics. Patients with properdin deficiency leading to insufficient terminal pathway activity should be vaccinated with the latest generation of vaccines since they often get infected with rare species. This is also the case for patients treated with a C5 blocker. They should have antibiotics at home and should be able to call a professional healthcare provider $24 / 7$ if they get symptoms. Interestingly, a question arises for the terminal pathway deficiencies: if the pathogenic strain is serum-sensitive, will the vaccine work if the response depends on C5b-9 formation only? The answer is most likely not, since the $\mathrm{C} 5$ is inactive; thus, the response will depend on the Fc-mediated phagocytosis (Jodele et al., 2016; Reher et al., 2018; Gäckler et al., 2020).

3. Liver Transplantation. Most of the complement components are produced in the liver, including the crucially important regulatory factor $\mathrm{H}$. Loss of function of factor $\mathrm{H}$ is relatively rare, but when occurring it often leads to severe diseases due to an extreme overactivation of the alternative pathway and subsequent activation of the terminal pathway. The prototypical example is the form of thrombotic microangiopathy, aHUS. This is one of the four FDA-approved diseases for C5 inhibition with eculizumab. The effects and results are excellent (Fakhouri et al., 2016; Wong and Kavanagh, 2018; Gonzalez Suarez et al., 2019), but still the factor $\mathrm{H}$ is mutated in the patient. In a few cases in which these patients have had both kidney and hepatic failure, a combined transplantation was performed (Jalanko et al., 2008; Tran et al., 2014; Nayagam et al., 2020). The patients got a new liver producing normal factor $\mathrm{H}$ and a new kidney that was not attacked by the host's previous overactivated complement. This will certainly be a limited offer to very few patients, but it is the only treatment to permanently replace the defective component with a normal one until genetic therapy might be a reality.

4. Triggering of Complement Activation in Individuals with a Normal Complement System: An Anticancer Approach. Often the clinical problem is that the imbalance in complement homeostasis is enhanced activation of complement, which needs to be attenuated. However, there is one particular condition we should not neglect, and that is patients treated with therapeutic antibodies. There are many of such antibodies, but the prototype is lymphoma treated with rituximab or recent similar antibodies that bind CD20+ B-cells. This 
strategy has changed the treatment of lymphoma substantially in the last few decades, and important treatment modifications have been proposed (Beurskens et al., 2012). Notably, cancer cells tend to increase their number of surface complement inhibitors, including CD59, as it is a protective mechanism for the cells to survive complement attack. In recent years, a new approach has been developed to block the complement inhibitors in combination with the antitumor antibodies, so-called bispecific antibodies, to increase the sensitivity of these cells to be killed by complement. This principle has not reached the clinic yet, and this review will not go further into this field of complement, but some important contributions are cited here (Maio et al., 1998; Jurianz et al., 1999; Fishelson and Kirschfink, 2019).

5. Gene Therapy. Even though it is a very attractive approach so far, gene therapy to modulate complement function has not reached the clinic. Gene silencing using RNA interference delivery has been attempted to reduce concentration of C5 using the compound ALN-CC5 for treatment of aHUS in phase 1 and phase 2 trials (https://clinicaltrials.gov/ct2/show/NCT03303313). No results have been published so far. However, preclinical studies of ALN-CC5 and efficacy of C5 silencing in rat models of myasthenia gravis support further clinical development of the RNA interference approach as a potential therapeutic complement-mediated disorder (Kusner et al., 2019). Another approach is to increase the local concentration of factor I by gene therapy, thus downregulating excessive activation of the complement system. This strategy is presently being tested in human phase 1 and phase 2 trials for local treatment of dry age-related macular degeneration (https://www. gyroscopetx.com). It must be assumed that different forms of gene therapies with different targets will emerge as attractive candidates for the treatment of complement-mediated diseases when this area is developed further.

\section{Role of Complement in Disease Pathophysiology}

Normally complement is a system in a fine-tuned balance between inhibition and amplification resulting in homeostasis (Fig. 2B). It has, however, a substantial potential to get out of control if there is a shift in this balance (Fig. 2A). Deficiencies or loss-of-function mutations of the ordinary complement components may lead to infections and autoimmune diseases (i.e., the balance is shifted to hypoactivation; Fig. 2C). However, the main reasons for acute complement dysfunction in the clinic, which can be life-threatening within hours or days, is an imbalance and dysfunction related to enhanced activation of the system (Fig. 2D). Thus, this is the main task for the future therapeutic approached-in other words, to dampen the activation by complement inhibitors thereby re-establishing the balance and homeostasis.

\section{A. Consequences of a Dysfunctional Complement System}

1. Decreased Regulatory Activity and Increased Activation Potential. It is crucially important to keep the complement system in balance. This is the case for any of the blood cascade systems. They are circulating in a preactivated form ready to act immediately, within seconds, as soon as a danger is sensed. Importantly, they should act locally_like coagulation making a clot to stop bleeding in a cut in a finger-and complement to stop and kill an intruder in the ear. The cascades can be compared with undetonated bombs: Normally they do no harm, but if they explode systemically, as in sepsis, they might kill the host (Fig. 2A). The cascades are built up by approximately as many ordinary activation components as regulatory inhibitors to keep the system in check.

This scenario is comparable to playing football. There are 11 players on each team, with each taking care of the other team's players; when a red card is given and one of the players has to leave, there is an unbalanced shift to one side. Thus, if in a cascade there is one defective inhibitor or one overactive component, the imbalance will occur with the same consequence (i.e., with a shift to the activation side). For the complement system a typical example is that a loss of function in factor $\mathrm{H}$ in one patient will frequently give the same phenotype as a gain of function of C3, typically leading to, for example, aHUS (Fig. 2D).

The aims of complement inhibition are thus to bring balance to the system both in acute and chronic diseases. In a systemic inflammation, such as with trauma and sepsis, it is important to immediately avoid the overactivation and explosion of the bomb, whereas in chronic inflammation it is important to over time reduce the complement activation and the subsequent tissue damage. Both cases have the aim of attenuating irreversible tissue damage and organ failure.

2. Pathophysiologic Role of an Uncontrolled Overactivated System. In pathophysiologic conditions it should be emphasized that it is the innate immune system that reacts immediately after danger appears, whether through external pathogen-associated molecular patterns (PAMPs) or internal damage-associated molecular patterns (DAMPs). Thus, the complement system will react within seconds to minutes and generate C5a. As mentioned above, the anaphylactic peptide $\mathrm{C} 5 \mathrm{a}$ in excess can be the most potent activator of an inflammatory response. C5a via C5aR1 signaling synergizes with Toll-like receptors (TLRs), TLR cofactor CD14 (Barratt-Due et al., 2017), $\mathrm{NF}_{\kappa} \mathrm{B}$ activation, and the nucleotide-binding oligomerization domain-like receptor 3 (NLRP3) inflammasome activation leading to proinflammatory cytokine production, such as IL-1 $\beta$ 
and tumor necrosis factor (Zhang et al., 2014a). C5a was found to increase the release of IL- $1 \beta$ and IL- 6 when added to $\mathrm{A} \beta$ amyloid-primed human monocytes in vitro (O'Barr and Cooper, 2000), and C5aR1 antagonists have been found to reduce proinflammatory cytokines like IL-1 $\beta$ in periodontal disease (Hajishengallis and Lambris, 2012; Recknagel et al., 2012). Importantly, C5a will start the further downstream sequelae, including reactive oxygen species generation as well as platelet activation and a number of other inflammatory mediators (Barratt-Due et al., 2017). This a major reason for blocking the upstream mediators, including C5a in particular, instead of one of all the hundreds of downstream inflammatory mediators generated as a result of C5a responses (Ward, 2004; Panayiotou et al., 2019; $\mathrm{Li}$ et al., 2020). In addition, it is possible that in the CNS, as in the periphery, C5a via C5aR1 signaling synergizes with TLR/NF $\kappa \mathrm{B}$ and the NLRP3 inflammasome activity to trigger potent detrimental inflammatory responses (Yang et al., 2020).

If unopposed or overwhelming, this can lead to the cytokine storm that systematically, as in sepsis and severe trauma, leads to shock and lethality or, if local, will generate tissue damage proportional to the imbalance of reactions. Suppressing the NLRP3 signaling cascade or the downstream cytokine response with the important IL-1 $\beta$ has long been suggested as a potential therapeutic strategy for diseases with a detrimental inflammatory component. However, use of a C5aR1 antagonist would eliminate the synergistic response while avoiding systemic direct suppression of critical NLRP3, thereby limiting or eliminating susceptibility to inflection.

In pathophysiologic conditions it should be emphasized that it is the innate immune system that reacts immediately after danger appears, whether through external PAMPs or internal DAMPs. Thus, the complement system will react within seconds to minutes and generate C5a. Thus, C5a is one of the most upstream mediators released and signals together with other upstream recognition receptors (e.g., TLR cofactor CD14) (Barratt-Due et al., 2017). Importantly, C5a will induce further downstream inflammation, including reactive oxygen species production, and release of the whole network of cytokines from monocytes and macrophages, platelet activation, and a number of other inflammatory mediators (Barratt-Due et al., 2012). This a major reason for blocking mediators like C5a in particular instead of one of all the hundreds of downstream inflammatory mediators generated as a result of C5a responses (Ward, 2004; Panayiotou et al., 2019; Li et al., 2020).

3. Complement Attack on Host Cells when They Lack Regulators. A unique property of cascade systems is their continuous low-grade activation under physiologic conditions. This has the advantage that they are ready to react immediately; as compared with driving a car, they do not need to start the engine first (Barratt-Due et al., 2012). This also implies that they will attack the host's own cells unless the cells are well protected by

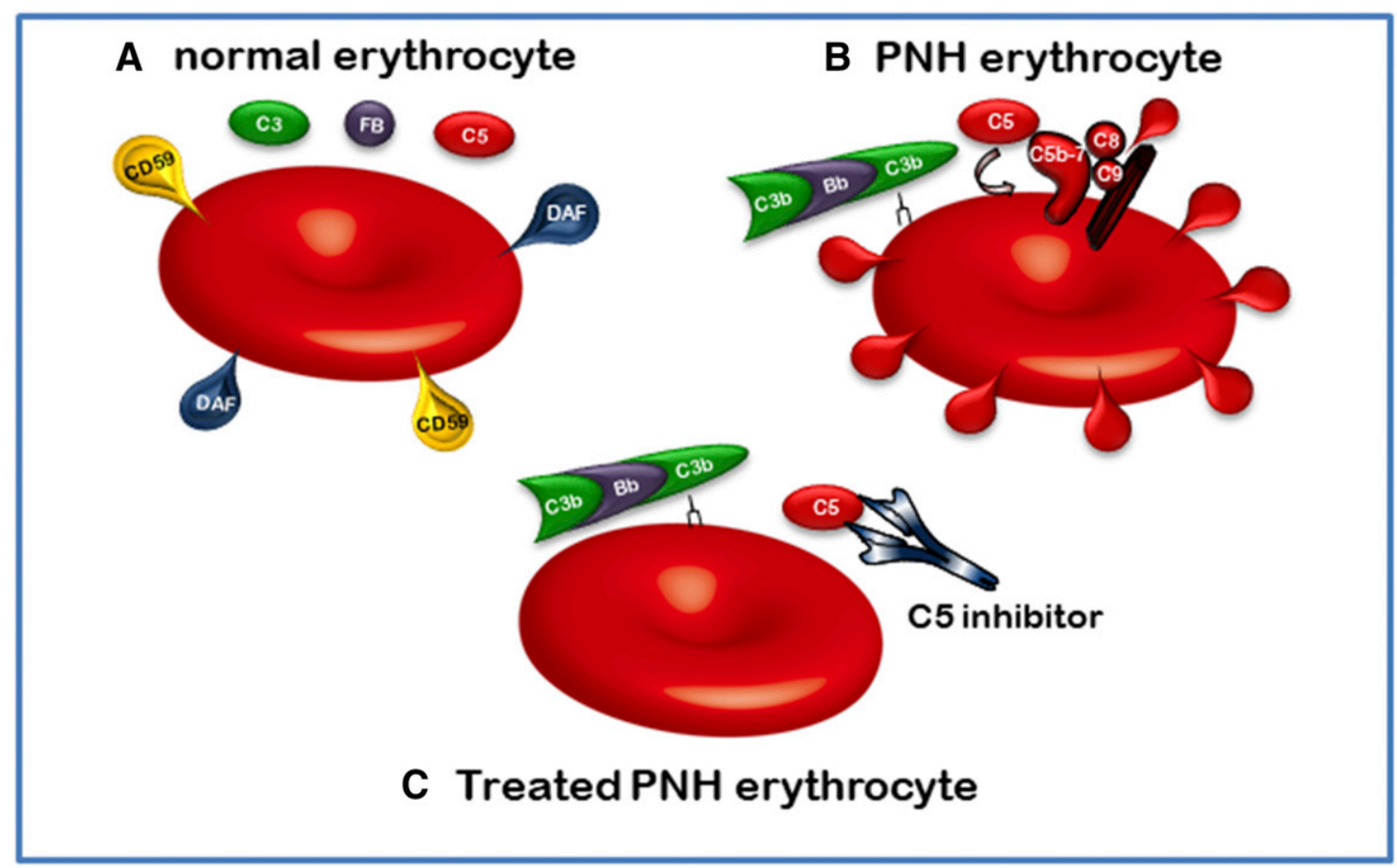

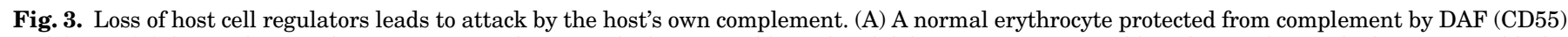

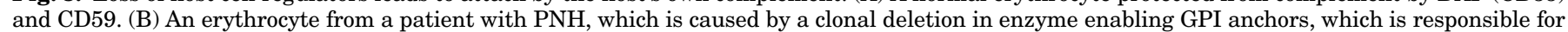

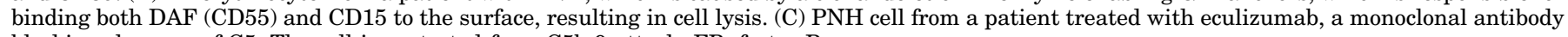
blocking cleavage of C5. The cell is protected from C5b-9 attack. FB, factor B. 
inhibitory regulators. CR1 binds $\mathrm{C} 3 \mathrm{~b}$ as ligand and is a cofactor for factor I that cleaves $\mathrm{C} 3 \mathrm{~b}$ to $\mathrm{iC} 3 \mathrm{~b}$, which can no longer form the $\mathrm{C} 3$ convertase $\mathrm{C} 3 \mathrm{bBb}$. On red cells the large amount of CR1 binds C3b opsonized particles, such as immune complexes, and traffics them to the liver for clearance (Cornacoff et al., 1983; Brekke et al., 2019).

Genetic deficiency of CD59 results in insertion of the C5b-9 complex into the membrane and is associated with a complex syndrome, including hemolysis seen in PNH (Tabib et al., 2017). CD55 is also a protective regulator of $\mathrm{C} 3 \mathrm{~b}$ activity on the cell surface, and a rare deficiency of this protein has shown pathophysiology mainly in the gastrointestinal tract (Ozen et al., 2017).

The most prominent disease with lack of complement inhibitors on its blood cells is PNH (Fig. 3). In contrast to those mention above, this is not a genetically inherited defect but a somatic mutation in the bone marrow of an enzyme required for membrane association of complement regulators. The Phosphatidylinositol $\mathrm{N}$-acetylglucosaminyltransferase subunit A (PIG-A) or subunit T $(P I G-T)$ genes are mutated for the GPI anchor (Takeda et al., 1993; Krawitz et al., 2013). More than 20 proteins that do not have a transmembrane signaling part are bound to the membrane via this GPI anchor, including the two important complement proteins CD55 (inhibiting at the C3 level) and CD59 (inhibiting the C8/C9 insertion into the membrane) (Fig. 3). The phenotype of the disease is red blood cell hemolysis to a severe degree, which often requires blood transfusions, and frequently thrombosis (Hill et al., 2013). Particularly serious are those developing in the gastrointestinal area, such as the Budd-Chiari (De-laIglesia et al., 2016). The details of treatment of PNH are given below.

4. Complement Attack in Tissue Damage and Common Pathophysiological Mechanisms to Treat a Broad Panel of Diseases. The main role of innate immunity, complement included, is to induce inflammation, both to protect from pathogenic intruders and repair damaged self. The mechanisms by which the system does this are principally the same (Chen and Nunez, 2010; Denk et al., 2012; Schaefer, 2014). With pathogenic invasion, the role for complement is to sense the conserved molecular patterns on the microbes (PAMPs) through the pattern-recognition molecules. During internal damage, typically when ischemia rereperfusion occurs, a number of DAMPs are exposed, reacting with naturally IgM molecules, which can activate both the classical and the lectin pathway (Zhang et al., 2006b) (Fig. 1). The physiologic consequences of inflammation are virtually identical whether PAMPs or DAMPs have initiated them (Fig. 4). Increases in blood flow due to the damage gives the classical heat, redness, swelling, and pain. Later, reduced function is added to this list (Fig. 4, last item).

An example is a patient presenting with these signs and symptoms. They might look quite similar, and this could be due to sterile inflammation, such as tennis elbow; rheumatoid arthritis; or fracture without

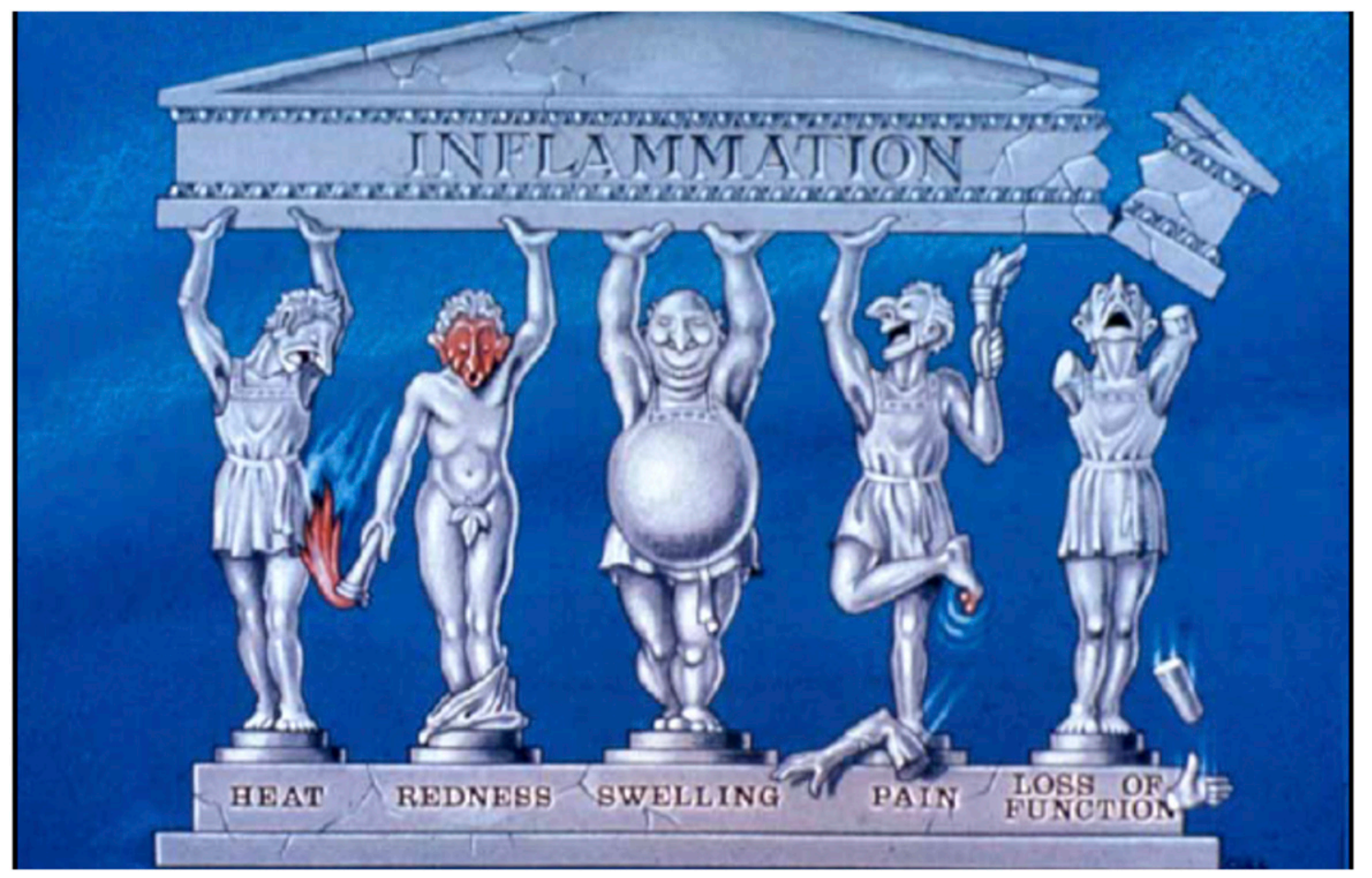

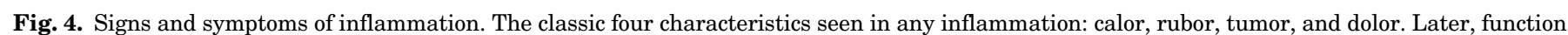

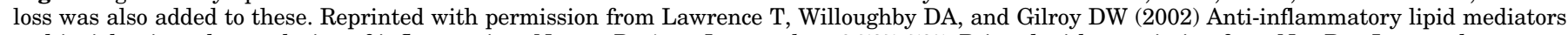
and insights into the resolution of inflammation. Nature Reviews Immunology 2:787-795. Printed with permission from Nat Rev Immunol. 
complications-or it could be due to nonsterile (infectious) inflammation like septic arthritis or complicated fracture with infection. The response is principally the same. The mechanisms behind the inflammation might be similar, and the treatment will certainly be different dependent on the diagnosis. It should be emphasized, however, that all these conditions might benefit from inhibition of the innate immune system, complement inhibition included. It remains be shown how many diseases will benefit from complement inhibition alone or in combination with regulation of other innate immune receptors as detailed in other parts of this review.

A notable idea emerging from these data with complement inhibition alone or combined with other innate immune system molecules is how far this strategy can be used for diseases with different etiology but with a common complement-induced pathogenesis. Surveying the literature, it seems like the list of possible candidates for complement inhibition might be very long, whereas very few diseases in which complement plays no role have been documented and confirmed.

\section{Therapeutic Complement Inhibition}

\section{A. Diseases with a Potential for Complement Therapeutic Modulation}

1. Introduction: The Search for Complement as Pathophysiologic Mediator. To select a certain disease as a possible candidate for complement inhibition, a number of criteria should be fulfilled. From clinical evaluation of the disease, plasma should be measured for complement activation products. Not all diseases with increased local activation release activation products to plasma, so biopsies of the suspected organ(s) are needed to see whether there is activated complement deposited in the tissue. If this in the case, in vitro experiments should be done with human material, and if confirmed, this should be followed up with animal experiments in a reliable animal model. Then the possible mechanism of activation should be studied, but that is a difficult task. If not possible, inhibition of possible pathogenic targets should be investigated (Fig. 1). Then the relevant inhibitors should be selected and investigated both in ex vivo human models and in animal models. Finally, different modes of the preparation and the actual routes of administration should be decided (see below). The pharmacological kinetics, halflife, and, not least, the cost must also be considered. It is crucially important to dissect the pathophysiology and the pathogenic mechanism before deciding the therapeutic strategy. Evaluation of efficacy versus adverse effects is obviously the most important one and will be revealed during clinical trials. It is equally important to evaluate costs versus the benefits and possibly adverse effects of a certain treatment.
2. Neurologic Diseases. The prevalence of neurodegenerative diseases worldwide is accelerating. The number of individuals with dementia alone is estimated at 50 million worldwide, creating a great financial as well as personal burden. There is increasing evidence for a role for complement in Alzheimer disease (Hong et al., 2016; Hernandez et al., 2017; Shi et al., 2017) and other neurodegenerative and neurologic disorders, such as amyotrophic lateral sclerosis (Lee et al., 2018; Parker et al., 2019), epilepsy (Chu et al., 2010; Schartz et al., 2018), stroke (Alawieh et al., 2015), traumatic brain injury (Sewell et al., 2004), multiple sclerosis, and schizoprenia (Sekar et al., 2016). Some of these indicators are genetic, such as schizophrenia, and may be related to aberrant deficient or excessive synaptic pruning, but many others are based on the presence of complement activation products in the affected region of the brain or spinal cords. An influx of complement components as a result of the disruption of the blood brain barrier, such as in stroke or traumatic brain injury, results in acute complement activation in the presence of tissue debris and other DAMPs. The resulting activation fragments or inappropriate opsonization of cells will then result in cascading increases in inflammation and further cell damage/death and loss of neuronal function. However, as discussed above, it is now well established that all components of the complement system can be synthesized in the brain (Reichwald et al., 2009) and thus are present in the brain in the absence of blood brain barrier breakdown. Although often undetected in the young uninjured brain, components are induced in what appears to be a measured response to levels of injury (Fonseca et al., 2011).

In animal models, the effect of genetic ablation on neurodegeneration has contributed to the understanding of the role of complement in these diseases. C1q, C3, CR3, C3aR, and C5aR1 knockouts have provided clear evidence of the roles of the early classical cascade on synaptic pruning. However, since elimination of $\mathrm{C} 1 \mathrm{q}$ and C3 would also prevent C3a and C5a generation, it is likely that the neuroinflammation induced by an everincreasing cycle of glial activation, particularly via C5aR1, neurotoxicity, and damage with further complement activation overwhelms the neuronal resilience to perturbation and thereby leads to loss of cognitive and other neurologic functions. For example, in the Arctic model of Alzheimer disease (Cheng et al., 2007; Fonseca et al., 2011) that was crossed to C5aR1 knockout mice, behavior deficits and loss of neuronal integrity were prevented in the absence of C5aR1 even in the continued presence of amyloid plaques. When microglia were isolated and RNA was sequenced at increasing ages, proinflammatory gene expression was lower in the C5aR1-deficient Arctic mice, whereas genes involved in phagocytosis and lysosomal function (for clearance and homeostatic functions) were increased in 
the Arctic mouse but even more so in the Arctic C5aR1 knockout mouse (Hernandez et al., 2017). These findings suggest preventing a C5aR1-induced program of gene expression lower in inflammation while allowing phagocytosis and clearance of neuronal blebs, apoptotic cells, and other debris to occur and be enhanced by the opsonic functions resulting from the unobstructed early components of complement $(\mathrm{C} 1 \mathrm{q} / \mathrm{Cl}$ and $\mathrm{C} 3)$.

In amyotrophic lateral sclerosis, Parkinson disease, and Huntington disease, current investigations also focus on determining the contribution of C5a signaling through C5aR1 (Tenner et al., 2018). Amyotrophic lateral sclerosis is characterized by the progressive death of motor neurons in cortex, brain stem, and spinal cord, resulting in muscle weakness, paralysis, and death. Complement activation fragments are elevated in blood and in post-mortem spinal cord, suggesting a contribution to the pathogenesis and/or progression of this disease (Sta et al., 2011; Mantovani et al., 2014). In mouse models, although deletion of C1q, C3, or C4 did not alter the course of the disease, genetic deletion or pharmacologic inhibition of C5aR1 did reduce infiltration of inflammatory cells and nerve loss while improving muscle function and survival (Woodruff et al., 2014; Lee et al., 2017).

CNS synthesis of complement components is induced and maintained for extended periods of time in animal models of stroke (Huang et al., 1999; Pavlovski et al., 2012) and traumatic brain injury (Bellander et al., 2001). In extensive analyses of the different sequelae in an occlusion model of stroke-acute, subacute, and long-term-Tomlinson and colleagues have demonstrated that a fusion molecule consisting of a singlechain monoclonal antibody directed toward a strokeinduced modified annexin IV linked to the murine CR1 ortholog Cr1-related protein Y prevented opsonic C3b/ iC3b deposition on neurons and prevented synaptic uptake (Alawieh et al., 2020) and neuronal phagocytosis by microglia (Alawieh et al., 2018a). In addition, the inhibition of complement prevented microglial activation, perhaps because of reduced generation of C5a, which otherwise persisted chronically in this model. The result was improved long-term motor function as well as cognitive ability (Alawieh et al., 2018a). As with the sequelae of events in stroke or reperfusion injury, traumatic brain injury presents with both acute and chronic neuropathology. Using a fusion construct that targets complement activation sites with CR2 (binds the covalently bound C3d activation fragment) and the regulatory protein factor $\mathrm{H}$ as a treatment as much as 12 hours after contusion, lesion and scarring volume were reduced, and motor and cognitive skills improved (Leinhase et al., 2006; Alawieh et al., 2018b).

In multiple sclerosis (MS) and other disorders, the evidence for detrimental aberrant synaptic pruning and activation-induced neuroinflammation has been increasing as animal models have been developed, and technological advances allow precision characterization of disease progression. In the case of two murine models of MS, delivery of adeno-associated virus encoding Crry resulted in decreased synaptic loss and visual impairment (Werneburg et al., 2020). In addition, tissue and biomarkers have become available to demonstrate complement deposition correlates with cognitive decline in humans (Vasek et al., 2016; Wu et al., 2019).

Thus, the search for dysfunction-modifying treatments for both neurodegenerative disease and neurologic disorders in which complement imbalance or even complement mediated slowly accumulating hits to normal processes is accelerating. Every branch point in the complement cascades, every activating protein, and every regulator protein can be considered an opportunity for precision pharmacologic inhibition. Of course, different points of inhibition may be optimal for different disorders, particularly those involving a compromised blood brain barrier caused by stroke, traumatic brain injury, and multiple sclerosis. In addition, it is clear that therapies for acute neurologic injury will have different considerations than those of chronic degenerative disorders. Fortunately, there is a growing number of therapeutics specific for different complement components in various stages of drug development and clinical trials and additionally at the preclinical stage as discussed below.

3. Eye Diseases. A couple of serious diseases of the eye seem to be closely related to a disturbed complement system regulation. The most frequent is AMD, which is the most common cause of blindness in the Western world (Troutbeck et al., 2012; Park et al., 2019). Several genetic mutations of complement genes have been associated with AMD (van Lookeren Campagne et al., 2016), and many of these are associated with other complement dysfunction diseases like aHUS. It is therefore a challenge to further search for the reason why some of the genetic defects in the same proteins can lead to such different phenotypes. The current treatment of selected patients with the wet form of AMD is injection of antibodies that block VEGF. Although the mice do not have traditional AMD, it is possible to induce a choroidal neovascularization process that precedes development of retinitis conditions, including AMD (Liu et al., 2011). In this model they showed that complement activation with generation of C5b-9 came much earlier than VEGF generation and that complement blockade prevented VEGF production. Thus, complement inhibitors should continue to be investigated to stop the initial pathogenic factors leading to this debilitating disease.

In addition to AMD, a couple of other eye diseases have been related to complement activation. If neuromyelitis optica spectrum disorder, which is close to a neurologic disease, can be considered an eye disease, its serious consequence is blindness. Previously it was regarded a part of MS, but now several entities have 
been described, including the one caused by autoantibodies to aquaporin 4 . This particular form has been shown to be highly complement-dependent and is now the latest of the four diseases approved by the FDA for routine treatment by eculizumab with so far good results (Frampton, 2020). Autoimmune uveoretinitis has also been efficiently treated experimentally with complement inhibitors (Chen et al., 2010; Copland et al., 2010), and, probably most surprisingly, glaucoma has come on the list of candidates for treatment because of promising experimental results (Howell et al., 2013; Reinehr et al., 2019).

4. Kidney Diseases. For a long time, it has been recognized that the pathogenesis of many kidney diseases is closely associated with complement activation (Thurman, 2020). More than 50 years ago, it was shown that the complement system is activated in the glomeruli of patients with immune-complex glomerulonephritis (Lachmann et al., 1962; Verroust et al., 1974). Over the last 15-20 years it has also become clear that the complement system is not only important to the pathogenesis of many nonimmune complex-mediated kidney diseases but also the primary driver in diseases, such as atypical hemolytic-uremic syndrome and C3 glomerulopathy (C3G) (Bu et al., 2014; Xiao et al., 2014). Certain kidney diseases are, therefore, a prime objective for complement-targeted therapy. Some examples of those that are expected to benefit from complement therapy are discussed below.

Hemolytic-uremic syndrome (HUS) is an ultra-rare disease defined by the triad of mechanical hemolytic anemia, thrombocytopenia, and acute kidney injury (Avila Bernabeu et al., 2020). Typical forms of HUS are related to infection by Shiga toxin-producing $E$. coli, whereas the atypical form of HUS termed aHUS is due to defects in alternative complement activation pathway (Avila Bernabeu et al., 2020). In 50\%-60\% of aHUS cases, genetic variants in proteins regulating the alternative pathway of complement are found, but it is a clear consensus that absence of molecular finding does not exclude an alternative pathway deregulation. The most commonly affected genes are factor $\mathrm{H}$, factor I MCP (CD46), and thrombomodulin, but acquired autoantibodies like antifactor $\mathrm{H}$ in association with inherited deletion of particularly the factor $\mathrm{H}$-related one to three genes might also be a cause of aHUS. Conversely, gainof-function mutations in factor B or C3 are also a cause of aHUS because of increased alternative pathway

A

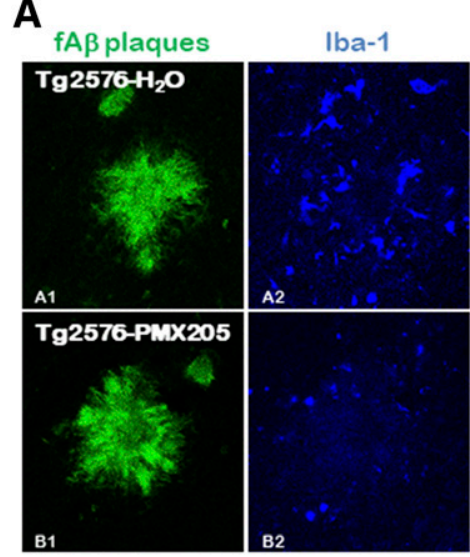

B

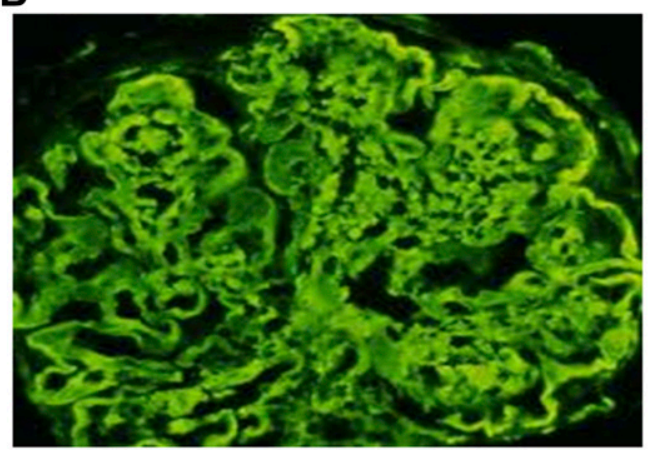

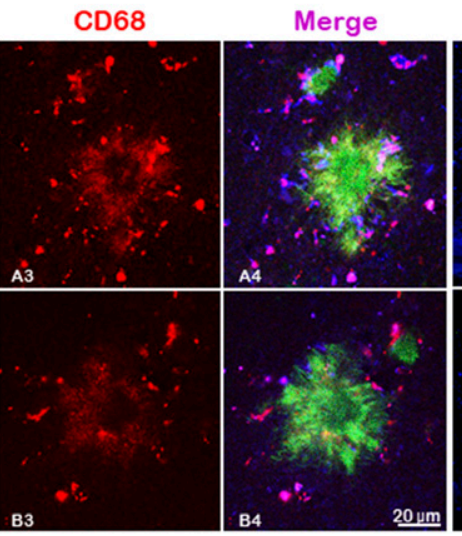
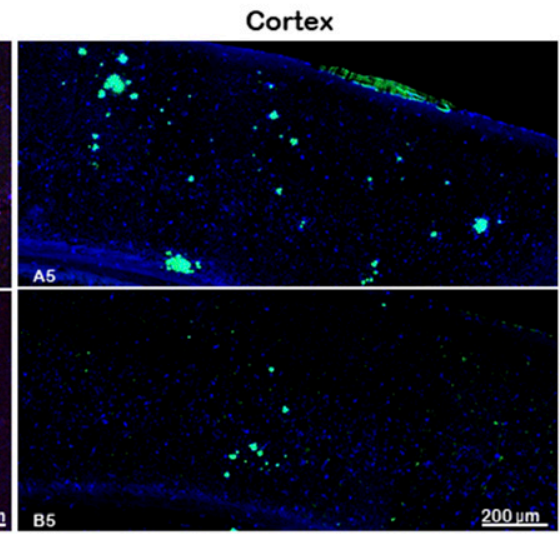

C

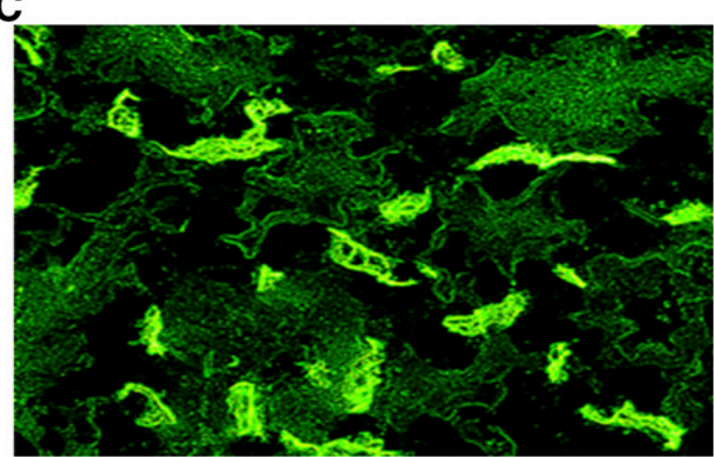

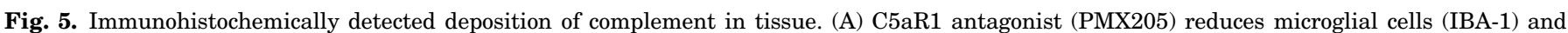

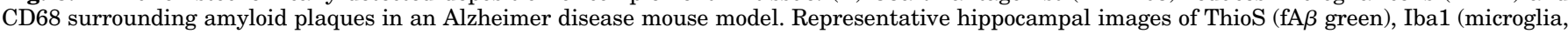

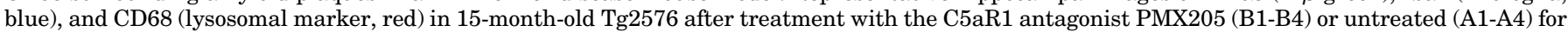

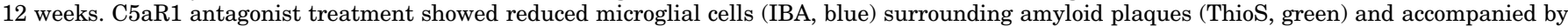

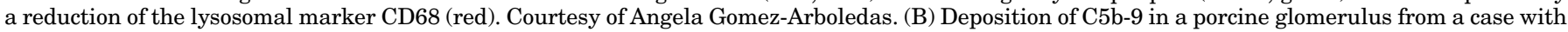

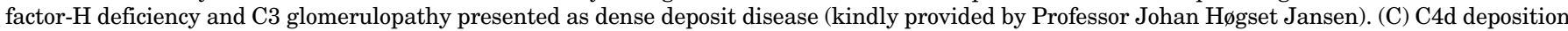

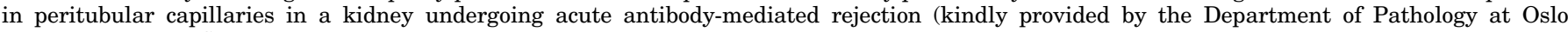
University Hospital). 
activity surpassing the capacity of regulators of the complement activation. There are pathogenic genetic variants not related to the complement system, such as diacylglycerol kinase $\varepsilon$, which is an endothelial cell and podocyte protein causing aHUS in small children. So far aHUS is the only approved complement-targeted indication for kidney diseases.

C3G is a rare group of kidney diseases with a poor long-term outcome (Ahmad and Bomback, 2020). It can be further divided into two forms: $\mathrm{C} 3$ glomerulonephritis (C3GN) and dense deposit disease (DDD). Both diseases are characterized by $\mathrm{C} 3$ glomerular deposits detected by immunofluorescence. Fig. 5B shows deposition of C5b-9 in a glomerulus from a DDD case. C3GN and DDD are difficult to distinguish from each other based on light microscope and immunofluorescence investigation. However, in electron microscopy that is mesangial and/or subendothelial, intramembranous and subepithelial deposits are seen in C3GN, whereas dense osmiophilic deposits are present along the glomerular basement membranes and in the mesangium in DDD. Both C3GN and DDD are distinguished from immune complex-mediated glomerulonephritis by the lack of immunoglobulin staining in immune fluorescence, and both are characterized by dysregulation of the alternative pathway, thus being mainly complement-driven. A major subset of C3G arises from so-called $\mathrm{NeFs}$, which as mentioned above are autoantibodies stabilizing the convertases and have been characterized recently as $\mathrm{C} 4, \mathrm{C} 3$, and $\mathrm{C} 5 \mathrm{NeFs}$, which react with the different convertases surpassing the effect of complement regulatory proteins. Finally, C3 glomerulopathy can be due to genetic mutations, affecting genes that encode for complement components or regulators. The most important seem to involve factor $\mathrm{H}-$, factor Iand factor $\mathrm{H}-$ related proteins. The $\mathrm{C} 3 \mathrm{Gs}$ are candidates for complement therapy, but the heterogeneity of the etiology behind the diseases implies that the therapeutic effect may vary (Nester and Smith, 2016).

IgA nephropathy is the most common form of glomerulopathies worldwide (Hassler, 2020). Its clinical presentation varies, but it often includes proteinuria and hematuria. The disease is associated with aberrant $O$-glycosylation of mucosal IgA1 with galactosedeficient IgA1 (Gd-IgA1), which plays a pivotal role in the progression of this nephropathy. Although there are genetic, ethnic, and environmental factors involved in the pathogenesis of IgA nephropathy, the exact etiology remains unknown. A multihit model has been suggested to explain the cause of the IgA nephropathy: An increased serum concentration of Gd-IgA1 (hit 1) can be recognized by overproduced variable heavy-chain autoantibodies, such as IgG or IgA (hit 2), inducing the formation of circulating pathogenic immune complexes (hit 3). These immune complexes will finally deposit on the renal glomeruli (hit 4). This deposition triggers complement and cell activation, cytokine release, and extracellular matrix expansion (Tortajada et al., 2019). Hence, IgA nephropathy is considered as a unique autoimmune disease whereby the pathogenesis may be driven by an autoantigen (Gd-IgA1) eliciting an autoantibody (IgG antiglycan) response.

Over the past years, increasing information from findings in kidney biopsies has emerged on the involvement of complement activation in both progression of native IgA nephropathy and after a renal allograft. Several lectin and alternative pathway components have been shown to codeposit in the glomerular deposits in these diseases (Floege and Daha, 2018). Components from the alternative pathway, such as C3, properdin, or factor $\mathrm{H}$, or from the lectin pathway, such as MBL alone or in combination with MASPs, ficolin-2, C4d or C4BP, are a consistent finding in kidney biopsies (Roos et al., 2006). Nonetheless, no strong involvement of the classical pathway has been associated yet (Suzuki et al., 2011). Besides the glomerular deposition of complement components, abnormal circulating levels, or genetic variations in $\mathrm{C} 3, \mathrm{MBL}$, factor $\mathrm{H}$, MASP-3, and factor H-related protein-5 have been associated with the severity of the prognosis. Based on this, there is a strong momentum to focus on intervention of complement activation in IgA nephropathy, as several studies have been initiated or are in the planning phase currently. For instance, an oral C5aR inhibitor, an oral factor B inhibitor, or an MASP-2 inhibitor are a few examples of phase-II/III ongoing studies on IgA nephropathy. Thus, IgA nephropathy may be one of the kidney diseases that is a candidate for complement inhibition treatment.

It is pertinent to mention that almost all kidney diseases appear to a have strong complement component related to their pathophysiology, which is outside the scope of this review but might be a target for complement therapy. A kidney disease in which complement target therapy has advanced to a stage wherein we may anticipate that it will be incorporated into the treatment arsenal is accompanied by necrotizing crescentic glomerulonephritis (Trivioli and Vaglio, 2020). This disease is discussed further under the systemic autoimmune chapter item 6 in the section below.

5. Hematologic Diseases. As presented already, $\mathrm{PNH}$ is the prototypical example of a disease that is one of the very few and "pure" complement-mediated diseases. It was the first complement disease to be approved for routine clinical therapy, and during the last 15 years, innumerable patients have been efficiently treated with very good effects and with minor adverse effects (Kelly et al., 2011; Hillmen et al., 2013; Loschi et al., 2016; Ninomiya et al., 2016). Importantly, patients with PHN suffer thrombosis as one of the main complications and reasons for morbidity and mortality and when treated with the complement inhibitor eculizumab do not suffer from these serious thromboses (Macrae et al., 2020). In some cases, there is residual lysis despite C5 inhibition, and it has been proposed 
that the C3 opsonization might be the reason for extravascular lysis, and that inhibition of C3 is an alternative to prevent this lysis (Risitano et al., 2019).

Hemolytic anemias vary with respect to the efficacy of complement inhibition. The "warm type" has a considerable IgG-mediated extravascular hemolysis at $37^{\circ} \mathrm{C}$, which is less affected by complement and more Fcdependent, whereas the cold agglutinin disease caused by $\operatorname{IgM}$ autoantibodies is a pure complement disease with intravascular complement-mediated lysis at low temperature (Berentsen, 2018). Since the lysis is selectively classical pathway-initiated, blocking of $\mathrm{C} 1 \mathrm{~s}$ has been shown to efficiently reduce the lysis (Shi et al., 2014). An alternative is to block C5 cleavage (Röth et al., 2009), as is used for treating $\mathrm{PNH}$, since C5b-9 is the effector molecule. A future possibility would be to block a component downstream of C5 to leave C5a active while blocking lysis.

Thrombotic microangiopathy is a serious complication in patients undergoing stem cell transplantation. There are data indicating that complement is important in the pathogenesis of this condition and that complement inhibition might be a promising treatment, as seen in a study of a large pediatric cohort (Jodele et al., 2020).

Finally, it should be mentioned that accidental ABO mismatch blood transfusions occur still, although fortunately this is very rare. With this, however, the situation might be life-threatening. Most likely the complement system is the driver by intravascular lysis by the IgM anti-A and anti-B antibodies. If the reaction is severe, the patient is brought immediately to the intensive care unit for treatment. It is possible that an ampulla of a complement inhibitor should be included in the acute kit. It works immediately with virtually no risk.

6. Autoimmune Diseases. The typical autoimmune diseases like rheumatoid arthritis and SLE have a complex etiology and pathophysiology with many branches of both the innate and adaptive immunity involved. Although experimental studies have documented a clear role for complement in rheumatoid arthritis (Kahn et al., 2003; Mehta et al., 2015), the clinical application of complement therapeutics is still in the future (Holers and Banda, 2018). The same is the case for SLE (BarillaLabarca et al., 2013). This is not surprising and is consistent with the multiple factors playing a role for disease progression. Probably there might be a place for certain subgroups, particularly those with kidney affliction as a supplement to the already established therapy.

There are, however, a group of autoimmune diseases with systemic manifestations that have a more simple and narrow pathophysiology-for example, the antineutrophilic cytoplasmic antibodies-associated vasculitis (AAV). These are autoantibodies against proteins in the neutrophil granulocytes (e.g., proteinase 3 and myeloperoxidase). Experimental studies in mice have shown that AAV is largely driven by the C5a-C5aR1 complement axis (Dick et al., 2018), and clinical studies using a C5aR1 inhibitor are promising (Jayne et al., 2017). Another systemic disease with a single autoantibody target is the antiphospholipid syndrome (APS) frequently seen in women with both venous and arterial thromboses as well as spontaneous abortion as main complications. Traditional treatment has been heparin to prevent thromboses. However, like with AAV, there is increasing evidence that complement is of importance (Salmon and Girardi, 2004; Meroni et al., 2016). Particularly when this condition exacerbates to a severe catastrophic APS (CAPS), a systemic life-threatening condition, complement inhibitor therapy has been very efficient (Tinti et al., 2019) and was most likely lifesaving in a patient with recurrent CAPS who repeatedly responded on complement inhibition (Barratt-Due et al., 2016). Based on what we know about the pathophysiology and what is published, we suggest that AAV and CAPS are reasonably good candidates on the list of diseases to be treated with complement inhibitors in the future.

However, the great limitation with most of the studies presenting results on complement inhibition is that the number of cases in most of these are too small to perform reliable, randomized controlled trials. Thus, the use of the inhibitors is to a great extent off-label and based on case reports or small uncontrolled cohorts. Furthermore, there is a high risk of bias in the literature since a number of negative results are not published both because the authors find them less important and because editors tend to prefer positive results when it comes to a decision when pressure is on journal space.

7. Transplantation. From a complement point of view, there are three important conditions related to transplantation that should be taken into account. The first and most basic condition is ischemia-reperfusion injury. An important experimental observation was that mice within the same genetic strain were given heart transplants and a slow, long-lasting rejection was observed without any adaptive immune responses, as reviewed in Parolari et al. (2002). This could be due to an extreme overactivation of complement by exposure to DAMPs that could be recognized by the innate immune system over time. This has important consequences for preserving the organ under conditions that inhibit ischemia-reperfusion injury. A complement inhibitor would be one such candidate.

The second and very serious complication for kidney transplantation is the acute antibody-mediated rejection, which frequently leads to organ failure (Montgomery et al., 2018). This effector mechanism is mainly from the classical pathway activation of complement, and the deposition of $\mathrm{C} 4 \mathrm{~d}$ in the peritubular capillaries (Fig. 5C) is one of the Banff criteria for the diagnosis. Complement inhibition has been used off- 
label with many successful outcomes (O'Neill and Pierson, 2017; Haas, 2019). Thus, acute antibodymediated rejection might be a future candidate for complement inhibition because the kidney may be saved. However, a question to be resolved is whether the therapy can be gradually tapered or has to be continued.

The third issue is the chronic rejection, which is more complex. Antibodies are involved, but T-cells are as well, and the relative roles of these are uncertain. In this case complement inhibition should be an option, wherein it would more likely be a supplement to traditional and new therapy.

8. Systemic Inflammation: Trauma Sepsis and the Pandemic Coronavirus Disease 2019. So far, complement inhibition with success has been limited to the rare diseases. One of the reasons for this is that these rare diseases often have a pathophysiology that has been shown to be mainly complement-driven, and a single treatment with a complement inhibitor can be sufficient to keep the disease under full control. When moving to trauma and sepsis, the pathophysiology is much more complex, although complement definitely plays an essential role. Complement is an upstream actor as first-line sensor of danger and thus may accentuate the inflammatory explosion. However, there are other first-line sensors as well (e.g., the Toll-like receptors), so combined inhibition of several of these sensors might be necessary, as we have shown for combining complement and CD14 (Huber-Lang et al., 2014). It has been speculated that inhibition of CD14 could be a possible treatment of coronavirus disease 2019 (COVID-19) (Martin et al., 2020). The challenge for future strategy of complement inhibition in sepsis will be to define subgroups of patients in which complement activation is dominating. This can be combined with other upstream bottleneck sensor molecules, whereas inhibition of single downstream mediators like cytokines is less likely to succeed because of the vast amounts of them, as in accordance with the many studies that have failed by blocking single downstream mediators.

The role of innate immunity with focus on complement in the pathophysiology in trauma and its potential for therapy is somewhat comparable with sepsis, although initially the DAMPs are most important. Secondary infection is, however, frequently seen with development of a full-blown sepsis. A comprehensive review on complement in trauma was recently published (Huber-Lang et al., 2018). We therefore do not cover trauma in this review. Similarly, a recent review on sepsis and complement was published (Mollnes and Huber-Lang, 2020). Both of these reviews concluded that trauma and sepsis are both complex syndromes that need more research to dissect the role of complement and to enable correct stratification and inclusion of patients that are of high risk of getting excessive activation of complement. Once complement has exploded, it may be too late to start treatment (Fig. 2A).

COVID-19 disease is a pandemic dramatic condition that this year has changed the world in many ways. Since complement is a main sensor of danger, a number of groups have started to work on complement and COVID-19 disease. Coronavirus 2 (severe acute respiratory syndrome-coronavirus 2) can lead to lifethreatening pneumonia and multiple organ failure, which is termed coronavirus disease 2019. Both bacterial and viral pneumonia have been associated with complement activation and respiratory failure (Langlois and Gawryl, 1988; Wang et al., 2015). Importantly, the coronaviruses severe acute respiratory syndrome and Middle East respiratory syndrome both were shown to potently activate complement associated with respiratory failure (Gralinski et al., 2018; Jiang et al., 2018). One of the first observations of increased complement activation in patients with COVID-19 was an increase in the activation products $\mathrm{C} 5 \mathrm{a}$ and sC5b-9, with a prolonged activation in the latter (Cugno et al., 2020). A role for the Ca-C5aR1 axis was further supported by detection of C5a in bronchoalveolar fluid as well as inhibition of lung injury in a human C5aR1 knock mouse model (Carvelli et al., 2020). In a clinical study of 39 patients, five different complement activation products from all pathways were measured in patients who were hospitalized. All activation products were consistently elevated in all patients (Holter et al., 2020), and second, C5b-9 was correlated with respiratory function. Interestingly, antibody titers were significantly correlated with respiratory function as well, although to a less extent. It is uncertain to what extent the classical pathway versus the lectin pathway contributed to $\mathrm{C} 4$ activation, but most likely they were both involved. Additionally, the $\mathrm{C} 3$ convertase $\mathrm{C} 3 \mathrm{bBbP}$ was significantly elevated, implying that a therapeutic approach for COVID-19 should be broad and cover all pathways (i.e., C3 or C5). The interaction between the complement system and the coronaviruses has been reviewed in Java et al. (2020) and Noris et al. (2020).

It has been speculated that pathophysiology of COVID-19 is similar to thrombotic microangiopathy, involving both complement and hemostatic dysfunctions (Chauhan et al., 2020; Conway and Pryzdial, 2020; Fletcher-Sandersjoo and Bellander, 2020; Gavriilaki and Brodsky, 2020; Java et al., 2020; Jodele and Kohl, 2020; Mangalmurti and Hunter, 2020; Merrill et al., 2020; Ramlall et al., 2020; Song and FitzGerald, 2020). Thus, it is reasonable to suggest that complement might be a target for treatment in COVID-19, but so far treatment has been limited to case reports, in which most show inhibition at the level of C5 (Potlukova and Kralikova, 2008; Kulasekararaj et al., 2020; Laurence et al., 2020) and a single report uses a C3 inhibitor (Mastaglio et al., 2020). Although the data are promising, from an open-labeled randomized trial with 15 
patients treated with an inhibitory anti-C5a antibody and 15 controls (Vlaar et al., 2020), it remains to be shown in larger randomized control trials whether complement inhibition is an option for treatment in COVID-19 (Lo et al., 2020).

\section{Mode of Complement Inhibition}

\section{A. Targets to Be Inhibited}

1. Introduction. There are numerous components, fragments, and receptors that are candidates for inhibition in the complement system. The question of which targets are the best to inhibit is a nonsense question. It will depend on a number of factors that we have described in the sections above. First, what is the pathophysiological mechanism of the disease? Some diseases are virtually completely complementdependent, such as $\mathrm{PNH}$ and the cold agglutinin syndrome, whereas others are partly dependent on complement from strongly to slightly, and there probably are no conditions wherein immune inflammation is involved when complement is not involved at all. The indications for treating a condition will therefore mainly depend on the extent on the scale to which the complement is involved. Second, there is a crucial difference between chronic life-long diseases wherein the patient normally is at home and acute lifethreatening conditions wherein the patients are in hospital or even at the intensive care unit under continuous monitoring and covered with antibiotics, etc., and needs inhibition just for a few days or weeks. Third, the cost of complement inhibition until now has been extremely high and limited to rare diseases. New and less expensive drugs are approaching the market, and for healthcare cost implications, this also has to be taken into consideration. A number of other factors will be of importance when discussing this essential item in the future.

Below we give some selected target molecules from the cascade that we suggest will be the most relevant in the future. This might change, as the research field is rapidly progressing. We need to emphasize that the only drug for complement inhibition that has been available for routine use is an engineered humanized monoclonal antibody targeting the cleavage of C5. Thus, the experience of blocking other targets was until recently missing. The targets we have selected as most relevant are illustrated in Fig. 1 with an asterisk.

2. Classical and Lectin Pathway. Immediately one would think that $\mathrm{C} 1 \mathrm{q}$ could be a good candidate. However, we argue that $\mathrm{C} 1 \mathrm{q}$ is a molecule involved in so many other processes than complement activation that it would not be an obvious good candidate. C1r and $\mathrm{C} 1 \mathrm{~s}$ are the serine proteases that are activated when the classical pathway is triggered, and, so far, there is some evidence that $\mathrm{C} 1 \mathrm{~s}$ might be a good candidate. However, this is a good rationale only if the classical pathway is triggered. The main concern of blocking the classical pathway activation is that the antibody-mediated effects of complement are lost.

In the lectin pathway MBL has been the most studied protein and might be a candidate in certain cases, but recently MASP-2 has also been proposed as an exciting candidate to block the lectin pathway. As in accordance with the C1q mentioned above, MBL is a recognition molecule with many functions, and MASP-2 might be a good candidate also because the lectin pathway is recognized by a number of other molecules, and the activation route goes mainly through MASP-2. The main concern of blocking the lectin pathway is that a substantial part of the recognition of danger function of complement is lost.

3. C3 and the Alternative Pathway. The ultimate and most robust molecule to inhibit is $\mathrm{C} 3$ since it blocks the whole system from C3 and downstream. This is because all three initial pathways merge at C3, and C3 is the main molecule of the alternative pathway amplification loop. Thus, if the intention is to target one molecule to block most of the system, C3 is the molecule of choice. Thus, there is a marked potential to slow down all complement-mediated functions by blocking $\mathrm{C} 3$.

For specific blocking of the alternative pathway there are three candidate molecules. Factor B is the main component but requires relatively large doses because of its high serum concentration, Although factor $\mathrm{D}$ is the only serine protease that is circulating in active form in plasma, it is also the rate-limiting step in the alternative pathway and requires relatively small doses of a drug. Blocking both factors $\mathrm{B}$ and $\mathrm{D}$ will inhibit the alternative completely, as will virtually be the case also for inhibiting properdin. Notably, in contrast with blocking $\mathrm{C} 3$, the cascade will not be fully blocked by the other components, since classical and lectin pathway activation will generate some C5 convertases, and a certain terminal pathway activation will occur. Thus, the most effective blocking of the system using one target would be to block C3. Nevertheless, blocking of C3a or the C3aR might also be an alternative option to block the anaphylatoxin activity of $\mathrm{C} 3$ cleavage, but this has not been tried in clinical trials.

The main concern of blocking C3 and the alternative components is the reduced opsonization and probably risk of increased infection. This should, however, be no concern during an acute condition, in which the patient is monitored and covered with antibiotics. This shorttime treatment will also not be a concern for a child. C3 is important for speeding up the B-cell antibody production, but short-time blocking of C3 would hardly influence this effect. Another concern regarding C3 is the abundance of $\mathrm{C} 3$ in the circulation and also that it is produced locally in many tissues, each of which could make inhibition difficult.

4. Terminal Pathway. Blocking of C5 has been used clinically for more than a decade. Thus, C5 is a main 
candidate also in the future. Additional targets to block are C5a, which will block both C5aR1 and C5aR2 effects. Alternatively, C5aR1 is a very good candidate because this receptor is known to signal production of substantial proinflammatory mediators. There is evidence that C5aR2 counteracts C5aR1, but lack of specific reagents to block C5aR2 are so far missing. The last target in the terminal pathway is to specifically block the assembly of C5b-9, thus preventing membrane attack complex formation but still having C5a released. This could be obtained by blocking, for example, C6 or $\mathrm{C} 7$. After $\mathrm{C} 8$ has bound, the leakage process through the membrane starts.

\section{B. Reagents to Be Used}

1. Monoclonal Antibodies and Their Derivatives. Over the last 3 decades, monoclonal antibodies have made a dramatic transformation from scientific tools to powerful human therapeutics (Buss et al., 2012). To overcome the inherent immunogenicity and reduced effector function of murine monoclonal antibodies in man, chimeric mouse-human antibodies were developed. To further improve monoclonal antibody properties, humanized mAbs (suffix: -zumab) that are used for anti-C5 inhibition were developed by grafting just the murine hypervariable regions onto a human antibody framework, resulting in a molecule that is more than 95\% human. These types of antibodies appear to overcome most of the inherent immunogenic problems of murine and chimeric monoclonal antibodies.

The advent of in vitro phage display technology and the generation of various transgenic mouse strains expressing human variable domains enabled the generation of fully human mAbs (suffix: -umab). Both humanized and fully human monoclonal antibodies have significantly reduced immunogenic potential and show properties like human endogenous IgG (Nelson et al., 2010). The disadvantage of using this technique is that it is quite laborious and expensive to manufacture in large scale.

As discussed above, an anti-C5 monoclonal antibody that blocks the cleavage of $\mathrm{C} 5$ and thus the generation of proinflammatory C5a and membranolytic C5b-9 has been the first complement-targeted monoclonal antibody therapeutic and has been tremendously effective for many patients with $\mathrm{PNH}$ and aHUS (Legendre et al., 2013). More recently (2017) the US FDA approved antiC5 use in refractory generalized myasthenia gravis (Howard et al., 2017; Dhillon, 2018) and also in neuromyelitis optica spectrum disorder (Pittock et al., 2019). Two caveats of this otherwise successful treatment are that first, there is a small population of patients (3\% of the Japanese population) that have a C5 polymorphism that is not recognized by the anti-C5 antibody eculizumab (Nishimura et al., 2014). Multiple other anti-C5 antibodies, as referred to above, that can provide both improvements on eculizumab and broader patient efficacy are in phase I and II trials at this time (Mastellos et al., 2019; Röth et al., 2020). Thus far, a lack of C5a generation and thus C5aR1 signaling have not been harmful for extended clinical use of the C5 inhibitory antibody. An anti-C5a monoclonal antibody has been shown to be well tolerated in humans (Giamarellos-Bourboulis et al., 2020) and is being proposed as a complement therapeutic (e.g., in COVID-19), but it remains to be shown whether this will be an efficient therapeutic in the future (Vlaar et al., 2020).

In development for some time, strategies available to suppress deleterious overactivation of the complement cascade include the use of a specific monoclonal antibody to target the injured or diseased site fused to an inhibitor of complement activation. Predominantly, the complement inhibitor targets deposited C3b to suppress the amplification process and thus the generation of excessive downstream detrimental complement activation products. As mentioned above, an example of this is B4/Cr1-related protein $\mathrm{Y}$, which has been shown to be effective in stroke and reperfusion injury in animal studies.

2. Small Molecular Peptides and Peptidomimetics. Protein-protein interactions are well recognized as mediators of a plethora of processes in biologic systems and are vitally important in the progression of many disease states (Robertson and Spring, 2018). These interactions can be inhibited but also stabilized by peptides and peptidomimetics and thus are a potentially tool for drug discovery. Indeed, more than 60 different types of peptides have been approved for clinic use. On the other hand, chemical structures that mimic the effect of peptides are also an attractive approach. Peptidomimetics can respond to peptide limitations by displaying higher metabolic stability, good bioavailability, and enhanced receptor affinity and selectivity. Various synthetic strategies have been developed over the years to modulate the conformational flexibility and the peptide character of peptidomimetic compounds.

Both strategies have advantages over antibodies generally in cost but, more importantly, the potential access to tissue, including the CNS. In animal models of Alzheimer disease (Fonseca et al., 2009), Huntington disease (Woodruff et al., 2006), immune complexassociated blood brain barrier disruption (Mahajan et al., 2015), stroke (Garrett et al., 2009), and traumatic brain injury (Sewell et al., 2004), C5aR1 antagonists have suppressed pathology, inflammation (Fig. 5A), and functional loss. Treatment with PMX53 also reduced the time length of a seizure and the likelihood of a second seizure in a kindling model of epilepsy, suggesting that blocking C5aR1 can have antiepileptic effects (Benson et al., 2015).

A detailed comparison of the available peptide and small-molecule C5aR1 antagonists has recently been published by Woodruff et al. (Li et al., 2020) as well as thorough pharmocokinetics of the two commonly used 
antagonists PMX53 and PMX205 that will facilitate additional testing in mouse models ( $\mathrm{Li}$ et al., 2020). Drug-receptor cocrystallization has identified drugbinding sites and resulting conformational changes (Liu et al., 2018). Most encouraging is that this approach has been found to be safe in human trials (Vergunst et al., 2007; Garrett et al., 2009; Bekker et al., 2016; Jayne et al., 2017; Liu et al., 2018). Indeed, a small-molecule C5aR1 antagonist (Avacopan; CCX168) has completed a successful phase 3 trial for AAV and is under review by the US FDA for approval for oral treatment of this disease. Targeting C5aR1 leaves the beneficial functions of other complement components, such as C1q, C3b, and C5b-9, intact while having positive effects on pathology and function, including cognitive behavior in models of neurodegenerative disorders (Fonseca et al., 2009; Benson et al., 2015; Hernandez et al., 2017).

APL-2 and AMY-101 are two derivatives of a family of cyclic peptides that inhibit C3 amplification and are currently in clinical trials as either combination therapy with eculizamab or as a monotherapy, as suppression of C3 cleavage would also prevent membrane attack complex formation. Peptides and chemical peptidomimetics are small molecules usually with short half-lifes. The advantage is that they may be useful for diseases in organs with membranes limiting passage of large molecules and for short-time need of treatment, whereas the disadvantage would be long-time systemic treatment. The latter could be solved by conjugating them to proteins increasing the half-life, as described under item 4 below.

3. Aptamers. Aptamers are single-stranded DNA or, more frequently, RNA molecules that can bind specifically to a target and neutralize the function of a protein. The molecular mass is between 5 and $15 \mathrm{kDa}$, and the half-life is in the range of a few hours. They are potential reagents to inhibit complement activation, and an aptamer blocking the cleavage of $\mathrm{C} 5$ has been characterized in detail (Biesecker et al., 1999). Aptamers have also been developed to block C5a (Yatime et al., 2015; Hyzewicz et al., 2017) and C5aR1 (Kumar, 2018). A mouse study showed protection against pneumococcal sepsis using an aptamer blocking C5a (Müller-Redetzky et al., 2020), but the aptamers have not yet reached the clinic.

\section{Recombinant Proteins and Conjugates.} Recombinant proteins are frequently made from the host's own complement regulatory proteins. CR1 is cofactor for factor I and a very efficient inhibitor of C3 by enhancing inactivation of C3b. It is present in large amounts on a number of cells, including red cells. It exists in small amounts in a soluble form, sCR1 (TP10), which lacks the transmembrane portion. A breakthrough in the field of complement inhibition was when sCR1 was produced recombinantly and could be used experimentally, wherein it was shown to reduce the size of myocardial infarction in mice (Weisman et al., 1990). When conjugated to the E-selectin ligand sialyl Lewis ${ }^{x}$ (sCR1/sialyl Lewis ${ }^{\mathrm{x}}$; TP20), the effect was increased when treating mice with experimental stroke (Huang et al., 1999). TP10 was used in some clinical trials with benefits in subgroups ( $\mathrm{Li}$ et al., 2006). Large recombinant molecules are expensive to produce, and TP10 never came to routine clinical use. Other regulators like CD55, CD46, and CD59 have also been made recombinantly as possible drugs and tested experimentally (Verbakel et al., 2000).

Another approach is to take only a small part that is the active domain in the protein and conjugate this to a specific targeting molecule, which leads to binding to the actual site that needs to be treated. TT30 consists of a small part of factor $\mathrm{H}$, "mini-factor $\mathrm{H}$," which contains the active C3b-binding site of factor $\mathrm{H}$ (Nichols et al., 2015) fused to CR2, which binds C3d deposited in the tissue (Risitano et al., 2012). This is a prototypical reagent for targeting tissues where complement is already ongoing and C3d is deposited (Fridkis-Hareli et al., 2011; Rich et al., 2016).

Thus, this will bind to any tissue where C3d is exposed and reduce the amount of free inhibitor in the fluid phase, which is a major advantage to preserving the activity of complement in the fluid phase. Another similar approach is to conjugate the inhibitor to a tissue-specific protein targeting (e.g., the synovium, to treat arthritis) (Macor et al., 2012). Finally, a small fragment of CR1 has been conjugated to an endothelial cell membrane-binding reagent (Microcept, ATP070) that will target damaged endothelium, typically after ischemia/reperfusion and is thus not organ-specific and does not depend on ongoing complement activation but is intended to prevent activation whether it is a whole body or local damage (Souza et al., 2005).

In other cases, it is important to keep the inhibitor in the fluid phase, such as in trauma, sepsis, or other systemic inflammatory diseases. Then a small inhibitor can be conjugated to an inert, nontargeting molecule just for the purpose of increasing its half-life (e.g., an Fc fragment), and the half-life can be increased from a few minutes to days (Hepburn et al., 2008).

\section{Routes of Distribution}

1. Locally. Depending on the disease, its location and accessibility, and the structure of the drug, there are several alternatives for local treatment. Fist, a cream could be administered, such as, for example, for the highly complement-dependent disease periodontitis (Hajishengallis and Lambris, 2012), wherein inhibition both at C3 and C5 level has been shown effective (Abe et al., 2012; Kajikawa et al., 2017); toothpaste could be an alternative. Liniment might be an alternative to treat psoriasis, as it is postulated to be partly complement-dependent (Schonthaler et al., 2013). Complement is important for several eye diseases (see separate section), and, depending on the 
drug, local injection might be required, but with small molecules that might penetrate, eye drops are obviously simple and uncomplicated. Obvious advantages with local treatment are that it is low-cost and, except for injection into the eye, the treatment can done by the patient or a relative.

Local application can also be an alternative for systemic treatment. Subcutaneous injection is already well established for continuous release for long-time treatment and can be established at home. Finally, in some cases, particularly in children, nasal spray might be an alternative and obviously the simplest one.

2. Intravenously. Until now, intravenous treatment has been the usual way of administration. Systemic adverse effects might occur, and in most cases, the patient needs to go to the hospital. Thus, the costs are substantially higher than the local alternatives (i.e., subcutaneous injection).

3. Orally. The main goal for any producer of a complement inhibitor is to succeed with a pill. Great effort should be done to obtain this endpoint, as it is definitely the best solution. Promising preclinical data exist, but oral administration has not come to routine use yet. The problems with short half-life and bioavailability must be resolved to produce the effective "pill."

\section{Assays for Diagnostics and for Treatment Follow-up}

\section{A. Principles of Complement Assays}

1. Detection of Complement Activation. There are a number of different assays to evaluate the complement system [for review, see Mollnes et al. (2007) and Harboe et al. (2011)]. Here we will only describe the two assay types that are most important to understand for those who are treating patients with complement inhibitors in clinical routine. The first is an assay that detects the degree of complement activation in vivo. A number of assays that detect specific activation products are available, but the TCC is a valuable biomarker since it indicates that C5 is activated and that both C5a and $\mathrm{C} 5 \mathrm{~b}-9$ are formed. This can be detected in plasma as sC5b-9 in a simple ELISA based on a monoclonal antibody reacting with a neoepitope exposed in C9 when C9 is incorporated in the complex but not present in the native C9 molecule (Fig. 6). The advantage of using this assay is that this complex has a relatively long half-life (1 hour) as compared with the C5a molecule with a very short half-life (1 minute). Furthermore, it will detect activation of the whole cascade to its very end. It is critically important that the blood samples are obtained using EDTA and that plasma is collected and snap-frozen to $-70^{\circ} \mathrm{C}$ (Frazer-Abel, 2018; Prohászka et al., 2018).

Increased levels of sC5b-9 in plasma indicate a disease process wherein complement is involved, and the condition may be a possible candidate for complement inhibition. However, complement might be activated

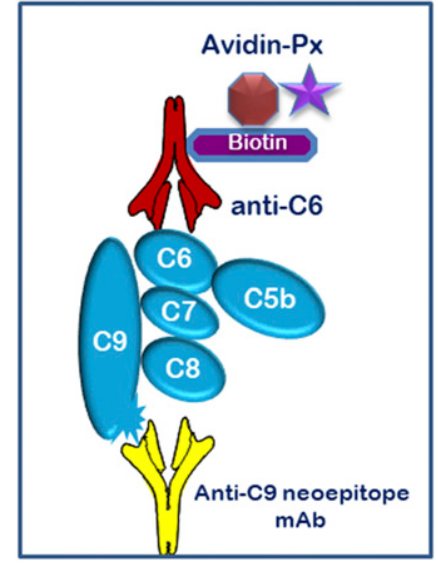

Fig. 6. Immunoassay for detection of complement activation. This ELISA illustrates the first specific assay for detection of sC5b-9 based on mAbE11 produced in our laboratory in 1985 reacting specifically with a neoepitope in C9 exposed only when C9 is incorporated in the C5b-9 complex (Mollnes et al., 1985). The assay is a traditional sandwich immunoassay, and many variants exist with different detection antibodies on the top, reacting with one of the other components of the complex. An increased level of sC5b-9 indicates that the complement cascade has been activated to the very end.

locally in organs without increased activation products in plasma (i.e., a normal sC5b-9 level does not exclude complement activation in tissue). Thus, biopsies may be the ultimate test for diagnosis in which activation product can easily be detected with fluorescence microscopy, as illustrated in Fig. 5B. Plasma sC5b-9 might also be helpful for evaluation of the effect of therapy in a patient with originally high levels before treatment is started. The ultimate test for such an evaluation is, however, the screening for total complement activity, as described below.

2. Screening for Total Complement Activity. This group of tests measures the functional activity of the whole complement cascade. Previously they were based on a complement hemolytic assay, but this has now been gradually replaced by more stable and sensitive enzyme immunoassays, like the total complement screen assay (also called Wielisa) (Fig. 7). In contrast with the sC5b-9 assay described above, this assay tests complement function in vitro and must therefore be done in serum (fresh or freshly stored at $-70^{\circ} \mathrm{C}$ ). The detection principle is as for the sC5b-9 ELISA, but the design is different. The wells are coated with specific activators of the three pathways, and if all components are present and active, the C5b-9 complex will assemble in the well and can be detected with the same anti-C9 neoepitope antibody. If the complement system is normal, it will be detected as $100 \%$ activity in the wells (Fig. 7A).

If a terminal component or C3 is genetically defective, the C5b-9 complex will not be formed, as for example in a patient deficient in C5 (Fig. 7B). Here all the three pathways will show $0 \%$ activity since the detection antibody will not recognize a C9 neoeptope. If the screen is negative in one or more of the assays, further testing has to be done to find the deficient component. If 

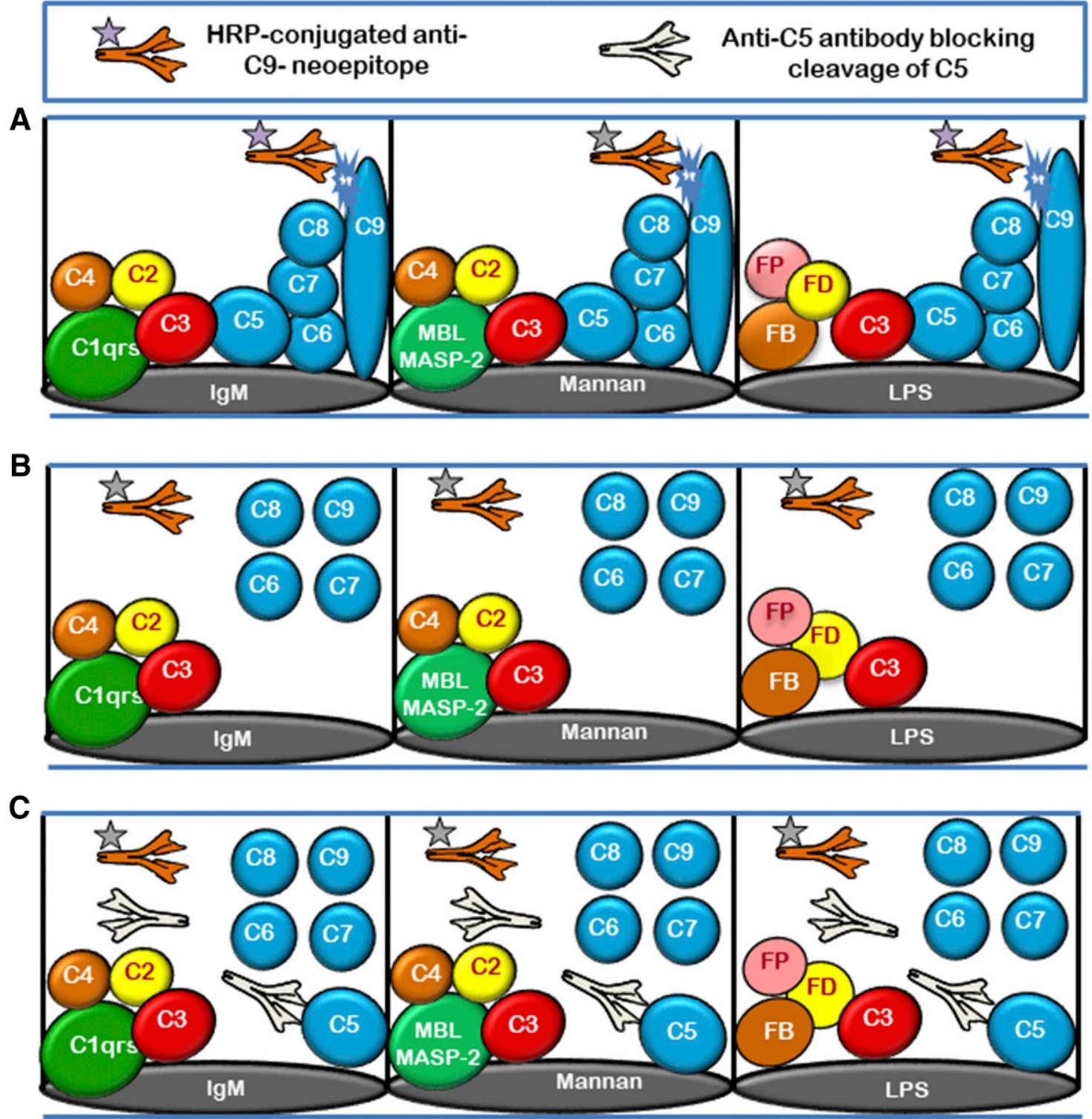

\section{Classical pathway Lectin pathway Alternative pathway}

Fig. 7. Immunoassay for detection of total complement function. This assay is used to screen for complement deficiencies in each activation pathway and to evaluate the effect of treating patients with, for example, a C5 inhibitor. (A) Normal serum leading to complete assembly of the C5b-9 being similar to the membrane attack complex complex, as it is bound to the plastic surface not measuring sC5b-9. All three pathways show 100\% activity. (B) Serum from a patient who is C5-deficient. The assembly will stop at the level of C5, and all three wells will have 0\% activity. (C) Serum from a patient treated in excess with the mAb eculizumab blocking $\mathrm{C} 5$ cleavage. This will give the same phenotype as the patient who is genetically deficient. If eculizumab is discontinued it will gradually disappear, and the situation will be similar to the one presented in (A), in which the inhibitory anti-C5 $\mathrm{mAb}$ is not present any longer, and the activity will be $00 \%$ as before treatment started. HRP, horseradish peroxidase.

a patient is receiving a complement inhibitor (e.g., a C5 blocker), this will give the same result as for the patient who is C5 genetic deficient if all C5 molecules are blocked (Fig. 7C), and the activity will be $0 \%$. For testing the effect of a C5 inhibitor, it is not necessary to use all the pathway assays. Either the classical or the alternative assay can be used to follow the patient, as the activity will gradually increase from $0 \%$ to $100 \%$ when C5 activity starts to increase, and finally all of the inhibitor is gone (Fig. 7, C and D). The half-life can vary substantially dependent upon which disease condition and stage of disease the patient presents. With these test results, an individualized treatment regimen can be established.

\section{Consequences of Therapeutic Complement Inhibition}

\section{A. Safety and Adverse Effects}

1. Safety and Adverse Effects of Established C5 Inhibition. Eculizumab has been the only complement inhibitor approved for clinical treatment until 2020. It 
was approved in 2007 for paroxysmal nocturnal hemoglobinuria. These patients have life-long treatment, and treatment has shown a high safety. In a study of 196 patients over 66 months, the drug was safe and well tolerated with no evidence of cumulative toxicity (Hillmen et al., 2013). Four deaths were not related to the treatment and no Neisseria infection was observed. The same was found in a Japanese study of patients with PNH (Kanakura et al., 2013). A systematic review based on 12 databases showed safe treatments without deaths or Neisseria infections (Rathbone et al., 2013). A number of other studies confirm the safety. However, in a large study including 1321 patients followed over 5 years, with patients who were both pediatric and adults, three cases of Neisseria infection was observed and one with a fatal outcome (Rondeau et al., 2019). Finally, a 10-year observation study comprising 28,518 patient-years confirmed the safety but also the risk of neisserial infection. A few other infections were observed, but whether they were related to treatment was uncertain (Socié et al., 2019). One fatal Neisseria infection was reported with a nongroupable strain has been reported (Nolfi-Donegan et al., 2018). Thus, C5 inhibition with eculizumab is a safe treatment with virtually no adverse effects, but the small risk of getting a Neisseeria infection should always be brought in mind.

2. Potential Adverse Effects of New Inhibitors. When new inhibitors come to clinical use, one should certainly be aware of other possible adverse effects. It cannot be excluded that inhibition at the initial recognition phases of all three pathways or inhibition at the level of C3 can lead to increased risk of other infections due to reduced opsonization. Short-time treatment when the patient is under observation should be of less concern and can even be the most effective treatment in certain acute phases.

\section{B. Efficacy of Treatment}

1. Fully Complement-Dependent Diseases. As described above under the indications for complement inhibition, the treatment is very efficient and also lifesaving when the disease is mainly complementdependent, such as with paroxysmal nocturnal hemoglobinuria and aHUS. As mentioned, there are a number of disease candidates in which complement plays a major (although not the whole) role in the pathophysiology. Controlled clinical trials should be performed before new diseases are added to the list. Occasionally, off-label use may be acceptable in patients who are critically ill in which it is reasonable to suggest complement-mediated pathophysiology, in particular when the disease is so rare that it is impossible to perform clinical trials with sufficient power.

\section{Diseases with Complex Pathophysiology.} Complement activation might be involved as a smaller part of the pathophysiology and in such complex conditions that the challenge will be to use experimental model and clinical trials with a combined strategy to examine whether complement inhibition may partly reduce disease activity.

\section{Conclusions and Future Perspectives}

As stated in the introduction, the aim of this study was to provide some background on the complement system and its physiologic activity with highlight on the mechanisms leading to complement dysfunction, subsequent tissue damage, and disease. We have given priority to these principles rather than include lists of ongoing clinical trials or of all the potential inhibitors that are available as therapeutic candidates. We recommend that the particularly interested reader use "complement" as a search key in https://clinicaltrials. gov/.

We hope this review has provided clear information to the reader for considering complement as an interesting and well documented target for treatment of many diseases in the clinic rather than merely being "an elegant model system." Furthermore, we emphasize the importance of increasing the research activity in this area to provide the basis for opportunities for clinical trials in the near future. It is reasonable to suggest that with an increase in the number of drugs targeting the complement system, the list of conditions to be treated with complement-modulating approaches will increase in parallel.

\section{Authorship Contributions}

Wrote or contributed to the writing of the manuscript: Garred, Tenner, Mollnes.

\section{References}

Abe T, Hosur KB, Hajishengallis E, Reis ES, Ricklin D, Lambris JD, and Hajishengallis G (2012) Local complement-targeted intervention in periodontitis: proof-of-concept using a C5a receptor (CD88) antagonist. J Immunol 189: 5442-5448.

Ahmad S, Pandya C, Kindelin A, Bhatia K, Chaudhary R, Dwivedi AK, Eschbacher JM, Liu Q, Waters MF, Hoda MN, et al. (2020) C3a receptor antagonist therapy is protective with or without thrombolysis in murine thromboembolic stroke. $\mathrm{Br}$ J Pharmacol 177:2466-2477.

Ahmad SB and Bomback AS (2020) C3 glomerulopathy: pathogenesis and treatment. Adv Chronic Kidney Dis 27:104-110.

Alawieh A, Elvington A, and Tomlinson S (2015) Complement in the homeostatic and ischemic brain. Front Immunol 6:417.

Alawieh A, Langley EF, and Tomlinson S (2018a) Targeted complement inhibition salvages stressed neurons and inhibits neuroinflammation after stroke in mice. Sci Transl Med 10:6459.

Alawieh A, Langley EF, Weber S, Adkins D, and Tomlinson S (2018b) Identifying the role of complement in triggering neuroinflammation after traumatic brain injury. $J$ Neurosci 38:2519-2532.

Alawieh AM, Langley EF, Feng W, Spiotta AM, and Tomlinson S (2020) Complement-dependent synaptic uptake and cognitive decline after stroke and reperfusion therapy. J Neurosci 40:4042-4058.

Albazli K, Kaminski HJ, and Howard JrJF (2020) Complement inhibitor therapy for myasthenia gravis. Front Immunol 11:917.

Ambrus G, Gál P, Kojima M, Szilágyi K, Balczer J, Antal J, Gráf L, Laich A, Moffatt BE, Schwaeble W, et al. (2003) Natural substrates and inhibitors of mannanbinding lectin-associated serine protease-1 and -2: a study on recombinant catalytic fragments. J Immunol 170:1374-1382.

Ames RS, Lee D, Foley JJ, Jurewicz AJ, Tornetta MA, Bautsch W, Settmacher B, Klos A, Erhard KF, Cousins RD, et al. (2001) Identification of a selective nonpeptide antagonist of the anaphylatoxin C3a receptor that demonstrates antiinflammatory activity in animal models. J Immunol 166:6341-6348.

Andersen P, Permin H, Andersen V, Schejbel L, Garred P, Svejgaard A and Barington T (2005) Deficiency of somatic hypermutation of the antibody light chain is associated with increased frequency of severe respiratory tract infection in common variable immunodeficiency. Blood 105:511-517. 
Avila Bernabeu AI, Cavero Escribano T, and Cao Vilarino M (2020) Atypical hemolytic uremic syndrome: new challenges in the complement blockage era. Nephron 144:537-549.

Babaha F, Abolhassani H, Hamidi Esfahani Z, Yazdani R, and Aghamohammadi A (2020) A new case of congenital ficolin-3 deficiency with primary immunodeficiency. Expert Rev Clin Immunol 16:733-738.

Bajic G, Degn SE, Thiel S, and Andersen GR (2015) Complement activation, regulation, and molecular basis for complement-related diseases. $E M B O J \mathbf{3 4}$ 2735-2757.

Bang P, Laursen I, Thornberg K, Schierbeck J, Nielsen B, Valdimarsson H, Koch C, and Christiansen M (2008) The pharmacokinetic profile of plasma-derived mannan-binding lectin in healthy adult volunteers and patients with Staphylococcus aureus septicaemia. Scand J Infect Dis 40:44-48.

Barilla-Labarca ML, Toder K, and Furie R (2013) Targeting the complement system in systemic lupus erythematosus and other diseases. Clin Immunol 148:313-321.

Barratt-Due A, Fløisand Y, Orrem HL, Kvam AK, Holme PA, Bergseth G, Tjønnfjord $\mathrm{GE}$, and Mollnes TE (2016) Complement activation is a crucial pathogenic factor in catastrophic antiphospholipid syndrome. Rheumatology (Oxford) 55:1337-1339.

Barratt-Due A, Pischke SE, Brekke OL, Thorgersen EB, Nielsen EW, Espevik T, Huber-Lang M, and Mollnes TE (2012) Bride and groom in systemic in flammation--the bells ring for complement and Toll in cooperation. Immunobiology 217:1047-1056.

Barratt-Due A, Pischke SE, Nilsson PH, Espevik T, and Mollnes TE (2017) Dual inhibition of complement and Toll-like receptors as a novel approach to treat inflammatory diseases-C3 or C5 emerge together with CD14 as promising targets. $J$ Leukoc Biol 101:193-204.

Basdemirci M, Sen A, and Ceylaner S (2019) Novel mutation in MASP1 gene in a new family with 3MC syndrome. Clin Dysmorphol 28:91-93.

Bay JT, Sørensen SS, Hansen JM, Madsen HO, and Garred P (2013) Low mannosebinding lectin serum levels are associated with reduced kidney graft survival. Kidney Int 83:264-271.

Bayarri-Olmos R, Hansen S, Henriksen ML, Storm L, Thiel S, Garred P, and Munthe-Fog L (2015) Genetic variation of COLEC10 and COLEC11 and association with serum levels of collectin liver 1 (CL-L1) and collectin kidney 1 (CLK1). PLoS One 10:e114883.

Bayarri-Olmos R, Kirketerp-Moller N, Pérez-Alós L, Skjodt K, Skjoedt MO, and Garred P (2018) Development of a quantitative assay for the characterization of human collectin-11 (CL-11, CL-K1). Front Immunol 9:2238.

Beckmann ND, Lin WJ, Wang M, Cohain AT, Charney AW, Wang P, Ma W, Wang YC, Jiang C, Audrain M, et al. (2020) Multiscale causal networks identify VGF as a key regulator of Alzheimer's disease. Nat Commun 11:3942.

Beecher G, Putko BN, Wagner AN, and Siddiqi ZA (2019) Therapies directed against B-cells and downstream effectors in generalized autoimmune myasthenia gravis: current status. Drugs 79:353-364.

Bekker P, Dairaghi D, Seitz L, Leleti M, Wang Y, Ertl L, Baumgart T, Shugarts S, Lohr L, Dang T, et al. (2016) Characterization of pharmacologic and pharmacokinetic properties of CCX168, a potent and selective orally administered complement 5 a receptor inhibitor, based on preclinical evaluation and randomized phase 1 clinical study. PLoS One 11:e0164646.

Bellander BM, Singhrao SK, Ohlsson M, Mattsson P, and Svensson M (2001) Complement activation in the human brain after traumatic head injury. $J$ Neurotrauma 18:1295-1311.

Ben-Zeev B, Tabib A, Nissenkorn A, Garti BZ, Gomori JM, Nass D, Goldshmidt H, Fellig Y, Anikster Y, Nevo Y, et al. (2015) Devastating recurrent brain ischemic infarctions and retinal disease in pediatric patients with CD59 deficiency. Eur $J$ Paediatr Neurol 19:688-693.

Bensa JC, Reboul A, and Colomb MG (1983) Biosynthesis in vitro of complement subcomponents $\mathrm{C} 1 \mathrm{q}, \mathrm{C} 1 \mathrm{~s}$ and $\mathrm{C} 1$ inhibitor by resting and stimulated human monocytes. Biochem J 216:385-392.

Benson MJ, Thomas NK, Talwar S, Hodson MP, Lynch JW, Woodruff TM and Borges K (2015) A novel anticonvulsant mechanism via inhibition of complement receptor C5ar1 in murine epilepsy models. Neurobiol Dis 76:87-97.

Berentsen S (2018) Complement activation and inhibition in autoimmune hemolytic anemia: focus on cold agglutinin disease. Semin Hematol 55:141-149.

Beurskens FJ, Lindorfer MA, Farooqui M, Beum PV, Engelberts P, Mackus WJ, Parren PW, Wiestner A, and Taylor RP (2012) Exhaustion of cytotoxic effector systems may limit monoclonal antibody-based immunotherapy in cancer patients. J Immunol 188:3532-3541.

Bhakdi S and Tranum-Jensen J (1991) Complement lysis: a hole is a hole. Immunol Today 12:318-320; discussion 321.

Bibert S, Piret J, Quinodoz M, Collinet E, Zoete V, Michielin O, Menasria R, Meylan P, Bihl T, Erard V, et al. (2019) Herpes simplex encephalitis in adult patients with MASP-2 deficiency. PLoS Pathog 15:e1008168.

Biesecker G (1990) The complement SC5b-9 complex mediates cell adhesion through a vitronectin receptor. J Immunol 145:209-214.

Biesecker G, Dihel L, Enney K, and Bendele RA (1999) Derivation of RNA aptamer inhibitors of human complement C5. Immunopharmacology 42:219-230.

Biesma DH, Hannema AJ, van Velzen-Blad H, Mulder L, van Zwieten R, Kluijt I, and Roos D (2001) A family with complement factor D deficiency. J Clin Invest 108: 233-240.

Bíró A, Rovó Z, Papp D, Cervenak L, Varga L, Füst G, Thielens NM, Arlaud GJ, and Prohászka Z (2007) Studies on the interactions between C-reactive protein and complement proteins. Immunology 121:40-50.

Blom AM, Villoutreix BO, and Dahlbäck B (2004) Complement inhibitor C4b-binding protein-friend or foe in the innate immune system? Mol Immunol 40:1333-1346.

Bohlson SS, Garred P, Kemper C, and Tenner AJ (2019) Complement nomenclaturedeconvoluted. Front Immunol 10:1308.

Boos L, Szalai AJ, and Barnum SR (2005) C3a expressed in the central nervous system protects against LPS-induced shock. Neurosci Lett 387:68-71.
Bordron A, Bagacean C, Tempescul A, Berthou C, Bettacchioli E, Hillion S, and Renaudineau Y (2020) Complement system: a neglected pathway in immunotherapy. Clin Rev Allergy Immunol 58:155-171.

Bossi F, Tripodo C, Rizzi L, Bulla R, Agostinis C, Guarnotta C, Munaut C, Baldassarre G, Papa G, Zorzet S, et al. (2014) C1q as a unique player in angiogenesis with therapeutic implication in wound healing. Proc Natl Acad Sci USA 111:4209-4214.

Botto M, Kirschfink M, Macor P, Pickering MC, Würzner R, and Tedesco F (2009) Complement in human diseases: lessons from complement deficiencies. Mol Immunol 46:2774-2783.

Brekke OL, Christiansen D, Kisserli A, Fure H, Dahl JA, Donvito B, Reveil B, Ludviksen JK, Tabary T, Mollnes TE, et al. (2019) Key role of the number of complement receptor 1 on erythrocytes for binding of Escherichia coli to erythrocytes and for leukocyte phagocytosis and oxidative burst in human whole blood. Mol Immunol 114:139-148.

Brodsky RA, Young NS, Antonioli E, Risitano AM, Schrezenmeier H, Schubert J, Gaya A, Coyle L, de Castro C, Fu CL, et al. (2008) Multicenter phase 3 study of the complement inhibitor eculizumab for the treatment of patients with paroxysmal nocturnal hemoglobinuria. Blood 111:1840-1847.

Brouwer N, Frakking FN, van de Wetering MD, van Houdt M, Hart M, Budde IK, Strengers PF, Laursen I, Houen G, Roos D, et al. (2009) Mannose-binding lectin (MBL) substitution: recovery of opsonic function in vivo lags behind MBL serum levels. J Immunol 183:3496-3504.

Bu F, Maga T, Meyer NC, Wang K, Thomas CP, Nester CM, and Smith RJ (2014) Comprehensive genetic analysis of complement and coagulation genes in atypical hemolytic uremic syndrome. J Am Soc Nephrol 25:55-64.

Buchner H (1891) Zur Nomenklatur der schutzenden Eiweisskorper. Centr Bakteriol Parasitenk 10:699-701.

Buss NA, Henderson SJ, McFarlane M, Shenton JM, and de Haan L (2012) Monoclonal antibody therapeutics: history and future. Curr Opin Pharmacol 12: $615-622$.

Carroll MC and Isenman DE (2012) Regulation of humoral immunity by complement. Immunity 37:199-207.

Carroll MV and Sim RB (2011) Complement in health and disease. Adv Drug Deliv Rev 63:965-975.

Carvelli J, Demaria O, Vely F, Batista L, Benmansour NC, Fares J, Carpentier S, Thibult ML, Morel A, Remark R, et al.; Explore COVID-19 IPH group; Explore COVID-19 Marseille Immunopole group (2020) Association of COVID-19 inflammation with activation of the C5a-C5aR1 axis. Nature 588:146-150.

Cedzyński M, Thielens NM, Mollnes TE, and Vorup-Jensen T (2019) Editorial: the role of complement in health and disease. Front Immunol 10:1869.

Chalmers JD, McHugh BJ, Doherty C, Smith MP, Govan JR, Kilpatrick DC, and Hill AT (2013) Mannose-binding lectin deficiency and disease severity in non-cystic fibrosis bronchiectasis: a prospective study. Lancet Respir Med 1:224-232.

Chauhan AJ, Wiffen LJ, and Brown TP (2020) COVID-19: a collision of complement, coagulation and inflammatory pathways. J Thromb Haemost 18:2110-2117.

Chen GY and Nuñez G (2010) Sterile inflammation: sensing and reacting to damage. Nat Rev Immunol 10:826-837.

Chen M, Muckersie E, Luo C, Forrester JV, and Xu H (2010) Inhibition of the alternative pathway of complement activation reduces inflammation in experimental autoimmune uveoretinitis. Eur J Immunol 40:2870-2881.

Cheng IH, Scearce-Levie K, Legleiter J, Palop JJ, Gerstein H, Bien-Ly N, Puoliväli J, Lesné S, Ashe KH, Muchowski PJ, et al. (2007) Accelerating amyloid-beta fibrillization reduces oligomer levels and functional deficits in Alzheimer disease mouse models. J Biol Chem 282:23818-23828.

Christiansen D, Milland J, Thorley BR, McKenzie IFC, and Loveland BE (1996) A functional analysis of recombinant soluble CD46 in vivo and a comparison with recombinant soluble forms of CD55 and CD35 in vitro. Eur J Immunol 26:578-585.

Chu Y, Jin X, Parada I, Pesic A, Stevens B, Barres B, and Prince DA (2010) Enhanced synaptic connectivity and epilepsy in C1q knockout mice. Proc Natl Acad Sci USA 107:7975-7980.

Cong Q, Soteros BM, Wollet M, Kim JH, and Sia GM (2020) The endogenous neuronal complement inhibitor SRPX2 protects against complement-mediated synapse elimination during development. Nat Neurosci 23:1067-1078.

Conway EM and Pryzdial ELG (2020) Is the COVID-19 thrombotic catastrophe complement-connected? J Thromb Haemost 18:2812-2822.

Copland DA, Hussain K, Baalasubramanian S, Hughes TR, Morgan BP, Xu H, Dick $\mathrm{AD}$, and Nicholson LB (2010) Systemic and local anti-C5 therapy reduces the disease severity in experimental autoimmune uveoretinitis. Clin Exp Immunol 159:303-314.

Cornacoff JB, Hebert LA, Smead WL, VanAman ME, Birmingham DJ, and Waxman FJ (1983) Primate erythrocyte-immune complex-clearing mechanism. J Clin Invest 71:236-247.

Cortesio CL and Jiang W (2006) Mannan-binding lectin-associated serine protease 3 cleaves synthetic peptides and insulin-like growth factor-binding protein 5. Arch Biochem Biophys 449:164-170.

Coulthard LG and Woodruff TM (2015) Is the complement activation product C3a a proinflammatory molecule? Re-evaluating the evidence and the myth. J Immunol 194:3542-3548.

Cugno M, Meroni PL, Gualtierotti R, Griffini S, Grovetti E, Torri A, Panigada M, Aliberti S, Blasi F, Tedesco F, et al. (2020) Complement activation in patients with COVID-19: A novel therapeutic target. J Allergy Clin Immunol 146:215-217.

Czerewaty M, Tarnowski M, Safranow K, Domanski L, and Pawlik A (2019) Mannose binding lectin 2 gene polymorphisms in patients after renal transplantation with acute graft rejection. Transpl Immunol 54:29-37.

Dadfar E, Furuhjelm C, Nilsson J, Dahle C, and Garred P (2020) Fatal pneumococcus meningitis in a child with complement factor ficolin-3 deficiency. J Allergy Clin Immunol Pract 8:778-779.

Daha MR, Fearon DT, and Austen KF (1976) C3 requirements for formation of alternative pathway C5 convertase. J Immunol 117:630-634. 
Daiger SP (2005) Genetics. Was the human genome project worth the effort? Science 308:362-364.

De-la-Iglesia S, Luzardo H, Lemes A, Torres M, Gómez-Casares MT, Cruz N, and Molero T (2016) Positive impact of eculizumab therapy on surgery for buddchiari syndrome in a patient with paroxysmal nocturnal hemoglobinuria and a long-term history of thrombosis. Hematol Rep 8:6562.

Degn SE, Hansen AG, Steffensen R, Jacobsen C, Jensenius JC, and Thiel S (2009) MAp44, a human protein associated with pattern recognition molecules of the complement system and regulating the lectin pathway of complement activation. $J$ Immunol 183:7371-7378.

Degn SE, Jensenius JC, and Thiel S (2011) Disease-causing mutations in genes of the complement system. Am J Hum Genet 88:689-705.

Dejanovic B, Huntley MA, De Mazière A, Meilandt WJ, Wu T, Srinivasan K, Jiang Z, Gandham V, Friedman BA, Ngu H, et al. (2018) Changes in the synaptic proteome in tauopathy and rescue of tau-induced synapse loss by C1q antibodies. Neuron 100:1322-1336.e7.

Denk S, Perl M, and Huber-Lang M (2012) Damage- and pathogen-associated molecular patterns and alarmins: keys to sepsis? Eur Surg Res 48:171-179.

Dhillon S (2018) Eculizumab: a review in generalized myasthenia gravis. Drugs 78: 367-376.

Dick J, Gan PY, Ford SL, Odobasic D, Alikhan MA, Loosen SH, Hall P, Westhorpe CL, Li A, Ooi JD, et al. (2018) C5a receptor 1 promotes autoimmunity, neutrophil dysfunction and injury in experimental anti-myeloperoxidase glomerulonephritis. Kidney Int 93:615-625.

Diebolder CA, Beurskens FJ, de Jong RN, Koning RI, Strumane K, Lindorfer MA Voorhorst M, Ugurlar D, Rosati S, Heck AJ, et al. (2014) Complement is activated by IgG hexamers assembled at the cell surface. Science 343:1260-1263.

Dobó J, Pál G, Cervenak L, and Gál P (2016a) The emerging roles of mannose-binding lectin-associated serine proteases (MASPs) in the lectin pathway of complement and beyond. Immunol Rev 274:98-111.

Dobó J, Szakács D, Oroszlán G, Kortvely E, Kiss B, Boros E, Szász R, Závodszky P, Gál P, and Pál G (2016b) MASP-3 is the exclusive pro-factor D activator in resting blood: the lectin and the alternative complement pathways are fundamentally linked. Sci Rep 6:31877.

Doni A, Garlanda C, Bottazzi B, Meri S, Garred P, and Mantovani A (2012) Interactions of the humoral pattern recognition molecule PTX3 with the complement system. Immunobiology 217:1122-1128.

Dorfman R, Sandford A, Taylor C, Huang B, Frangolias D, Wang Y, Sang R, Pereira L, Sun L, Berthiaume Y, et al. (2008) Complex two-gene modulation of lung disease severity in children with cystic fibrosis. J Clin Invest 118:1040-1049.

Du Clos TW and Mold C (2011) Pentraxins (CRP, SAP) in the process of complement activation and clearance of apoptotic bodies through Fcy receptors. Curr Opin Organ Transplant 16:15-20.

Ehrlich PMJ (1899) Zur theorie der lysinwirkung. Berliner Klinische Wochenschrift 1: 6-9.

Ehrnthaller C, Ignatius A, Gebhard F, and Huber-Lang M (2011) New insights of an old defense system: structure, function, and clinical relevance of the complement system. Mol Med 17:317-329.

Eisen DP and Minchinton RM (2003) Impact of mannose-binding lectin on susceptibility to infectious diseases. Clin Infect Dis 37:1496-1505.

Ekdahl KN, Teramura Y, Hamad OA, Asif S, Duehrkop C, Fromell K, Gustafson E, Hong J, Kozarcanin H, Magnusson PU, et al. (2016) Dangerous liaisons: complement, coagulation, and kallikrein/kinin cross-talk act as a linchpin in the events leading to thromboinflammation. Immunol Rev 274:245-269.

El Gaamouch F, Audrain M, Lin WJ, Beckmann N, Jiang C, Hariharan S, Heeger PS, Schadt EE, Gandy S, Ehrlich ME, et al. (2020) VGF-derived peptide TLQP-21 modulates microglial function through C3aR1 signaling pathways and reduces neuropathology in 5xFAD mice. Mol Neurodegener 15:4

Endo Y, Matsushita M, and Fujita T (2015) New insights into the role of ficolins in the lectin pathway of innate immunity. Int Rev Cell Mol Biol 316:49-110.

Ermert D and Blom AM (2016) C4b-binding protein: the good, the bad and the deadly. Novel functions of an old friend. Immunol Lett 169:82-92

Esser AF (1991) Big MAC attack: complement proteins cause leaky patches. Immunol Today 12:316-318; discussion 321.

Fakhouri F, Hourmant M, Campistol JM, Cataland SR, Espinosa M, Gaber AO, Menne J, Minetti EE, Provôt F, Rondeau E, et al. (2016) Terminal complement inhibitor eculizumab in adult patients with atypical hemolytic uremic syndrome: a single-arm, open-label trial. Am J Kidney Dis 68:84-93

Fearon DT (1980) Identification of the membrane glycoprotein that is the C3b receptor of the human erythrocyte, polymorphonuclear leukocyte, B lymphocyte, and monocyte. J Exp Med 152:20-30.

Fevang B, Mollnes TE, Holm AM, Ueland T, Heggelund L, Damås JK, Aukrust P, and Frøland SS (2005) Common variable immunodeficiency and the complement system; low mannose-binding lectin levels are associated with bronchiectasis. Clin Exp Immunol 142:576-584.

Fishelson Z and Kirschfink M (2019) Complement C5b-9 and cancer: mechanisms of cell damage, cancer counteractions, and approaches for intervention. Front Immunol 10:752.

Fleming SD and Tsokos GC (2006) Complement, natural antibodies, autoantibodies and tissue injury. Autoimmun Rev 5:89-92.

Fletcher-Sandersjöö A and Bellander BM (2020) Is COVID-19 associated thrombosis caused by overactivation of the complement cascade? A literature review. Thromb Res 194:36-41.

Floege J and Daha MR (2018) IgA nephropathy: new insights into the role of complement. Kidney Int 94:16-18.

Fonseca MI, Ager RR, Chu SH, Yazan O, Sanderson SD, LaFerla FM, Taylor SM Woodruff TM, and Tenner AJ (2009) Treatment with a C5aR antagonist decrease pathology and enhances behavioral performance in murine models of Alzheimer's disease. J Immunol 183:1375-1383.
Fonseca MI, Chu SH, Berci AM, Benoit ME, Peters DG, Kimura Y, and Tenner AJ (2011) Contribution of complement activation pathways to neuropathology differs among mouse models of Alzheimer's disease. J Neuroinflammation 8:4.

Forneris F, Wu J, Xue X, Ricklin D, Lin Z, Sfyroera G, Tzekou A, Volokhina E, Granneman JC, Hauhart R, et al. (2016) Regulators of complement activity mediate inhibitory mechanisms through a common C3b-binding mode. EMBO $J \mathbf{3 5}$ : 1133-1149.

Frampton JE (2020) Eculizumab: a review in neuromyelitis optica spectrum disorder Drugs 80:719-727.

Frazer-Abel A (2018) The effect on the immunology laboratory of the expansion in complement therapeutics. J Immunol Methods 461:30-36.

Fredslund F, Laursen NS, Roversi P, Jenner L, Oliveira CL, Pedersen JS, Nunn MA Lea SM, Discipio R, Sottrup-Jensen L, et al. (2008) Structure of and influence of a tick complement inhibitor on human complement component 5. Nat Immunol 9:753-760.

Fridkis-Hareli M, Storek M, Mazsaroff I, Risitano AM, Lundberg AS, Horvath CJ, and Holers VM (2011) Design and development of TT30, a novel C3d-targeted C3/ C5 convertase inhibitor for treatment of human complement alternative pathwaymediated diseases. Blood 118:4705-4713.

Fromell K, Adler A, Åman A, Manivel VA, Huang S, Dührkop C, Sandholm K, Ekdah $\mathrm{KN}$, and Nilsson B (2020) Assessment of the role of $\mathrm{C} 3\left(\mathrm{H}_{2} \mathrm{O}\right)$ in the alternative pathway. Front Immunol 11:530.

Fukumori Y, Yoshimura K, Ohnoki S, Yamaguchi H, Akagaki Y, and Inai S (1989) A high incidence of C9 deficiency among healthy blood donors in Osaka, Japan. Int Immunol 1:85-89.

Fumagalli S, Perego C, Zangari R, De Blasio D, Oggioni M, De Nigris F, Snider F, Garred P, Ferrante AM, and De Simoni MG (2017) Lectin pathway of complement activation is associated with vulnerability of atherosclerotic plaques. Front Immunol 8:288.

Gaboriaud C, Juanhuix J, Gruez A, Lacroix M, Darnault C, Pignol D, Verger D, Fontecilla-Camps JC, and Arlaud GJ (2003) The crystal structure of the globular head of complement protein C1q provides a basis for its versatile recognition properties. J Biol Chem 278:46974-46982.

Gäckler A, Kaulfuß M, Rohn H, Vogel U, Claus H, Feldkamp T, Kribben A and Witzke $\mathrm{O}$ (2020) Failure of first meningococcal vaccination in patients with atypical haemolytic uraemic syndrome treated with eculizumab. Nephrol Dial Transplant 35:298-303.

Gajek G, Świerzko AS, and Cedzyński M (2020) Association of polymorphisms of MASP1/3, COLEC10, and COLEC11 genes with 3MC syndrome. Int J Mol Sci 21: $5483-5483$

García-Laorden MI, Hernández-Brito E, Muñoz-Almagro C, Pavlovic-Nesic S, RúaFigueroa I, Briones ML, Rajas O, Borderías L, Payeras A, Lorente L, et al. (2020) Should MASP-2 deficiency be considered a primary immunodeficiency? Relevance of the lectin pathway. $J$ Clin Immunol 40:203-210.

Garred P, Genster N, Pilely K, Bayarri-Olmos R, Rosbjerg A, Ma YJ, and Skjoedt MO (2016) A journey through the lectin pathway of complement-MBL and beyond Immunol Rev 274:74-97.

Garred P, Larsen F, Madsen HO, and Koch C (2003) Mannose-binding lectin deficiency--revisited. Mol Immunol 40:73-84.

Garred P, Larsen F, Seyfarth J, Fujita R, and Madsen HO (2006) Mannose-binding lectin and its genetic variants. Genes Immun 7:85-94.

Garred P, Pressler T, Lanng S, Madsen HO, Moser C, Laursen I, Balstrup F, Koch C, and Koch C (2002) Mannose-binding lectin (MBL) therapy in an MBL-deficient patient with severe cystic fibrosis lung disease. Pediatr Pulmonol 33:201-207.

Garred P, Pressler T, Madsen HO, Frederiksen B, Svejgaard A, Høiby N, Schwartz M, and Koch C (1999) Association of mannose-binding lectin gene heterogeneity with severity of lung disease and survival in cystic fibrosis. $J$ Clin Invest 104:431-437.

Garrett MC, Otten ML, Starke RM, Komotar RJ, Magotti P, Lambris JD, Rynkowsk MA, and Connolly ES (2009) Synergistic neuroprotective effects of C3a and C5a receptor blockade following intracerebral hemorrhage. Brain Res 1298:171-177.

Gavriilaki E and Brodsky RA (2020) Severe COVID-19 infection and thrombotic microangiopathy: success does not come easily. $\mathrm{Br}$ J Haematol 189:e227-e230.

Gedebjerg A, Bjerre M, Kjaergaard AD, Steffensen R, Nielsen JS, Rungby J, Friborg SG, Brandslund I, Thiel S, Beck-Nielsen H, et al. (2020) Mannose-binding lectin and risk of cardiovascular events and mortality in type 2 diabetes: a Danish cohort study. Diabetes Care 43:2190-2198.

Ghebrehiwet B, Geisbrecht BV, Xu X, Savitt AG, and Peerschke EIB (2019) The C1d Receptors: focus on $\mathrm{gC} 1 \mathrm{qR} / \mathrm{p} 33$ (C1qBP, p32, HABP-1) ${ }^{1}$. Semin Immunol 45: 101338.

Ghebrehiwet B and Peerschke EI (2014) Purification of C1q receptors and functional analysis. Methods Mol Biol 1100:319-327.

Gialeli C, Gungor B, and Blom AM (2018) Novel potential inhibitors of complement system and their roles in complement regulation and beyond. Mol Immunol 102: 73-83.

Giamarellos-Bourboulis EJ, Argyropoulou M, Kanni T, Spyridopoulos T, Otto I, Zenker O, Guo R, and Riedemann NC (2020) Clinical efficacy of complement C5a inhibition by IFX-1 in hidradenitis suppurativa: an open-label single-arm trial in patients not eligible for adalimumab. Br J Dermatol 183:176-178.

Goicoechea de Jorge E, López Lera A, Bayarri-Olmos R, Yebenes H, Lopez-Trascasa M, and Rodríguez de Córdoba S (2018) Common and rare genetic variants of complement components in human disease. Mol Immunol 102:42-57.

Golshayan D, Wójtowicz A, Bibert S, Pyndiah N, Manuel O, Binet I, Buhler LH, Huynh-Do U, Mueller T, Steiger J, et al.; Swiss Transplant Cohort Study (2016) Polymorphisms in the lectin pathway of complement activation influence the incidence of acute rejection and graft outcome after kidney transplantation. Kidney Int 89:927-938.

Gonzalez Suarez ML, Thongprayoon C, Mao MA, Leeaphorn N, Bathini T, and Cheungpasitporn W (2019) Outcomes of kidney transplant patients with atypical hemolytic uremic syndrome treated with eculizumab: a systematic review and meta-analysis. J Clin Med 8:919-934. 
Gralinski LE, Sheahan TP, Morrison TE, Menachery VD, Jensen K, Leist SR, Whitmore A, Heise MT, and Baric RS (2018) Complement activation contributes to severe acute respiratory syndrome coronavirus pathogenesis. MBio 9 : e01753-e01818.

Graul-Neumann LM, Mensah MA, Klopocki E, Uebe S, Ekici AB, Thiel CT, Reis A, and Zweier C (2018) Biallelic intragenic deletion in MASP1 in an adult female with 3MC syndrome. Eur J Med Genet 61:363-368.

Györffy BA, Kun J, Török G, Bulyáki É, Borhegyi Z, Gulyássy P, Kis V, Szocsics P, Micsonai A, Matkó J, et al. (2018) Local apoptotic-like mechanisms underlie complement-mediated synaptic pruning. Proc Natl Acad Sci USA 115:6303-6308.

Györffy BA, Toth V, Torok G, Gulyassy P, Kovacs RA, Vadaszi H, Micsonai A, Toth ME, Santha M, Homolya L, Drahos L, Juhasz G, Kekesi KA, and Kardos J (2020) Synaptic mitochondrial dysfunction and septin accumulation are linked to complement-mediated synapse loss in an Alzheimer's disease animal model. Cell Mol Life Sci 77:5243-5258.

Haas M (2019) Eculizumab as primary therapy for active antibody-mediated rejection of renal allografts: a matter of timing, severity, and donor-specific antibodies. Transplantation 103:2219-2220.

Hageman GS, Anderson DH, Johnson LV, Hancox LS, Taiber AJ, Hardisty LI, Hageman JL, Stockman HA, Borchardt JD, Gehrs KM, et al. (2005) A common haplotype in the complement regulatory gene factor $\mathrm{H}(\mathrm{HF} 1 / \mathrm{CFH})$ predisposes individuals to age-related macular degeneration. Proc Natl Acad Sci USA 102: $7227-7232$

Hajishengallis G and Lambris JD (2012) Complement and dysbiosis in periodontal disease. Immunobiology 217:1111-1116.

Hajishengallis G, Reis ES, Mastellos DC, Ricklin D, and Lambris JD (2017) Novel mechanisms and functions of complement. Nat Immunol 18:1288-1298.

Hansen SW, Ohtani K, Roy N, and Wakamiya N (2016) The collectins CL-L1, CL-K1 and CL-P1, and their roles in complement and innate immunity. Immunobiology 221:1058-1067.

Harboe M, Garred P, Borgen MS, Stahl GL, Roos A, and Mollnes TE (2006) Design of a complement mannose-binding lectin pathway-specific activation system applicable at low serum dilutions. Clin Exp Immunol 144:512-520.

Harboe M, Johnson C, Nymo S, Ekholt K, Schjalm C, Lindstad JK, Pharo A, Hellerud BC, Nilsson Ekdahl K, Mollnes TE, et al. (2017) Properdin binding to complement activating surfaces depends on initial C3b deposition. Proc Natl Acad Sci USA 114: E534-E539.

Harboe M and Mollnes TE (2008) The alternative complement pathway revisited J Cell Mol Med 12:1074-1084.

Harboe M, Thorgersen EB, and Mollnes TE (2011) Advances in assay of complement function and activation. Adv Drug Deliv Rev 63:976-987.

Harboe M, Ulvund G, Vien L, Fung M, and Mollnes TE (2004) The quantitative role of alternative pathway amplification in classical pathway induced terminal complement activation. Clin Exp Immunol 138:439-446.

Harris CL, Heurich M, Rodriguez de Cordoba S, and Morgan BP (2012) The complotype: dictating risk for inflammation and infection. Trends Immunol $\mathbf{3 3}$ 513-521.

Harris CL, Pouw RB, Kavanagh D, Sun R, and Ricklin D (2018) Developments in anti-complement therapy; from disease to clinical trial. Mol Immunol 102:89-119. Hassler JR (2020) IgA nephropathy: a brief review. Semin Diagn Pathol 37:143-147. Hayashi M, Machida T, Ishida Y, Ogata Y, Omori T, Takasumi M, Endo Y, Suzuki T, Sekimata M, Homma Y, et al. (2019) Cutting edge: role of MASP-3 in the physiological activation of factor $\mathrm{D}$ of the alternative complement pathway. J Immunol 203:1411-1416.

He JQ, Wiesmann C, and van Lookeren Campagne M (2008) A role of macrophage complement receptor CRIg in immune clearance and inflammation. Mol Immunol 45:4041-4047.

Heinen S, Józsi M, Hartmann A, Noris M, Remuzzi G, Skerka C, and Zipfel PF (2007) Hemolytic uremic syndrome: a factor $\mathrm{H}$ mutation (E1172Stop) causes defective complement control at the surface of endothelial cells. J Am Soc Nephrol 18: 506-514.

Héja D, Kocsis A, Dobó J, Szilágyi K, Szász R, Závodszky P, Pál G, and Gál P (2012) Revised mechanism of complement lectin-pathway activation revealing the role of serine protease MASP-1 as the exclusive activator of MASP-2. Proc Natl Acad Sci USA 109:10498-10503.

Hellemann D, Larsson A, Madsen HO, Bonde J, Jarløv JO, Wiis J, Faber T, Wetterslev J, and Garred P (2007) Heterozygosity of mannose-binding lectin (MBL2) genotypes predicts advantage (heterosis) in relation to fatal outcome in intensive care patients. Hum Mol Genet 16:3071-3080.

Henriksen ML, Brandt J, Andrieu JP, Nielsen C, Jensen PH, Holmskov U, Jorgensen TJ, Palarasah Y, Thielens NM, and Hansen S (2013) Heteromeric complexes of native collectin kidney 1 and collectin liver 1 are found in the circulation with MASPs and activate the complement system. J Immunol 191:6117-6127.

Hepburn NJ, Chamberlain-Banoub JL, Williams AS, Morgan BP, and Harris CL (2008) Prevention of experimental autoimmune myasthenia gravis by rat Crry-Ig: a model agent for long-term complement inhibition in vivo. Mol Immunol 45: 395-405.

Hernandez MX, Jiang S, Cole TA, Chu SH, Fonseca MI, Fang MJ, Hohsfield LA, Torres MD, Green KN, Wetsel RA, et al. (2017) Prevention of C5aR1 signaling delays microglial inflammatory polarization, favors clearance pathways and suppresses cognitive loss. Mol Neurodegener 12:66.

Hiemstra PS, Langeler E, Compier B, Keepers Y, Leijh PC, van den Barselaar MT, Overbosch D, and Daha MR (1989) Complete and partial deficiencies of complement factor D in a Dutch family. J Clin Invest 84:1957-1961.

Hill A, Kelly RJ, and Hillmen P (2013) Thrombosis in paroxysmal nocturnal hemoglobinuria. Blood 121:4985-4996; quiz 5105.

Hillmen P, Muus P, Röth A, Elebute MO, Risitano AM, Schrezenmeier H, Szer J, Browne P, Maciejewski JP, Schubert J, et al. (2013) Long-term safety and efficacy of sustained eculizumab treatment in patients with paroxysmal nocturnal haemoglobinuria. Br J Haematol 162:62-73.
Hobart M (1984) Agreement now the norm. Immunol Today 5:121-125.

Holers VM (2014) Complement and its receptors: new insights into human disease. Annu Rev Immunol 32:433-459.

Holers VM and Banda NK (2018) Complement in the initiation and evolution of rheumatoid arthritis. Front Immunol 9:1057.

Holter JC, Pischke SE, de Boer E, Lind A, Jenum S, Holten AR, Tonby K, BarrattDue A, Sokolova M, Schjalm C, et al. (2020) Systemic complement activation is associated with respiratory failure in COVID-19 hospitalized patients. Proc Natl Acad Sci USA 117:25018-25025.

Hong S, Beja-Glasser VF, Nfonoyim BM, Frouin A, Li S, Ramakrishnan S, Merry KM, Shi Q, Rosenthal A, Barres BA, et al. (2016) Complement and microglia mediate early synapse loss in Alzheimer mouse models. Science 352:712-716.

Howard JF Jr, Nowak RJ, Wolfe GI, Freimer ML, Vu TH, Hinton JL, Benatar M, Duda PW, MacDougall JE, Farzaneh-Far R, et al. Zilucoplan MG Study Group (2020) Clinical effects of the self-administered subcutaneous complement inhibitor zilucoplan in patients with moderate to severe generalized myasthenia gravis: results of a phase 2 randomized, double-blind, placebo-controlled, multicenter clinical trial. JAMA Neurol 77:582-592.

Howard JF Jr, Utsugisawa K, Benatar M, Murai H, Barohn RJ, Illa I, Jacob S, Vissing J, Burns TM, Kissel JT, et al. REGAIN Study Group (2017) Safety and efficacy of eculizumab in anti-acetylcholine receptor antibody-positive refractory generalised myasthenia gravis (REGAIN): a phase 3, randomised, double-blind, placebo-controlled, multicentre study. Lancet Neurol 16:976-986.

Howell GR, Soto I, Ryan M, Graham LC, Smith RS, and John SW (2013) Deficiency of complement component 5 ameliorates glaucoma in DBA/2J mice. $J$ Neuroinflammation 10:76.

Huang J, Kim LJ, Mealey R, Marsh HC Jr, Zhang Y, Tenner AJ, Connolly ES Jr, and Pinsky DJ (1999) Neuronal protection in stroke by an sLex-glycosylated complement inhibitory protein. Science 285:595-599.

Huber-Lang M, Barratt-Due A, Pischke SE, Sandanger Ø, Nilsson PH, Nunn MA, Denk S, Gaus W, Espevik T, and Mollnes TE (2014) Double blockade of CD14 and complement C5 abolishes the cytokine storm and improves morbidity and survival in polymicrobial sepsis in mice. J Immunol 192:5324-5331.

Huber-Lang M, Lambris JD, and Ward PA (2018) Innate immune responses to trauma. Nat Immunol 19:327-341.

Hyzewicz J, Tanihata J, Kuraoka M, Nitahara-Kasahara Y, Beylier T, Ruegg UT, Vater A, and Takeda S (2017) Low-intensity training and the C5a complement antagonist NOX-D21 rescue the mdx phenotype through modulation of inflammation. Am J Pathol 187:1147-1161.

Iwaki D, Kanno K, Takahashi M, Endo Y, Matsushita M, and Fujita T (2011) The role of mannose-binding lectin-associated serine protease-3 in activation of the alternative complement pathway. $J$ Immunol 187:3751-3758.

Jalanko H, Peltonen S, Koskinen A, Puntila J, Isoniemi H, Holmberg C, Pinomäki A, Armstrong E, Koivusalo A, Tukiainen E, et al. (2008) Successful liver-kidney transplantation in two children with aHUS caused by a mutation in complement factor H. Am J Transplant 8:216-221.

Janssen BJ, Huizinga EG, Raaijmakers HC, Roos A, Daha MR, Nilsson-Ekdahl K, Nilsson B, and Gros P (2005) Structures of complement component C3 provide insights into the function and evolution of immunity. Nature 437:505-511.

Jarlhelt I, Pilely K, Clausen JB, Skjoedt MO, Bayarri-Olmos R, and Garred P (2020) Circulating ficolin-2 and ficolin-3 form heterocomplexes. $J$ Immunol 204 1919-1928.

Java A, Apicelli AJ, Liszewski MK, Coler-Reilly A, Atkinson JP, Kim AH and Kulkarni HS (2020) The complement system in COVID-19: friend and foe? JCI Insight 5:e140711.

Jayne DRW, Bruchfeld AN, Harper L, Schaier M, Venning MC, Hamilton P, Burst V, Grundmann F, Jadoul M, Szombati I, et al.; CLEAR Study Group (2017) Randomized trial of C5a receptor inhibitor avacopan in ANCA-associated vasculitis. J Am Soc Nephrol 28:2756-2767.

Jensenius JC, Jensen PH, McGuire K, Larsen JL, and Thiel S (2003) Recombinant mannan-binding lectin (MBL) for therapy. Biochem Soc Trans 31:763-767.

Jiang Y, Zhao G, Song N, Li P, Chen Y, Guo Y, Li J, Du L, Jiang S, Guo R, et al. (2018) Blockade of the C5a-C5aR axis alleviates lung damage in hDPP4-transgenic mice infected with MERS-CoV. Emerg Microbes Infect 7:77.

Jodele S, Dandoy CE, Danziger-Isakov L, Myers KC, El-Bietar J, Nelson A, Wallace G, Teusink-Cross A, and Davies SM (2016) Terminal complement blockade after HSCT is safe without meningococcal vaccination. Biol Blood Marrow Transplant 22:1337-1340. Jodele S, Dandoy CE, Lane A, Laskin BL, Teusink-Cross A, Myers KC, Wallace G, Nelson A, Bleesing J, Chima RS, et al. (2020) Complement blockade for TA-TMA: lessons learned from a large pediatric cohort treated with eculizumab. Blood 135: $1049-1057$

Jodele S and Kohl J (2020) Tackling COVID-19 infection through complementtargeted immunotherapy. $\mathrm{Br} J$ Pharmacol DOI: 10.1111/bph.15187 [published ahead of print].

Jokiranta TS, Cheng ZZ, Seeberger H, Jòzsi M, Heinen S, Noris M, Remuzzi G, Ormsby R, Gordon DL, Meri S, et al. (2005) Binding of complement factor H to endothelial cells is mediated by the carboxy-terminal glycosaminoglycan binding site. Am J Pathol 167:1173-1181.

Jürgensen HJ, Nørregaard KS, Sibree MM, Santoni-Rugiu E, Madsen DH, Wassilew K, Krustrup D, Garred P, Bugge TH, Engelholm LH, et al. (2019) Immune regulation by fibroblasts in tissue injury depends on uPARAP-mediated uptake of collectins. J Cell Biol 218:333-349.

Jurianz K, Ziegler S, Garcia-Schüler H, Kraus S, Bohana-Kashtan O, Fishelson Z, and Kirschfink M (1999) Complement resistance of tumor cells: basal and induced mechanisms. Mol Immunol 36:929-939.

Kahn D, Smith SA, and Kotwal GJ (2003) Dose-dependent inhibition of complement in baboons by vaccinia virus complement control protein: implications in xenotransplantation. Transplant Proc 35:1606-1608.

Kajikawa T, Briones RA, Resuello RRG, Tuplano JV, Reis ES, Hajishengallis E, Garcia CAG, Yancopoulou D, Lambris JD, and Hajishengallis G (2017) Safety and 
efficacy of the complement inhibitor AMY-101 in a natural model of periodontitis in non-human primates. Mol Ther Methods Clin Dev 6:207-215.

Kanakura Y, Ohyashiki K, Shichishima T, Okamoto S, Ando K, Ninomiya H, Kawaguchi T, Nakao S, Nakakuma H, Nishimura J, et al. (2013) Long-term efficacy and safety of eculizumab in Japanese patients with PNH: AEGIS trial. Int $J$ Hematol 98:406-416.

Katschke KJ Jr, Helmy KY, Steffek M, Xi H, Yin J, Lee WP, Gribling P, Barck KH, Carano RAD, Taylor RE, et al. (2007) A novel inhibitor of the alternative pathway of complement reverses inflammation and bone destruction in experimental arthritis. J Exp Med 204:1319-1325.

Kelly RJ, Hill A, Arnold LM, Brooksbank GL, Richards SJ, Cullen M, Mitchell LD, Cohen DR, Gregory WM, and Hillmen P (2011) Long-term treatment with eculizumab in paroxysmal nocturnal hemoglobinuria: sustained efficacy and improved survival. Blood 117:6786-6792.

Kemper C and Köhl J (2018) Back to the future - non-canonical functions of complement. Semin Immunol 37:1-3.

Keshari RS, Silasi R, Popescu NI, Patel MM, Chaaban H, Lupu C, Coggeshall KM, Mollnes TE, DeMarco SJ, and Lupu F (2017) Inhibition of complement C5 protects against organ failure and reduces mortality in a baboon model of Escherichia coli sepsis. Proc Natl Acad Sci USA 114:E6390-E6399.

Kinoshita $\mathrm{T}$ (2018) Congenital defects in the expression of the glycosylphosphatidylinositol-anchored complement regulatory proteins CD59 and decay-accelerating factor. Semin Hematol 55:136-140.

Kirschfink M, Petry F, Khirwadkar K, Wigand R, Kaltwasser JP, and Loos M (1993) Complete functional C1q deficiency associated with systemic lupus erythematosus (SLE). Clin Exp Immunol 94:267-272.

Krawitz PM, Höchsmann B, Murakami Y, Teubner B, Krüger U, Klopocki E, Neitzel H, Hoellein A, Schneider C, Parkhomchuk D, et al. (2013) A case of paroxysmal nocturnal hemoglobinuria caused by a germline mutation and a somatic mutation in PIGT. Blood 122:1312-1315

Kulasekararaj AG, Hill A, Rottinghaus ST, Langemeijer S, Wells R, Gonzalez-Fernandez FA, Gaya A, Lee JW, Gutierrez EO, Piatek CI, et al. (2019) Ravulizumab (ALXN1210) vs eculizumab in C5-inhibitor-experienced adult patients with $\mathrm{PNH}$ : the 302 study. Blood 133:540-549.

Kulasekararaj AG, Lazana I, Large J, Posadas K, Eagleton H, Lord Villajin J, Zuckerman M, Gandhi S, and Marsh JCW (2020) Terminal complement inhibition dampens the inflammation during COVID-19. Br J Haematol 190:e141-e143.

Kumar PKR (2018) Aptamers that bind to the human complement component receptor hC5aR1 interfere with hC5aR1 interaction to its hC5a ligand. Mol Biol Rep 45:851-864.

Kusner LL, Yucius K, Sengupta M, Sprague AG, Desai D, Nguyen T, Charisse K, Kuchimanchi S, Kallanthottathil R, Fitzgerald K, et al. (2019) Investigationa RNAi therapeutic targeting C5 is efficacious in pre-clinical models of myasthenia gravis. Mol Ther Methods Clin Dev 13:484-492.

Lachmann PJ and Müller-Eberhard HJ (1968) The demonstration in human serum of "conglutinogen-activating factor" and its effect on the third component of complement. J Immunol 100:691-698.

Lachmann PJ, Muller-Eberhard HJ, Kunkel HG, and Paronetto F (1962) The localization of in vivo bound complement in tissue section. J Exp Med 115:63-82.

Lachmann PJ and Thompson RA (1970) Reactive lysis: the complement-mediated lysis of unsensitized cells. II. The characterization of activated reactor as C56 and the participation of C8 and C9. J Exp Med 131:643-657.

Langlois PF and Gawryl MS (1988) Accentuated formation of the terminal C5b-9 complement complex in patient plasma precedes development of the adult respiratory distress syndrome. Am Rev Respir Dis 138:368-375.

Larsen F, Madsen HO, Sim RB, Koch C, and Garred P (2004) Disease-associated mutations in human mannose-binding lectin compromise oligomerisation and activity of the final protein. J Biol Chem 279:21301-21311.

Laurence J, Mulvey JJ, Seshadri M, Racanelli A, Harp J, Schenck EJ, Zappetti D, Horn EM, and Magro CM (2020) Anti-complement C5 therapy with eculizumab in three cases of critical COVID-19. Clin Immunol 219:108555.

Laursen I (2003) Mannan-binding lectin (MBL) production from human plasma. Biochem Soc Trans 31:758-762.

Laursen NS, Magnani F, Gottfredsen RH, Petersen SV, and Andersen GR (2012) Structure, function and control of complement C5 and its proteolytic fragments. Curr Mol Med 12:1083-1097.

Lee CK, Weindruch R, and Prolla TA (2000) Gene-expression profile of the ageing brain in mice. Nat Genet 25:294-297.

Lee JD, Kumar V, Fung JN, Ruitenberg MJ, Noakes PG, and Woodruff TM (2017) Pharmacological inhibition of complement C5a-C5 $\mathrm{a}_{1}$ receptor signalling ameliorates disease pathology in the hSOD ${ }^{\mathrm{G} 93 \mathrm{~A}}$ mouse model of amyotrophic lateral sclerosis. Br J Pharmacol 174:689-699.

Lee JD, Levin SC, Willis EF, Li R, Woodruff TM, and Noakes PG (2018) Complement components are upregulated and correlate with disease progression in the TDP$43^{\mathrm{Q} 331 \mathrm{~K}}$ mouse model of amyotrophic lateral sclerosis. J Neuroinflammation 15 : 171.

Lee JW and Kulasekararaj AG (2020) Ravulizumab for the treatment of paroxysmal nocturnal hemoglobinuria. Expert Opin Biol Ther 20:227-237.

Lee JW, Sicre de Fontbrune F, Wong Lee Lee L, Pessoa V, Gualandro S, Füreder W, Ptushkin V, Rottinghaus ST, Volles L, Shafner L, et al. (2019) Ravulizumab (ALXN1210) vs eculizumab in adult patients with PNH naive to complement inhibitors: the 301 study. Blood 133:530-539.

Legendre CM, Licht C, Muus P, Greenbaum LA, Babu S, Bedrosian C, Bingham C, Cohen DJ, Delmas Y, Douglas K, et al. (2013) Terminal complement inhibitor eculizumab in atypical hemolytic-uremic syndrome. N Engl J Med 368:2169-2181.

Lehrman EK, Wilton DK, Litvina EY, Welsh CA, Chang ST, Frouin A, Walker AJ, Heller MD, Umemori H, Chen C, et al. (2018) CD47 protects synapses from excess microglia-mediated pruning during development. Neuron 100:120-134.e6.

Leinhase I, Holers VM, Thurman JM, Harhausen D, Schmidt OI, Pietzcker M, Taha ME, Rittirsch D, Huber-Lang M, Smith WR, et al. (2006) Reduced neuronal cell death after experimental brain injury in mice lacking a functional alternative pathway of complement activation. BMC Neurosci 7:55.

Lepow IH, Naff GB, Todd EW, Pensky J, and Hinz CF (1963) Chromatographic resolution of the first component of human complement into three activities. $J$ Exp Med 117:983-1008.

Li JS, Jaggers J, and Anderson PA (2006) The use of TP10, soluble complement receptor 1, in cardiopulmonary bypass. Expert Rev Cardiovasc Ther 4:649-654.

Li XX, Lee JD, Kemper C, and Woodruff TM (2019) The complement receptor C5aR2: a powerful modulator of innate and adaptive immunity. J Immunol 202: $3339-3348$

Li XX, Lee JD, Massey NL, Guan C, Robertson AAB, Clark RJ, and Woodruff TM (2020) Pharmacological characterisation of small molecule C5aR1 inhibitors in human cells reveals biased activities for signalling and function. Biochem Pharmacol 180:114156

Litzman J, Freiberger T, Grimbacher B, Gathmann B, Salzer U, Pavlík T, Vlcek J, Postránecká V, Trávnícková Z, and Thon V (2008) Mannose-binding lectin gene polymorphic variants predispose to the development of bronchopulmonary complications but have no influence on other clinical and laboratory symptoms or signs of common variable immunodeficiency. Clin Exp Immunol 153:324-330.

Liu H, Kim HR, Deepak RNVK, Wang L, Chung KY, Fan H, Wei Z, and Zhang C (2018) Orthosteric and allosteric action of the C5a receptor antagonists. Nat Struct Mol Biol 25:472-481.

Liu J, Jha P, Lyzogubov VV, Tytarenko RG, Bora NS, and Bora PS (2011) Relationship between complement membrane attack complex, chemokine (C-C motif) ligand 2 (CCL2) and vascular endothelial growth factor in mouse model of laserinduced choroidal neovascularization. J Biol Chem 286:20991-21001.

Lo MW, Kemper C, and Woodruff TM (2020) COVID-19: complement, coagulation, and collateral damage. J Immunol 205:1488-1495.

Lo MW and Woodruff TM (2020) Complement: bridging the innate and adaptive immune systems in sterile inflammation. J Leukoc Biol 108:339-351.

Lohman RJ, Hamidon JK, Reid RC, Rowley JA, Yau MK, Halili MA, Nielsen DS, Lim J, Wu KC, Loh Z, et al. (2017) Exploiting a novel conformational switch to control innate immunity mediated by complement protein C3a. Nat Commun 8:351.

Loirat C, Fakhouri F, Ariceta G, Besbas N, Bitzan M, Bjerre A, Coppo R, Emma F, Johnson S, Karpman D, et al.; HUS International (2016) An international consensus approach to the management of atypical hemolytic uremic syndrome in children. Pediatr Nephrol 31:15-39.

Loschi M, Porcher R, Barraco F, Terriou L, Mohty M, de Guibert S, Mahe B, Lemal R, Dumas PY, Etienne G, et al. (2016) Impact of eculizumab treatment on paroxysmal nocturnal hemoglobinuria: a treatment versus no-treatment study. Am J Hematol 91:366-370.

Lu J, Wiedemann H, Timpl R, and Reid KB (1993) Similarity in structure between $\mathrm{C} 1 \mathrm{q}$ and the collectins as judged by electron microscopy. Behring Inst Mitt 93:6-16.

Lui H, Zhang J, Makinson SR, Cahill MK, Kelley KW, Huang HY, Shang Y, Oldham MC, Martens LH, Gao F, et al. (2016) Progranulin deficiency promotes circuit-specific synaptic pruning by microglia via complement activation. Cell 165:921-935.

Luque A, Serrano I, and Aran JM (2019) Complement components as promoters of immunological tolerance in dendritic cells. Semin Cell Dev Biol 85:143-152.

Ma YJ, Hein E, Munthe-Fog L, Skjoedt MO, Bayarri-Olmos R, Romani L, and Garred $\mathrm{P}$ (2015) Soluble collectin-12 (CL-12) is a pattern recognition molecule initiating complement activation via the alternative pathway. J Immunol 195:3365-3373.

Ma YJ, Lee BL, and Garred P (2017) An overview of the synergy and crosstalk between pentraxins and collectins/ficolins: their functional relevance in complement activation. Exp Mol Med 49:e320.

Macor P, Durigutto P, De ML, Garrovo C, Biffi S, Cortini A, Fischetti F, Sblattero D, Pitzalis C, Marzari R, et al. (2012) Treatment of experimental arthritis models by targeting synovial endothelium with a neutralizing recombinant antibody to $\mathrm{C5}$. Arthritis Rheum 64:2559-2567.

Macrae FL, Peacock-Young B, Bowman P, Baker SR, Quested S, Linton E, Hillmen P, Griffin M, Munir T, Payne D, et al. (2020) Patients with paroxysmal nocturnal hemoglobinuria demonstrate a prothrombotic clotting phenotype which is improved by complement inhibition with eculizumab. Am J Hematol 95:944-952.

Mahajan SD, Parikh NU, Woodruff TM, Jarvis JN, Lopez M, Hennon T, Cunningham P, Quigg RJ, Schwartz SA, and Alexander JJ (2015) C5a alters blood-brain barrier integrity in a human in vitro model of systemic lupus erythematosus. Immunology 146:130-143.

Maio M, Brasoveanu LI, Coral S, Sigalotti L, Lamaj E, Gasparollo A, Visintin A, Altomonte M, and Fonsatti E (1998) Structure, distribution, and functional role of protectin (CD59) in complement-susceptibility and in immunotherapy of human malignancies (Review). Int J Oncol 13:305-318.

Mangalmurti N and Hunter CA (2020) Cytokine storms: understanding COVID-19. Immunity 53:19-25.

Manthey HD, Woodruff TM, Taylor SM, and Monk PN (2009) Complement component 5a (C5a). Int J Biochem Cell Biol 41:2114-2117.

Mantovani S, Gordon R, Macmaw JK, Pfluger CM, Henderson RD, Noakes PG, McCombe PA, and Woodruff TM (2014) Elevation of the terminal complement activation products C5a and C5b-9 in ALS patient blood. $J$ Neuroimmunol 276: 213-218.

Martin TR, Wurfel MM, Zanoni I, and Ulevitch R (2020) Targeting innate immunity by blocking CD14: novel approach to control inflammation and organ dysfunction in COVID-19 illness. EBioMedicine 57:102836.

Mastaglio S, Ruggeri A, Risitano AM, Angelillo P, Yancopoulou D, Mastellos DC, Huber-Lang M, Piemontese S, Assanelli A, Garlanda C, et al. (2020) The first case of COVID-19 treated with the complement C3 inhibitor AMY-101. Clin Immunol 215:108450.

Mastellos DC, Reis ES, Ricklin D, Smith RJ, and Lambris JD (2017) Complement C3targeted therapy: replacing long-held assertions with evidence-based discovery. Trends Immunol 38:383-394.

Mastellos DC, Ricklin D, and Lambris JD (2019) Clinical promise of next-generation complement therapeutics. Nat Rev Drug Discov 18:707-729. 
Matsushita M and Fujita T (1992) Activation of the classical complement pathway by mannose-binding protein in association with a novel C1s-like serine protease. J Exp Med 176:1497-1502.

McGrath FDG, Brouwer MC, Arlaud GJ, Daha MR, Hack CE, and Roos A (2006) Evidence that complement protein $\mathrm{C} 1 \mathrm{q}$ interacts with C-reactive protein through its globular head region. J Immunol 176:2950-2957.

McKeage K (2019) Ravulizumab: first global approval. Drugs 79:347-352.

Mehta G, Scheinman RI, Holers VM, and Banda NK (2015) A new approach for the treatment of arthritis in mice with a novel conjugate of an anti-C5aR1 antibody and C5 small interfering RNA. $J$ Immunol 194:5446-5454.

Meri S (1994) Protectin (CD59) - complement lysis inhibitor and prototype domain in a new protein superfamily. Immunologist 2:149-155.

Meri S (2013) Complement activation in diseases presenting with thrombotic microangiopathy. Eur J Intern Med 24:496-502.

Merle NS, Church SE, Fremeaux-Bacchi V, and Roumenina LT (2015) Complement system Part I - molecular mechanisms of activation and regulation. Front Immunol 6.262.

Meroni PL, Macor P, Durigutto P, De Maso L, Gerosa M, Ferraresso M, Borghi MO, Mollnes TE, and Tedesco F (2016) Complement activation in antiphospholipid syndrome and its inhibition to prevent rethrombosis after arterial surgery. Blood 127:365-367.

Merrill JT, Erkan D, Winakur J, and James JA (2020) Emerging evidence of a COVID-19 thrombotic syndrome has treatment implications. Nat Rev Rheumatol 16:581-589.

Michalski M, Szala A, St Swierzko A, Lukasiewicz J, Maciejewska A, Kilpatrick DC, Matsushita M, Domzalska-Popadiuk I, Borkowska-Klos M, Sokolowska A, et al. (2012) H-ficolin (ficolin-3) concentrations and FCN3 gene polymorphism in neonates. Immunobiology 217:730-737.

Michelfelder S, Parsons J, Bohlender LL, Hoernstein SNW, Niederkrüger H, Busch A, Krieghoff N, Koch J, Fode B, Schaaf A, et al. (2017) Moss-produced, glycosylation-optimized human factor $\mathrm{H}$ for therapeutic application in complement disorders. J Am Soc Nephrol 28:1462-1474.

Minutti CM, Jackson-Jones LH, García-Fojeda B, Knipper JA, Sutherland TE, Logan N, Ringqvist E, Guillamat-Prats R, Ferenbach DA, Artigas A, et al. (2017) Local amplifiers of IL-4R $\alpha$-mediated macrophage activation promote repair in lung and liver. Science 356:1076-1080.

Mollnes TE and Huber-Lang M (2020) Complement in sepsis-when science meets clinics. FEBS Lett 594:2621-2632.

Mollnes TE, Jokiranta TS, Truedsson L, Nilsson B, Rodriguez de Cordoba S, and Kirschfink M (2007) Complement analysis in the 21st century. Mol Immunol 44:3838-3849.

Mollnes TE, Lea T, Harboe M, and Tschopp J (1985) Monoclonal antibodies recognizing a neoantigen of poly(C9) detect the human terminal complement complex in tissue and plasma. Scand J Immunol 22:183-195.

Montgomery RA, Loupy A, and Segev DL (2018) Antibody-mediated rejection: new approaches in prevention and management. Am J Transplant 18 (Suppl 3):3-17.

Morgan BP and Campbell AK (1985) The recovery of human polymorphonuclear leucocytes from sublytic complement attack is mediated by changes in intracellular free calcium. Biochem $J$ 231:205-208.

Muller-Eberhard HJ, Nilsson U, and Aronsson T (1960) Isolation and characterization of two beta1-glycoproteins of human serum. J Exp Med 111:201-215.

Müller-Redetzky H, Kellermann U, Wienhold SM, Gutbier B, Lienau J, Hellwig K, Reppe K, Letsiou E, Tschernig T, Scholz M, et al. (2020) Neutralizing complement C5a protects mice with pneumococcal pulmonary sepsis. Anesthesiology 132 795-807.

Munthe-Fog L, Hummelshøj T, Honoré C, Madsen HO, Permin H, and Garred P (2009) Immunodeficiency associated with FCN3 mutation and ficolin-3 deficiency. N Engl J Med 360:2637-2644.

Munye MM, Diaz-Font A, Ocaka L, Henriksen ML, Lees M, Brady A, Jenkins D, Morton J, Hansen SW, Bacchelli C, et al. (2017) COLEC10 is mutated in 3MC patients and regulates early craniofacial development. PLoS Genet 13:e1006679.

Murugaiah V, Tsolaki AG, and Kishore U (2020) Collectins: innate immune pattern recognition molecules. Adv Exp Med Biol 1204:75-127.

Nayagam JS, McGrath S, Montasser M, Delaney M, Cairns TD, Marchbank KJ, Denton H, Yang Y, Sacks SH, Cook HT, et al. (2020) Successful simultaneous liverkidney transplantation for renal failure associated with hereditary complement C3 deficiency. Am J Transplant 20:2260-2263.

Nelson AL, Dhimolea E, and Reichert JM (2010) Development trends for human monoclonal antibody therapeutics. Nat Rev Drug Discov 9:767-774.

Nesargikar PN, Spiller B, and Chavez R (2012) The complement system: history, pathways, cascade and inhibitors. Eur J Microbiol Immunol (Bp) 2:103-111.

Nester CM and Smith RJ (2016) Complement inhibition in C3 glomerulopathy. Semin Immunol 28:241-249.

Neth O, Hann I, Turner MW, and Klein NJ (2001) Deficiency of mannose-binding lectin and burden of infection in children with malignancy: a prospective study. Lancet 358:614-618.

Nichols EM, Barbour TD, Pappworth IY, Wong EK, Palmer JM, Sheerin NS, Pickering MC, and Marchbank KJ (2015) An extended mini-complement factor $\mathrm{H}$ molecule ameliorates experimental C3 glomerulopathy. Kidney Int 88:1314-1322.

Ninomiya H, Obara N, Chiba S, Usuki K, Nishiwaki K, Matsumura I, Shichishima T, Okamoto S, Nishimura JI, Ohyashiki K, et al. (2016) Interim analysis of postmarketing surveillance of eculizumab for paroxysmal nocturnal hemoglobinuria in Japan. Int J Hematol 104:548-558.

Nishimura J, Yamamoto M, Hayashi S, Ohyashiki K, Ando K, Brodsky AL, Noji H Kitamura K, Eto T, Takahashi T, et al. (2014) Genetic variants in C5 and poor response to eculizumab. $N$ Engl J Med 370:632-639.

Nolfi-Donegan D, Konar M, Vianzon V, MacNeil J, Cooper J, Lurie P, Sedivy J, Wang X, Granoff DM, and McNamara L (2018) Fatal nongroupable Neisseria meningitidis disease in vaccinated patient receiving eculizumab. Emerg Infect Dis 24: 1561-1564.
Noris M, Benigni A, and Remuzzi G (2020) The case of complement activation in COVID-19 multiorgan impact. Kidney Int 98:314-322.

O'Barr S and Cooper NR (2000) The C5a complement activation peptide increases IL1 beta and IL- 6 release from amyloid-beta primed human monocytes: implications for Alzheimer's disease. J Neuroimmunol 109:87-94.

O'Flynn J, Dixon KO, Faber Krol MC, Daha MR, and van Kooten C (2014) Myeloperoxidase directs properdin-mediated complement activation. J Innate Immun 6 : $417-425$.

O’Neill NA and Pierson RN III (2017) Proximal blockade of complement: a "neoclassical" approach to prevent antibody-mediated rejection. Transplantation 101: 2271-2272.

Øhlenschlaeger T, Garred P, Madsen HO, and Jacobsen S (2004) Mannose-binding lectin variant alleles and the risk of arterial thrombosis in systemic lupus erythematosus. N Engl J Med 351:260-267.

Oroszlán G, Kortvely E, Szakács D, Kocsis A, Dammeier S, Zeck A, Ueffing M, Závodszky P, Pál G, Gál P et al (2016) MASP-1 and MASP-2 do not activate profactor D in resting human blood, whereas MASP-3 is a potential activator: kinetic analysis involving specific MASP-1 and MASP-2 inhibitors. J Immunol 196: $857-865$.

Ozen A, Comrie WA, Ardy RC, Domínguez Conde C, Dalgic B, Beser OF, Morawski AR, Karakoc-Aydiner E, Tutar E, Baris S, et al. (2017) CD55 deficiency, early-onset protein-losing enteropathy, and thrombosis. N Engl J Med 377:52-61.

Panayiotou E, Fella E, Andreou S, Papacharalambous R, Gerasimou P, Costeas P, Angeli S, Kousiappa I, Papacostas S, and Kyriakides T (2019) C5aR agonist enhances phagocytosis of fibrillar and non-fibrillar $\mathrm{A} \beta$ amyloid and preserves memory in a mouse model of familial Alzheimer's disease. PLoS One 14:e0225417. Papanastasiou M, Koutsogiannaki S, Sarigiannis Y, Geisbrecht BV, Ricklin D, and Lambris JD (2017) Structural implications for the formation and function of the complement effector protein iC3b. J Immunol 198:3326-3335.

Park DH, Connor KM, and Lambris JD (2019) The challenges and promise of complement therapeutics for ocular diseases. Front Immunol 10:1007.

Parker C (2009) Eculizumab for paroxysmal nocturnal haemoglobinuria. Lancet $\mathbf{3 7 3}$ 759-767.

Parker SE, Hanton AM, Stefanou SN, Noakes PG, Woodruff TM, and Lee JD (2019) Revisiting the role of the innate immune complement system in ALS. Neurobiol Dis 127:223-232.

Parolari A, Rubini P, Cannata A, Bonati L, Alamanni F, Tremoli E, and Biglioli P (2002) Endothelial damage during myocardial preservation and storage. Ann Thorac Surg 73:682-690.

Pavlovski D, Thundyil J, Monk PN, Wetsel RA, Taylor SM, and Woodruff TM (2012) Generation of complement component C5a by ischemic neurons promotes neuronal apoptosis. FASEB J 26:3680-3690.

Perlmutter DH and Colten HR (1986) Molecular immunobiology of complement biosynthesis: a model of single-cell control of effector-inhibitor balance. Annu Rev Immunol 4:231-251.

Petersen KA, Matthiesen F, Agger T, Kongerslev L, Thiel S, Cornelissen K, and Axelsen M (2006) Phase I safety, tolerability, and pharmacokinetic study of recombinant human mannan-binding lectin. $J$ Clin Immunol 26:465-475.

Peterslund NA, Koch C, Jensenius JC, and Thiel S (2001) Association between deficiency of mannose-binding lectin and severe infections after chemotherapy. Lancet 358:637-638.

Pillemer L (1955) The properdin system. Trans N Y Acad Sci 17:526-530.

Pillemer L, Blum L, Lepow IH, Ross OA, Todd EW, and Wardlaw AC (1954) The properdin system and immunity. I. Demonstration and isolation of a new serum protein, properdin, and its role in immune phenomena. Science 120:279-285.

Pittock SJ, Berthele A, Fujihara K, Kim HJ, Levy M, Palace J, Nakashima I, Terzi M, Totolyan N, Viswanathan S, et al. (2019) Eculizumab in aquaporin-4-positive neuromyelitis optica spectrum disorder. N Engl J Med 381:614-625.

Podack ER, Esser AF, Biesecker G, and Müller-Eberhard HJ (1980) Membrane attack complex of complement: a structural analysis of its assembly. J Exp Med 151 301-313.

Potlukova E and Kralikova P (2008) Complement component c1q and anti-c1q antibodies in theory and in clinical practice. Scand J Immunol 67:423-430.

Presanis JS, Hajela K, Ambrus G, Gál P, and Sim RB (2004) Differential substrate and inhibitor profiles for human MASP-1 and MASP-2. Mol Immunol 40:921-929.

Prohászka Z, Kirschfink M, and Frazer-Abel A (2018) Complement analysis in the era of targeted therapeutics. Mol Immunol 102:84-88.

Ramlall V, Thangaraj PM, Meydan C, Foox J, Butler D, Kim J, May B, De Freitas JK, Glicksberg BS, Mason CE, et al. (2020) Immune complement and coagulation dysfunction in adverse outcomes of SARS-CoV-2 infection. Nat Med 26:1609-1615.

Rathbone J, Kaltenthaler E, Richards A, Tappenden P, Bessey A, and Cantrell A (2013) A systematic review of eculizumab for atypical haemolytic uraemic syndrome (aHUS), BMJ Open 3:e003573.

Recknagel S, Bindl R, Kurz J, Wehner T, Schoengraf P, Ehrnthaller C, Qu H, Gebhard F, Huber-Lang M, Lambris JD, et al. (2012) C5aR-antagonist significantly reduces the deleterious effect of a blunt chest trauma on fracture healing. J Orthop Res 30:581-586.

Reher D, Fuhrmann V, Kluge S, and Nierhaus A (2018) A rare case of septic shock due to Neisseria meningitidis serogroup $B$ infection despite prior vaccination in a young adult with paroxysmal nocturnal haemoglobinuria receiving eculizumab. Vaccine 36:2507-2509.

Reichwald J, Danner S, Wiederhold KH, and Staufenbiel M (2009) Expression of complement system components during aging and amyloid deposition in APP transgenic mice. J Neuroinflammation 6:35.

Reid KB, Lowe DM, and Porter RR (1972) Isolation and characterization of C1q a subcomponent of the first component of complement, from human and rabbit sera. Biochem $J$ 130:749-763.

Reinehr S, Gomes SC, Gassel CJ, Asaad MA, Stute G, Schargus M, Dick HB and Joachim SC (2019) Intravitreal therapy against the complement factor C5 
prevents retinal degeneration in an experimental autoimmune glaucoma model. Front Pharmacol 10:1381.

Reis ES, Mastellos DC, Hajishengallis G, and Lambris JD (2019) New insights into the immune functions of complement. Nat Rev Immunol 19:503-516.

Reis ES, Falcão DA, and Isaac L (2006) Clinical aspects and molecular basis of primary deficiencies of complement component C3 and its regulatory proteins factor I and factor H. Scand J Immunol 63:155-168.

Rich MC, Keene CN, Neher MD, Johnson K, Yu ZX, Ganivet A, Holers VM, and Stahel PF (2016) Site-targeted complement inhibition by a complement receptor 2-conjugated inhibitor (mTT30) ameliorates post-injury neuropathology in mouse brains. Neurosci Lett 617:188-194.

Ricklin D, Barratt-Due A, and Mollnes TE (2017) Complement in clinical medicine: clinical trials, case reports and therapy monitoring. Mol Immunol 89:10-21.

Ricklin D, Hajishengallis G, Yang K, and Lambris JD (2010) Complement: a key system for immune surveillance and homeostasis. Nat Immunol 11:785-797.

Ricklin D and Lambris JD (2013) Complement in immune and inflammatory disorders: pathophysiological mechanisms. J Immunol 190:3831-3838.

Ricklin D, Mastellos DC, Reis ES, and Lambris JD (2018) The renaissance of complement therapeutics. Nat Rev Nephrol 14:26-47.

Risitano AM, Marotta S, Ricci P, Marano L, Frieri C, Cacace F, Sica M, Kulasekararaj A, Calado RT, Scheinberg P, et al. (2019) Anti-complement treatment for paroxysmal nocturnal hemoglobinuria: time for proximal complement inhibition? A position paper from the SAAWP of the EBMT. Front Immunol 10:1157.

Risitano AM, Notaro R, Pascariello C, Sica M, Del VL, Horvath CJ, Fridkis-Hareli M, Selleri C, Lindorfer MA, Taylor RP, et al. (2012) The complement receptor $2 /$ factor $\mathrm{H}$ fusion protein TT30 protects paroxysmal nocturnal hemoglobinuria erythrocytes from complement-mediated hemolysis and C3 fragment. Blood 119:6307-6316.

Robertson NS and Spring DR (2018) Using peptidomimetics and constrained peptides as valuable tools for inhibiting Protein ${ }^{-}$Protein interactions. Molecules 23 959 .

Rondeau E, Cataland SR, Al-Dakkak I, Miller B, Webb NJA, and Landau D (2019) Eculizumab safety: five-year experience from the global atypical hemolytic uremic syndrome registry. Kidney Int Rep 4:1568-1576.

Rooryck C, Diaz-Font A, Osborn DP, Chabchoub E, Hernandez-Hernandez V, Shamseldin H, Kenny J, Waters A, Jenkins D, Kaissi AA, et al. (2011) Mutations in lectin complement pathway genes COLEC11 and MASP1 cause 3MC syndrome. Nat Genet 43:197-203.

Roos A, Rastaldi MP, Calvaresi N, Oortwijn BD, Schlagwein N, van Gijlswijk-Janssen DJ, Stahl GL, Matsushita M, Fujita T, van Kooten C, et al. (2006) Glomerular activation of the lectin pathway of complement in IgA nephropathy is associated with more severe renal disease. J Am Soc Nephrol 17:1724-1734.

Rossi V, Cseh S, Bally I, Thielens NM, Jensenius JC, and Arlaud GJ (2001) Substrate specificities of recombinant mannan-binding lectin-associated serine proteases-1 and -2. J Biol Chem 276:40880-40887.

Röth A, Hüttmann A, Rother RP, Dührsen U, and Philipp T (2009) Long-term efficacy of the complement inhibitor eculizumab in cold agglutinin disease. Blood 113 $3885-3886$

Röth A, Nishimura JI, Nagy Z, Gaàl-Weisinger J, Panse J, Yoon SS, Egyed M, Ichikawa S, Ito Y, Kim JS, et al. (2020) The complement C5 inhibitor crovalimab in paroxysmal nocturnal hemoglobinuria. Blood 135:912-920.

Salmon JE and Girardi G (2004) The role of complement in the antiphospholipid syndrome. Curr Dir Autoimmun 7:133-148.

Sato T, Endo Y, Matsushita M, and Fujita T (1994) Molecular characterization of a novel serine protease involved in activation of the complement system by mannose-binding protein. Int Immunol 6:665-669.

Schaefer L (2014) Complexity of danger: the diverse nature of damage-associated molecular patterns. J Biol Chem 289:35237-35245.

Schafer DP, Lehrman EK, Kautzman AG, Koyama R, Mardinly AR, Yamasaki R, Ransohoff RM, Greenberg ME, Barres BA, and Stevens B (2012) Microglia sculpt postnatal neural circuits in an activity and complement-dependent manner. $\mathrm{Neu}$ ron 74:691-705.

Schartz ND, Wyatt-Johnson SK, Price LR, Colin SA, and Brewster AL (2018) Status epilepticus triggers long-lasting activation of complement C1q-C3 signaling in the hippocampus that correlates with seizure frequency in experimental epilepsy. Neurobiol Dis 109:163-173.

Schejbel L, Fadnes D, Permin H, Lappegård KT, Garred P, and Mollnes TE (2013) Primary complement C5 deficiencies - molecular characterization and clinical review of two families. Immunobiology 218:1304-1310.

Schejbel L, Rosenfeldt V, Marquart H, Valerius NH, and Garred P (2009) Properdin deficiency associated with recurrent otitis media and pneumonia, and identification of male carrier with Klinefelter syndrome. Clin Immunol 131:456-462.

Schlapbach LJ, Thiel S, Kessler U, Ammann RA, Aebi C, and Jensenius JC (2011) Congenital $\mathrm{H}$-ficolin deficiency in premature infants with severe necrotising enterocolitis. Gut 60:1438-1439.

Schmidt CQ, Lambris JD, and Ricklin D (2016) Protection of host cells by complement regulators. Immunol Rev 274:152-171.

Schonthaler HB, Guinea-Viniegra J, Wculek SK, Ruppen I, Ximénez-Embún P, GuíoCarrión A, Navarro R, Hogg N, Ashman K, and Wagner EF (2013) S100A8-S100A9 protein complex mediates psoriasis by regulating the expression of complement factor C3. Immunity 39:1171-1181.

Schuster MC, Ricklin D, Papp K, Molnar KS, Coales SJ, Hamuro Y, Sfyroera G, Chen H, Winters MS, and Lambris JD (2008) Dynamic structural changes during complement C3 activation analyzed by hydrogen/deuterium exchange mass spectrometry. Mol Immunol 45:3142-3151.

Seelen MA, Roos A, Wieslander J, Mollnes TE, Sjöholm AG, Wurzner R, Loos M, Tedesco F, Sim RB, Garred P, et al. (2005) Functional analysis of the classical, alternative, and MBL pathways of the complement system: standardization and validation of a simple ELISA. J Immunol Methods 296:187-198.

Sekar A, Bialas AR, de Rivera H, Davis A, Hammond TR, Kamitaki N, Tooley K, Presumey J, Baum M, Van Doren V, et al.; Schizophrenia Working Group of the
Psychiatric Genomics Consortium (2016) Schizophrenia risk from complex variation of complement component 4. Nature 530:177-183.

Selmaj K and Selmaj I (2019) Novel emerging treatments for NMOSD. Neurol Neurochir Pol 53:317-326.

Sewell DL, Nacewicz B, Liu F, Macvilay S, Erdei A, Lambris JD, Sandor M and Fabry Z (2004) Complement C3 and C5 play critical roles in traumatic brain cryoinjury: blocking effects on neutrophil extravasation by C5a receptor antagonist. J Neuroimmunol 155:55-63.

Shi J, Rose EL, Singh A, Hussain S, Stagliano NE, Parry GC, and Panicker S (2014) TNT003, an inhibitor of the serine protease C1s, prevents complement activation induced by cold agglutinins. Blood 123:4015-4022.

Shi Q, Chowdhury S, Ma R, Le KX, Hong S, Caldarone BJ, Stevens B, and Lemere CA (2017) Complement C3 deficiency protects against neurodegeneration in aged plaque-rich APP/PS1 mice. Sci Transl Med 9:eaaf6295.

Sim RB, Schwaeble W, and Fujita T (2016) Complement research in the 18th-21st centuries: progress comes with new technology. Immunobiology 221:1037-1045.

Singer L, Colten HR, and Wetsel RA (1994) Complement C3 deficiency: human, animal, and experimental models. Pathobiology 62:14-28.

Singhrao SK, Neal JW, Rushmere NK, Morgan BP, and Gasque P (1999) Differential expression of individual complement regulators in the brain and choroid plexus. Lab Invest 79:1247-1259.

Sirmaci A, Walsh T, Akay H, Spiliopoulos M, Sakalar YB, Hasanefendioğlu-Bayrak A, Duman D, Farooq A, King MC, and Tekin M (2010) MASP1 mutations in patients with facial, umbilical, coccygeal, and auditory findings of Carnevale, Malpuech, OSA, and Michels syndromes. Am J Hum Genet 87:679-686.

Sjöberg AP, Trouw LA, and Blom AM (2009) Complement activation and inhibition: a delicate balance. Trends Immunol 30:83-90.

Sjöholm AG, Jönsson G, Braconier JH, Sturfelt G, and Truedsson L (2006) Complement deficiency and disease: an update. Mol Immunol 43:78-85.

Sjöholm AG, Kuijper EJ, Tijssen CC, Jansz A, Bol P, Spanjaard L, and Zanen HC (1988) Dysfunctional properdin in a Dutch family with meningococcal disease. N Engl J Med 319:33-37.

Skarnes RC and Watson DW (1957) Antimicrobial factors of normal tissues and fluids. Bacteriol Rev 21:273-294.

Skattum L, van Deuren M, van der Poll T, and Truedsson L (2011) Complement deficiency states and associated infections. Mol Immunol 48:1643-1655.

Skjoedt MO, Hummelshoj T, Palarasah Y, Honore C, Koch C, Skjodt K, and Garred P (2010) A novel mannose-binding lectin/ficolin-associated protein is highly expressed in heart and skeletal muscle tissues and inhibits complement activation. $J$ Biol Chem 285:8234-8243.

Skjoedt MO, Roversi P, Hummelshoj T, Palarasah Y, Rosbjerg A, Johnson S, Lea SM, and Garred P (2012) Crystal structure and functional characterization of the complement regulator mannose-binding lectin (MBL)/ficolin-associated protein-1 (MAP-1). J Biol Chem 287:32913-32921.

Slade C, Bosco J, Unglik G, Bleasel K, Nagel M, and Winship I (2013) Deficiency in complement factor B. N Engl J Med 369:1667-1669.

Socié G, Caby-Tosi MP, Marantz JL, Cole A, Bedrosian CL, Gasteyger C, Mujeebuddin A, Hillmen P, Vande Walle J, and Haller H (2019) Eculizumab in paroxysmal nocturnal haemoglobinuria and atypical haemolytic uraemic syndrome: 10 year pharmacovigilance analysis. Br J Haematol 185:297-310.

Song WC and FitzGerald GA (2020) COVID-19, microangiopathy, hemostatic activation, and complement. $J$ Clin Invest 130:3950-3953.

Souza DG, Esser D, Bradford R, Vieira AT, and Teixeira MM (2005) APT070 (Mirococept), a membrane-localised complement inhibitor, inhibits inflammatory responses that follow intestinal ischaemia and reperfusion injury. $\mathrm{Br} J$ Pharmacol 145:1027-1034.

Spitzer D, Unsinger J, Bessler M, and Atkinson JP (2004) ScFv-mediated in vivo targeting of DAF to erythrocytes inhibits lysis by complement. Mol Immunol 40: 911-919.

Sprong T, Roos D, Weemaes C, Neeleman C, Geesing CL, Mollnes TE, and van Deuren M (2006) Deficient alternative complement pathway activation due to factor $\mathrm{D}$ deficiency by 2 novel mutations in the complement factor $\mathrm{D}$ gene in a family with meningococcal infections. Blood 107:4865-4870.

Sta M, Sylva-Steenland RM, Casula M, de Jong JM, Troost D, Aronica E, and Baas F (2011) Innate and adaptive immunity in amyotrophic lateral sclerosis: evidence of complement activation. Neurobiol Dis 42:211-220.

Steinsson K, Erlendsson K, and Valdimarsson H (1989) Successful plasma infusion treatment of a patient with $\mathrm{C} 2$ deficiency and systemic lupus erythematosus: clinical experience over forty-five months. Arthritis Rheum 32:906-913.

Stengaard-Pedersen K, Thiel S, Gadjeva M, Møller-Kristensen M, Sørensen R, Jensen LT, Sjøholm AG, Fugger L, and Jensenius JC (2003) Inherited deficiency of mannan-binding lectin-associated serine protease 2. N Engl J Med 349:554-560.

Stern RM and Connell NT (2019) Ravulizumab: a novel C5 inhibitor for the treatment of paroxysmal nocturnal hemoglobinuria. Ther Adv Hematol 10 2040620719874728

Stevens B, Allen NJ, Vazquez LE, Howell GR, Christopherson KS, Nouri N, Micheva $\mathrm{KD}$, Mehalow AK, Huberman AD, Stafford B, et al. (2007) The classical complement cascade mediates CNS synapse elimination. Cell 131:1164-1178.

Stover CM, Thiel S, Thelen M, Lynch NJ, Vorup-Jensen T, Jensenius JC, and Schwaeble WJ (1999) Two constituents of the initiation complex of the mannan-binding lectin activation pathway of complement are encoded by a single structural gene. J Immunol 162:3481-3490.

Suzuki H, Kiryluk K, Novak J, Moldoveanu Z, Herr AB, Renfrow MB, Wyatt RJ, Scolari F, Mestecky J, Gharavi AG, et al. (2011) The pathophysiology of IgA nephropathy. J Am Soc Nephrol 22:1795-1803.

Szilágyi A and Fust G (2008) Diseases associated with the low copy number of the C4B gene encoding C4, the fourth component of complement. Cytogenet Genome Res 123:118-130.

Tabib A, Karbian N, and Mevorach D (2017) Demyelination, strokes, and eculizumab: lessons from the congenital CD59 gene mutations. Mol Immunol 89:69-72. 
Tack BF, Harrison RA, Janatova J, Thomas ML, and Prahl JW (1980) Evidence for presence of an internal thiolester bond in third component of human complement. Proc Natl Acad Sci USA 77:5764-5768.

Takeda J, Miyata T, Kawagoe K, Iida Y, Endo Y, Fujita T, Takahashi M, Kitani T, and Kinoshita T (1993) Deficiency of the GPI anchor caused by a somatic mutation of the PIG-A gene in paroxysmal nocturnal hemoglobinuria. Cell 73:703-711.

Tedesco F, Nürnberger W, and Perissutti S (1993) Inherited deficiencies of the terminal complement components. Int Rev Immunol 10:51-64.

Tenner AJ (2020) Complement-mediated events in Alzheimer's disease: mechanisms and potential therapeutic targets. J Immunol 204:306-315.

Tenner AJ, Robinson SL, Borchelt J, and Wright JR (1989) Human pulmonary surfactant protein (SP-A), a protein structurally homologous to C1q, can enhance FcRand CR1-mediated phagocytosis. J Biol Chem 264:13923-13928.

Tenner AJ, Stevens B, and Woodruff TM (2018) New tricks for an ancient system: physiological and pathological roles of complement in the CNS. Mol Immunol 102:3-13.

Thiel S, Vorup-Jensen T, Stover CM, Schwaeble W, Laursen SB, Poulsen K, Willis AC, Eggleton P, Hansen S, Holmskov U, et al. (1997) A second serine protease associated with mannan-binding lectin that activates complement. Nature $\mathbf{3 8 6}$ 506-510.

Thielens NM, Tedesco F, Bohlson SS, Gaboriaud C, and Tenner AJ (2017) C1q: a fresh look upon an old molecule. Mol Immunol 89:73-83.

Thurman JM (2020) Complement and the kidney: an overview. Adv Chronic Kidney Dis 27:86-94.

Tinti MG, Carnevale V, Inglese M, Molinaro F, Bernal M, Migliore A, and De Cata A (2019) Eculizumab in refractory catastrophic antiphospholipid syndrome: a case report and systematic review of the literature. Clin Exp Med 19:281-288.

Titomanlio L, Bennaceur S, Bremond-Gignac D, Baumann C, Dupuy O, and Verloes A (2005) Michels syndrome, Carnevale syndrome, OSA syndrome, and Malpuech syndrome: variable expression of a single disorder (3MC syndrome)? Am J Med Genet A 137A:332-335.

Tomlinson S and Thurman JM (2018) Tissue-targeted complement therapeutics. Mol Immunol 102:120-128.

Tortajada A, Gutierrez E, Pickering MC, Praga Terente M, and Medjeral-Thomas N (2019) The role of complement in IgA nephropathy. Mol Immunol 114:123-132.

Tran H, Chaudhuri A, Concepcion W, and Grimm PC (2014) Use of eculizumab and plasma exchange in successful combined liver-kidney transplantation in a case of atypical HUS associated with complement factor $\mathrm{H}$ mutation. Pediatr Nephrol 29:477-480.

Trapp RG, Fletcher M, Forristal J, and West CD (1987) C4 binding protein deficiency in a patient with atypical Behcet's disease. J Rheumatol 14:135-138.

Trivioli G and Vaglio A (2020) The rise of complement in ANCA-associated vasculitis: from marginal player to target of modern therapy. Clin Exp Immunol 202:403-406.

Troelsen LN, Garred P, Christiansen B, Torp-Pedersen C, Christensen IJ, Narvestad E, and Jacobsen S (2010) Double role of mannose-binding lectin in relation to carotid intima-media thickness in patients with rheumatoid arthritis. Mol Immunol 47:713-718.

Troldborg A, Steffensen R, Trendelenburg M, Hauser T, Winther KG, Hansen AG, Stengaard-Pedersen K, Voss A, and Thiel S (2019) Ficolin-3 deficiency is associated with disease and an increased risk of systemic lupus erythematosus. $J$ Clin Immunol 39:421-429.

Troutbeck R, Al-Qureshi S, and Guymer RH (2012) Therapeutic targeting of the complement system in age-related macular degeneration: a review. Clin Exp Ophthalmol 40:18-26.

Truedsson L (2015) Classical pathway deficiencies - a short analytical review. Mol Immunol 68:14-19.

Tschumi S, Gugger M, Bucher BS, Riedl M, and Simonetti GD (2011) Eculizumab in atypical hemolytic uremic syndrome: long-term clinical course and histological findings. Pediatr Nephrol 26:2085-2088.

Valdimarsson H, Stefansson M, Vikingsdottir T, Arason GJ, Koch C, Thiel S, and Jensenius JC (1998) Reconstitution of opsonizing activity by infusion of mannan-binding lectin (MBL) to MBL-deficient humans. Scand J Immunol 48 116-123.

van Lookeren Campagne M, Strauss EC, and Yaspan BL (2016) Age-related macular degeneration: complement in action. Immunobiology 221:733-739.

Vasek MJ, Garber C, Dorsey D, Durrant DM, Bollman B, Soung A, Yu J, PerezTorres C, Frouin A, Wilton DK, et al. (2016) A complement-microglial axis drives synapse loss during virus-induced memory impairment. Nature 534:538-543.

Vengen IT, Madsen HO, Garred P, Platou C, Vatten L, and Videm V (2012) Mannosebinding lectin deficiency is associated with myocardial infarction: the HUNT2 study in Norway. PLoS One 7:e42113.

Verbakel CAE, Bonthuis F, Eerhart SE, van Dixhoorn M, Grosveld F, Marquet RL, and IJzermans JNM (2000) Relative roles of hCD46 and hCD55 in the regulation of hyperacute rejection. Transplant Proc 32:903-904.

Vergunst CE, Gerlag DM, Dinant H, Schulz L, Vinkenoog M, Smeets TJ, Sanders ME, Reedquist KA, and Tak PP (2007) Blocking the receptor for C5a in patients with rheumatoid arthritis does not reduce synovial inflammation. Rheumatology (Oxford) 46:1773-1778.

Verroust PJ, Wilson CB, Cooper NR, Edgington TS, and Dixon FJ (1974) Glomerular complement components in human glomerulonephritis. J Clin Invest 53:77-84.

Vlaar APJ, de Bruin S, Busch M, Timmermans SAMEG, van Zeggeren IE, Koning R, Ter Horst L, Bulle EB, van Baarle FEHP, van de Poll MCG, et al. (2020) Anti-C5a antibody IFX-1 (vilobelimab) treatment versus best supportive care for patients with severe COVID-19 (PANAMO): an exploratory, open-label, phase 2 randomised controlled trial. Lancet Rheumatol 2:e764-e773.

Vukojicic A, Delestrée N, Fletcher EV, Pagiazitis JG, Sankaranarayanan S, Yednock TA, Barres BA, and Mentis GZ (2019) The classical complement pathway mediates microglia-dependent remodeling of spinal motor circuits during development and in SMA. Cell Rep 29:3087-3100.e7.

Wang C, Yue H, Hu Z, Shen Y, Ma J, Li J, Wang XD, Wang L, Sun B, Shi P, et al. (2020) Microglia mediate forgetting via complement-dependent synaptic elimination. Science 367:688-694.
Wang H, Ricklin D, and Lambris JD (2017) Complement-activation fragment C4a mediates effector functions by binding as untethered agonist to protease-activated receptors 1 and 4. Proc Natl Acad Sci USA 114:10948-10953.

Wang R, Xiao H, Guo R, Li Y, and Shen B (2015) The role of C5a in acute lung injury induced by highly pathogenic viral infections. Emerg Microbes Infect 4:e28.

Ward PA (2004) The dark side of C5a in sepsis. Nat Rev Immunol 4:133-142.

Weisman HF, Bartow T, Leppo MK, Marsh HC Jr, Carson GR, Concino MF, Boyle MP, Roux KH, Weisfeldt ML, and Fearon DT (1990) Soluble human complement receptor type 1: in vivo inhibitor of complement suppressing post-ischemic myocardial inflammation and necrosis. Science 249:146-151.

Werneburg S, Jung J, Kunjamma RB, Ha SK, Luciano NJ, Willis CM, Gao G, Biscola NP, Havton LA, Crocker SJ, et al. (2020) Targeted complement inhibition at synapses prevents microglial synaptic engulfment and synapse loss in demyelinating disease. Immunity 52:167-182.e7.

West EE, Kunz N, and Kemper C (2020) Complement and human T cell metabolism: location, location, location. Immunol Rev 295:68-81.

Wong EKS and Kavanagh D (2018) Diseases of complement dysregulation-an overview. Semin Immunopathol 40:49-64.

Wood AJT, Vassallo A, Summers C, Chilvers ER, and Conway-Morris A (2018) C5a anaphylatoxin and its role in critical illness-induced organ dysfunction. Eur J Clin Invest 48: 13028 .

Woodruff TM, Crane JW, Proctor LM, Buller KM, Shek AB, de Vos K, Pollitt S, Williams HM, Shiels IA, Monk PN, et al. (2006) Therapeutic activity of C5a receptor antagonists in a rat model of neurodegeneration. FASEB J 20:1407-1417.

Woodruff TM, Lee JD, and Noakes PG (2014) Role for terminal complement activation in amyotrophic lateral sclerosis disease progression. Proc Natl Acad Sci USA 111:E3-E4.

$\mathrm{Wu} \mathrm{J}$ and Sun X (2019) Complement system and age-related macular degeneration: drugs and challenges. Drug Des Devel Ther 13:2413-2425.

Wu T, Dejanovic B, Gandham VD, Gogineni A, Edmonds R, Schauer S, Srinivasan K, Huntley MA, Wang Y, Wang TM, et al. (2019) Complement C3 is activated in human $\mathrm{AD}$ brain and is required for neurodegeneration in mouse models of amyloidosis and tauopathy. Cell Rep 28:2111-2123.e6.

Würzner R (2000) Modulation of complement membrane attack by local C7 synthesis Clin Exp Immunol 121:8-10.

Würzner R, Joysey VC, and Lachmann PJ (1994) Complement component C7. Assessment of in vivo synthesis after liver transplantation reveals that hepatocytes do not synthesize the majority of human C7. J Immunol 152:4624-4629.

Würzner R, Orren A, and Lachmann PJ (1992) Inherited deficiencies of the terminal components of human complement. Immunodefic Rev 3:123-147.

Xiao X, Pickering MC, and Smith RJ (2014) C3 glomerulopathy: the genetic and clinical findings in dense deposit disease and C3 glomerulonephritis. Semin Thromb Hemost 40:465-471.

Yamashina M, Ueda E, Kinoshita T, Takami T, Ojima A, Ono H, Tanaka H, Kondo N, Orii T, Okada N, et al. (1990) Inherited complete deficiency of 20-kilodalton homologous restriction factor (CD59) as a cause of paroxysmal nocturnal hemoglobinuria. $N$ Engl J Med 323:1184-1189.

Yan C and Gao H (2012) New insights for C5a and C5a receptors in sepsis. Front Immunol 3:368.

Yang J, Wise L, and Fukuchi KI (2020) TLR4 cross-talk with NLRP3 inflammasome and complement signaling pathways in Alzheimer's disease. Front Immunol 11:724.

Yang Y, Chung EK, Wu YL, Savelli SL, Nagaraja HN, Zhou B, Hebert M, Jones KN, Shu Y, Kitzmiller K, et al. (2007) Gene copy-number variation and associated polymorphisms of complement component $\mathrm{C} 4$ in human systemic lupus erythematosus (SLE): low copy number is a risk factor for and high copy number is a protective factor against SLE susceptibility in European Americans. Am J Hum Genet 80:1037-1054.

Yaseen S, Demopulos G, Dudler T, Yabuki M, Wood CL, Cummings WJ, Tjoelker LW, Fujita T, Sacks S, Garred P, et al. (2017) Lectin pathway effector enzyme mannanbinding lectin-associated serine protease-2 can activate native complement $\mathrm{C} 3$ in absence of C4 and/or C2. FASEB J 31:2210-2219.

Yatime L, Maasch C, Hoehlig K, Klussmann S, Andersen GR, and Vater A (2015) Structural basis for the targeting of complement anaphylatoxin C5a using a mixed L-RNA/L-DNA aptamer. Nat Commun 6:6481.

Yongqing T, Drentin N, Duncan RC, Wijeyewickrema LC, and Pike RN (2012) Mannose-binding lectin serine proteases and associated proteins of the lectin pathway of complement: two genes, five proteins and many functions? Biochim Biophys Acta 1824:253-262.

Zhang C, Li Y, Wang C, Wu Y, Cui W, Miwa T, Sato S, Li H, Song WC, and Du J (2014a) Complement 5a receptor mediates angiotensin II-induced cardiac inflammation and remodeling. Arterioscler Thromb Vasc Biol 34:1240-1248.

Zhang J, Li Y, Shan K, Wang L, Qiu W, Lu Y, Zhao D, Zhu G, He F, and Wang Y (2014b) Sublytic C5b-9 induces IL-6 and TGF- $\beta 1$ production by glomerular mesangial cells in rat Thy-1 nephritis through p300-mediated C/EBP $\beta$ acetylation. FASEB J 28:1511-1525.

Zhang J, Song L, Pedersen DV, Li A, Lambris JD, Andersen GR, Mollnes TE, Ma YJ, and Garred P (2020) Soluble collectin-12 mediates C3-independent docking of properdin that activates the alternative pathway of complement. eLife 9:e60908-e60927.

Zhang M, Michael LH, Grosjean SA, Kelly RA, Carroll MC, and Entman ML (2006a) The role of natural IgM in myocardial ischemia-reperfusion injury. $\mathrm{J}$ Mol Cell Cardiol 41:62-67.

Zhang M, Takahashi K, Alicot EM, Vorup-Jensen T, Kessler B, Thiel S, Jensenius JC, Ezekowitz RA, Moore FD, and Carroll MC (2006b) Activation of the lectin pathway by natural IgM in a model of ischemia/reperfusion injury. J Immunol 177:4727-4734

Zhou F, Zhang H, Kulkarni SD, Lorsch JR, and Hinnebusch AG (2020) eIF1 discriminates against suboptimal initiation sites to prevent excessive uORF translation genome-wide. RNA 26:419-438.

Ziccardi RJ (1982) Spontaneous activation of the first component of human complement (C1) by an intramolecular autocatalytic mechanism. J Immunol 128: $2500-2504$ 